\title{
ARQUEOLOGIA E SOCIEDADE NO MUNICÍPIO DE RIBEIRÃO GRANDE, SUL DE SÃO PAULO: AÇÕES EM ARQUEOLOGIA PÚBLICA LIGADAS AO PROJETO DE AMPLIAÇÃO DA MINA CALCÁRIA LIMEIRA.
}

Erika Marion Robrahn-González*

Resumo: 0 presente artigo visa analisar o desenvolvimento da Arqueologia Pública enquanto prática e conceituação científica, e apresentar uma iniciativa de aplicação que vem sendo desenvolvida junto à comunidade do município de Ribeirão Grande, localizado na região sul do Estado de São Paulo, com apoio da Companhia de Cimento Ribeirão Grande.

Palavras-chave: Arqueologia Pública, Ribeirão Grande, Arqueologia de São Paulo

\section{I ntrodução}

Todo ser humano é, em algum ponto de sua essência, um arqueólogo. Isto significa dizer que a Arqueologia existe, em primeiro lugar, da necessidade do ser humano em registrar sua própria história, seja através dos documentos escritos, das narrativas orais ou dos diferentes marcos deixados no mundo que o rodeia, como a construção de templos, o registro de cenas pintadas em paredes rochosas, a implantação de sinais que delimitem os territórios ocupados, e assim por diante. Esses marcos, em especial, são produzidos pelas sociedades humanas para que sejam reconhecidos tanto pelos próprios membros de sua sociedade, como também por outras sociedades, definindo seu universo político, econômico, social e cultu-

(*) Núcleo de Estudos Estratégicos / UNICAMP arqueo@terra.com.br ral. Nos dias de hoje, não mais nos limitamos a deixar registros em nosso próprio planeta, mas lançamos artefatos ao espaço (como a placa metálica enviada pelos EUA contendo a figura humana desenhada por Leonardo da Vinci e fórmulas matemáticas). Estamos preparando, portanto, vestígios arqueológicos para que nossa história possa ser lida por cientistas de muito mais além.

Por outro lado, todo ser humano tem necessidade de conhecer sua história, construindo, a partir dela, suas referências de vida. A experiência acumulada pelo homem fornece a sustentação necessária para olhar o futuro: seja perpetuando antigas formas de vida, seja negando estas formas e construindo novas alternativas de desenvolvimento.

O ser humano necessita, por fim, compreender formas de vida muito diferentes das suas, como foram, por exemplo, as sociedades da América para os colonizadores europeus quando alcançaram nosso continente, no século $X V$. 
A Arqueologia é, em essência, a busca desta história de experiências humanas. Milênios antes da Arqueologia se firmar como disciplina no ocidente membros de diferentes sociedades procuravam explicar o passado das mais variadas formas, onde se incluem desde os mitos de criação do universo apresentados por grupos indígenas, até escritos gregos datados em 800 anos a.C. que fazem referência à primeira divisão do passado humano em eras culturais (Idade do Ouro, Idade da Prata, Idade do Bronze, Idade Heróica e Idade do Ferro).

Estes foram, sem dúvida, os arqueólogos de seu tempo. De fato, a História da Arqueologia é, antes de mais nada, uma história de idéias e de descobertas, de formas de olhar o passado. E cada olhar constitui um reflexo ou produto de seu próprio tempo. Se no início podemos chamar, com certa liberdade poética, de "arqueólogo" aquele que registrava cenas de sua cultura em paredes de pedra, hoje chamamos de arqueólogo aquele que se vale de modernos conceitos teóricos, técnicas sofisticadas e grandes organizações de trabaIho para explicar, segundo os atuais preceitos da Ciência, o mesmo velho tema: a história humana.

Enquanto arqueólogos deste início do século XXI, trazemos no currículo pelo menos cinco séculos de experiência, contados desde os primórdios da disciplina no continente europeu, ainda durante o século XV. Se fôssemos capazes de contabilizar o investimento intelectual e o volume de estudos realizados, certamente nos surpreenderíamos com o resultado: milhares (ou miIhões) de trabalhos de campo, de acervos pesquisados, de datações adquiridas, de publicações, apresentações em reuniões e congressos, debates científicos, exposições e muitos itens mais.

Dos colecionadores de peças exóticas da Antiguidade aos dias atuais, a Arqueologia não foi apenas capaz de acumular um conhecimento respeitável sobre o passado humano; discutiu incansavelmente, também, sua responsabilidade ética sobre este pas- sado, à medida em que apontava novas e mais abrangentes perspectivas de abordar 0 desenvolvimento das sociedades ao longo do tempo.

Como conseqüência e continuidade desta dinâmica, mais uma vez a Arqueologia se encontra no divã. Todavia, enquanto ao Iongo de sua história os agentes motivadores de mudança foram, principalmente, membros de dentro de sua própria comunidade científica, desta vez eles vêm de fora e podem ser sintetizados em uma única palavra: sociedade.

Este movimento vem sendo internacionalmente denominado "Arqueologia Pública", voltada ao relacionamento entre a pesquisa e o manejo de bens culturais com os grupos sociais interessados, de forma a promover a participação da sociedade na gestão de seu patrimônio arqueológico e histórico.

Essa abordagem prescinde, todavia, de uma profunda mudança de postura com respeito ao nosso "objeto de estudo" e procedimentos de trabalho. Hoje entendemos não ser mais possível que a Arqueologia continue voltada ao desenvolvimento de um ser abstrato chamado "Ciência", colecionador insaciável de novas teorias, novas descobertas, novas abordagens, novas discussões. Valendo-me de uma imagem da nossa velha conhecida Teoria de Sistemas, o turning point da Arqueologia pode ser sintetizado em uma única palavra: sociedade.

Temos, assim, uma mudança essencial de foco, onde a Arqueologia deixa de ser uma ciência com olhar voltado ao passado para assumir sua responsabilidade na compreensão do presente e na promoção do futuro.

0 presente trabalho visa apresentar uma reflexão sobre o tema, apoiado em uma discussão teórica e conceitual e apresentando uma síntese dos resultados até o momento abtidos pela pesquisa que vem sendo desenvolvida em parceria com a empresa Companhia de Cimento Ribeirão Grande (CCRG) por conta do licenciamento ambiental do Projeto de Ampliação da Mina Limeira, localizada na região sul de São Paulo, município de Ribeirão Grande. 


\section{Conceituação}

A busca em compreender o passado humano se deu, inicialmente, através de manifestações oriundas da própria sociedade, como nos exemplificam os mitos de criação do mundo, ou mesmo a atividade quase instintiva de colecionar objetos que remetessem e materializassem a própria existência deste passado. À medida que a Arqueologia foi se firmando enquanto disciplina (especialmente a partir do século XIX), o estudo e interpretação da história humana constitui domínio e atribuição de profissionais cientistas, em busca de um "passado objetivo real". A própria terminologia cada vez mais técnica da Arqueologia, em boa parte adquirida através da New Archaeology, já no século $X X$, perpetua a mistificação da disciplina, e sua prática pressupõe uma crescente alienação junto ao público, fazendo crer que pouco há para ser aprendido com a participação da sociedade nas pesquisas.

Esse distanciamento do arqueólogo junto ao público pode ser bem ilustrado por uma situação apresentada em artigo de Shackel (2002:13), em que relata escavações realizadas no Parque Nacional Harpers Ferry/EUA, na década de 1970. Na chegada ao local de trabalho possíveis visitantes eram recepcionados por uma placa contendo os seguintes dizeres:

Yes - we are archaeologists.

Yes - we are doing archaeology.

Please do not disturb us.

Os primeiros arqueólogos a atravessar a fronteira entre a audiência científica e a audiência pública foram duramente criticados, incluindo um certo questionamento sobre a própria sustentação científica de seus trabalhos.

Essa iniciativa se deveu à Arqueologia Pós-processualista que, a partir do início da década de 1980, alertava sobre os cuidados e responsabilidades referentes ao conteúdo das mensagens transmitidas sobre 0 passado, considerando as dimensões sociais e políticas envolvidas. Isto se aplicava tanto à divulgação científica quanto à divulgação voltada ao público em geral (para uma revisão do tema vide Moser 2001).

Observou-se assim uma crescente preocupação, no cenário internacional, com os aspectos públicos da Arqueologia, entendidos como as questões de planejamento econômico, ações sociais e políticas envolvidas na prática da disciplina. Com a fundação da WAC (World Archaeological Congress) em 1986, a Arqueologia tem tratado de forma mais sistemática o relacionamento entre a pesquisa e manejo de bens culturais e os grupos sociais interessados. 0 surgimento da primeira publicação periódica sobre o tema, Public Archaeology (Londres, James \& James), em 2000, assinala o amadurecimento das discussões estratégicas sobre o caráter público da disciplina e sua importância social.

Em vários outros países do mundo, incluindo o Brasil, a Arqueologia deixou por muito tempo para uma equipe de não-arqueólogos (incluindo caçadores de tesouros, amadores, saqueadores e romancistas) a missão de propagar suas descobertas e interpretações, não raro de modo distorcido. Nos últimos anos, todavia, os arqueólogos começaram a introduzir em sua rotina de trabalho diferentes ações referentes à agenda em Arqueologia Pública, como educação, integração com a comunidade e proteção/ preservação de sítios arqueológicos.

Inicialmente as ações em Arqueologia Pública estiveram mais voltadas à proteção e preservação do patrimônio arqueológico, haja visto que os profissionais se depararam com um ritmo cada vez mais acelerado de degradação e destruição deste patrimônio. A perda de patrimônio cultural é comparável à extinção de espécies vegetais ou animais: é para sempre. A manutenção dos vestígios do passado (sejam eles artefatos, sítios arqueológicos, paisagens ou qualquer tipo de estrutura) constitui elemento fundamental 
para continuar havendo uma ligação tangível com o passado, elemento crítico de toda vida social. Assim sendo, independente de como o passado é estruturado, compreendêlo e proteger seus símbolos constitui parte integrante da experiência coletiva humana e da classe arqueológica em particular (Smith \& Ehrenhard 2002:121).

Mas rapidamente os arqueólogos perceberam que necessitavam reconhecer não somente sua responsabilidade sobre os vestígios arqueológicos, mas igualmente sobre as pessoas cuja herança histórica e cultural se relacionava a estes vestígios (Little 2002:10). Um dos benefícios públicos da Arqueologia está justamente em contribuir para o fortalecimento dos vínculos existentes entre a comunidade e seu passado, ampliando o interesse da sociedade sobre o patrimônio e criando, assim, a sustentação necessária às medidas de preservação.

Nessa empreitada devemos explorar 0 grande interesse e fascínio que a Arqueologia desperta nas pessoas, por conta de seu perfil de descobertas e da busca pelo passado. De fato, a Arqueologia parece constituir a segunda profissão de mais da metade da população. Freqüentemente nos deparamos com frases como "se eu não fosse engenheiro (ou médico, ou professor, ou qualquer outra profissão), seria arqueólogo".

A relação que a Arqueologia estabelece com as diferentes áreas de conhecimento uma vez que é uma ciência verdadeiramente interdisciplinar, fruto da somatória de cada disciplina científica e humanista - é mais um dos fatores que faz com que muitas pessoas se sintam próximas a ela. Isto se aplica, por exemplo, ao caso da estabilidade e mudança ambiental: através do conhecimento da sucessão de experiências humanas ocorridas sobre um ecossistema, é possível refletir sobre alternativas de gestão e manejo, trazendo uma visão mais global e tangível ao tema (Little 2002: 9; De Vries 2003).

Podemos citar ainda como fator de aproximação entre a Arqueologia e o público em geral o crescente interesse e uso de tecnologia no mundo moderno. A Arqueolo- gia não só utiliza uma série de tecnologias nas pesquisas, onde se incluem as datações radiocarbônicas, sensoriamento remoto, análises químicas, entre outros (McManamon 2000:13), assuntos que despertam grande interesse do público em geral, e do estudantil em particular - como por intermédio de seus estudos é possível conhecer o desenvolvimento tecnológico desde a pré-história até os dias atuais e outros aspectos do desenvolvimento humano, como a agricultura e a metalurgia.

Fatores como os acima mencionados levam muitas pessoas a considerar a Arqueologia importante, estando, na maior parte das vezes, interessadas em aprender sobre ela. Acreditam que seu estudo traz ferramentas importantes também para entender o mundo moderno, ressaltando seu valor educativo, artístico, estético e até espiritual. A Arqueologia pode, assim, desenvolver elos entre presente e passado, fortalecendo-os mutuamente e trazendo ensinamentos sobre a experiência humana como um todo (Little 2002:16).

Se expandirmos nossa visão para reconhecer os sucessos e insucessos das sociedades ao longo dos tempos, nossa tolerância social deverá ser expandida. Hoje os estudantes necessitam compreender a história do mundo e de pessoas de diferentes culturas e contextos que desenvolveram idéias, instituições e formas de vida diferentes da sua. Nesse sentido, o conhecimento de diferentes formas de vida, experiências e perspectivas da humanidade no passado podem contribuir em criar cidadãos mais pacientes e respeitosos, especialmente com grupos excluídos ou minorias étnicas, em nossa sociedade crescentemente pluralista (Shiva 2003; National Center for History in the Schools 1996:1, citado por Little 2002:12).

Hoje temos necessidade de sermos competentes num mundo multicultural, e a Arqueologia pode proporcionar ferramentas que auxiliem a viver nesta sociedade crescentemente complexa, ensinando as pessoas sobre outras culturas e tempos, fornecendo-Ihes ferramentas para melhor com- 
preender a diversidade humana, ao expandir suas visões de mundo (Little 2002:13).

Essa compreensão da diversidade leva à tolerância, que permite a inserção de diversos segmentos da sociedade, tornando todos os indivíduos sujeitos plenos de direitos e deveres: cidadãos. Assim, um dos benefícios públicos da Arqueologia é o mesmo que oferece a história e a ciência: a educação da cidadania. Do mesmo modo que o multiculturalismo pode ser representado tanto pela existência de uma multiplicidade de culturas do mundo, como pela co-existência de culturas diversas no espaço de um mesmo Estado-nação e as interinfluências que ocorrem tanto dentro como além do Estadonação (Santos 2003), o conceito de cidadania não presume limites estritos: pode-se, ao mesmo tempo, ser cidadão de um município, de um país, ou cidadão do mundo (Ribeiro 2000), e a Arqueologia transita entre estes diferentes níveis o tempo todo.

Assim, como bem coloca McManamon (1991, 1994, citado por Smith \& Ehrenhard 123), não temos apenas um público a considerar, mas vários. Devemos refletir sobre a maneirar como nossa sociedade se posiciona com relação ao seu passado: Qual o passado que merece ser resgatado? Quais os mecanismos que a sociedade utiliza para registrar e perpetuar sua própria história?

Em oposição às ciências naturais, a ciência social necessita ser, particularmente nestes tempos pós-modernos, pluralista em essência. A admissão de diferenças não põe em cheque a autoridade da disciplina. Ao contrário: o reconhecimento de que as idéias e interpretações são produto de condições históricas específicas amplia o debate e sua contribuição. Segundo define Molyneaux (1994:6), se desejamos obter uma compreensão do passado que abranja a complexidade e diversidade de suas mensagens possíveis, então precisamos reconhecer a existência de um público igualmente diverso, e aprender a lidar com ele. Para assim proceder mostra-se necessário reconhecer e respeitar todos os valores atribuídos à herança arqueológica, incluindo a científica.
É preciso, assim, reconhecer a pluralidade de interesses e graus de percepção do passado, bem como as necessidades políticas do presente. Para tanto, os programas de pesquisa devem envolver aspectos culturais e identitários da comunidade envolvida, elementos que exigem novas posturas e abordagens, trazendo alterações essenciais aos estudos arqueológicos (Gosden 2001; Fagan 2002).

A Arqueologia pode construir elos entre a comunidade no presente, assim como no passado, no momento em que sua herança cultural é valorizada, preservando histórias e tradições. Por essa razão o conteúdo da mensagem a ser transmitida ao público deve estar, antes de mais nada, atrelado à história local, de forma a construir um elo de percepção junto ao público, partindo daí para contextos mais gerais. Isso pode incluir objetos identificados no local, sítios ou vestígios mais conhecidos, dados sobre como os grupos humanos do passado viveram naquele mesmo espaço geográfico, entre tantos outros (McManamon 2000:13; Lerner 1991, citado por McManamon 2000:14). Por outro lado a mensagem deve também conter dados sobre a importância deste patrimônio, 0 fato dele ser único e não renovável, e também o esforço e detalhamento da pesquisa científica necessária para construir o conhecimento, visando sensibilizar o público sobre sua valorização e necessidade de preservação.

No caso brasileiro, onde a sociedade nacional foi formada através de uma ruptura entre as ocupações indígenas que aqui se encontravam e o elemento europeu, mais tarde acrescido pela cultura africana, é freqüente a comunidade atual não reconhecer vínculos com o contexto arqueológico, embora tenha interesse pelo seu sentido exótico. Isso se agrava pelo fato de que até mesmo a construção da História do Brasil tenha sido tradicionalmente feita a partir de sua classe intelectual dominante, resultando em um baixo ou nulo reconhecimento da população em geral como sendo esta a "sua história". O próprio currículo escolar não inclui uma efetiva história das minorias, apesar de 
sua participação fundamental na formação e desenvolvimento da sociedade nacional.

Contexto muito próximo ocorre em pesquisas no sul da África, onde os vestígios arqueológicos e a herança patrimonial foram, durante todo o longo período colonial, tratados a partir dos interesses da aristocracia e não a partir das aspirações das comunidades locais. Assim, como parte do processo político e da própria perspectiva da pesquisa arqueológica realizada, parte do legado coIonial foi justamente causar a alienação das comunidades locais com sua herança cultural (Ndoro \& Pwiti 2001:21).

Nesse sentido os vestígios arqueológicos, enquanto elementos materiais tangíveis, proporcionam uma experiência que auxilia no reconhecimento de que existe um passado, constituindo uma ponte concreta entre 0 antes e o agora e proporcionando, como define Lowenthal (1985:XXIII, citado por McManamon 2002:32), uma metáfora que ilumina o processo da história e da memória.

No caminho ressurge uma das questões fundamentais da Arqueologia: quem controla e a quem pertence o passado (ou, nos termos acadêmicos, a quem concerne sua propriedade intelectual?). Certamente os arqueólogos não são os únicos a poder contar histórias, nem tampouco exercem o poder absoluto sobre o passado das comunidades vivas, como ocorre com aquelas que não têm mais voz. Não podemos impor nossa versão do passado ao mundo, ignorando histórias tradicionais e outras perspectivas que a comunidade nos traz. A ciência não é onipotente ou exclusiva: todos nós controlamos e a todos nós pertence o passado, incluindo povos dos quatro cantos da terra. Temos apenas perspectivas diferentes sobre ele, valores culturais específicos e expectativas diversas sobre as lições que pode nos ensinar. Assim, um dos instrumentos mais valiosos da Arqueologia Pública é trazer tolerância e compreensão das diversidades culturais e das diversidades sobre 0 passado (para uma discussão sobre o tema, vide Thomas 2000, citado por Little 2002:6; Kuwanwisiwma 2002).
De modo análogo os arqueólogos necessitam considerar as diferenças fundamentais entre os grupos humanos no que se refere à própria compreensão da dimensão do tempo. A noção ocidental sobre a passagem do tempo é geralmente adotada como real e natural, mas existem vários exemplos antropológicos e etnográficos contrários. Os grupos Inuit do noroeste do Canadá concebem sua realidade vivendo apenas no presente, sem reconhecer sequenciamentos cronológicos onde organizem seus eventos: o passado é compreendido como parte do presente (Smith \& Ehrenhard 2002:122-3; Crist 2002).

Considerando esse conjunto de aspectos, mostra-se essencial que a pesquisa arqueológica seja realizada em conjunto com os descendentes vivos da sociedade que criou ou herdou os vestígios estudados. Assim será possível conduzir os trabalhos a partir de uma perspectiva de "arqueologia democrática", como define Faulkner (2000), que compreende a realização de trabalhos com base na comunidade, de forma não excludente e não hierárquica, e dedicados a um desenho de pesquisa que pressuponha interação entre os vestígios materiais, a metodologia de trabalho e a interpretação. Dentre outros exemplos frutíferos de pesquisas arqueológicas realizadas contando com a participação de membros da comunidade podemos citar 0 realizado por Field (Field et al 2000) entre os aborígines Australianos e o de Faulkner (2000) com a sociedade inglesa contemporânea.

Contudo, segundo Fabian (1983), o reconhecimento da mudança não nega aspectos de continuidade mas aponta a necessidade de tratar tanto a mudança como a continuidade como questões empíricas. As culturas não correspondem a entidades estáticas que existem à margem da História (Wolf 1984) e a Arqueologia deve analisar as sociedades contemporâneas a partir desta perspectiva. Nesse contexto a Arqueologia é capaz de trazer o poder do passado para a legitimação das comunidades e seu fortalecimento no presente. 
Nas últimas décadas muitos estudos têm se dedicado, por exemplo, a definir de forma mais clara e precisa a natureza e resultado das mudanças geradas pelo processo de colonização, especialmente em sociedades da América e da África (Atkinson 1989; Campbell 1988; Lamphear 1988; Handler 1968; Huffman 1982, 1986; Schmidt 1990; Stahl 1994; Upham 1987; Whitehead 1990, entre outros).

Os benefícios públicos que a Arqueologia poderá trazer, junto a comunidades indígenas ou a comunidades de qualquer natureza, porém, dependem fortemente da solidez e credibilidade científica das pesquisas. Sem isso, o interesse da comunidade será diminuído e sua atenção deverá recair, fatalmente, ao aspecto exótico e fantasioso da disciplina (Lipe 2000:20 in Little).

0 desafio do arqueólogo está, entre outros, em estabelecer um significado científico e histórico às "coisas do passado", ou seja, aos objetos retirados das escavações, que devem ser utilizados como ponte entre a experiência do público e um mundo passado reconstruído a partir de inúmeras outras evidências (onde se incluem a história oral, os mitos e os conhecimentos tradicionais). Nessa tarefa o arqueólogo necessita, mais do que nunca, de uma equipe interdisciplinar que possa transitar em todos os campos de conhecimento e esferas sociais de atuação. Cabe a ele não apenas fornecer os dados de pesquisa que possui, necessários à evolução do trabalho, mas principalmente fornecer seu olhar sobre o passado, para que profissionais nas áreas de antropologia, sociologia, história, educação, publicidade, marketing, turismo e tantas outras, possam trabalhar de forma séria e criativa.

A tudo isto podemos denominar "Ciência Aplicada", correspondendo ao amplo leque de contribuições que a Arqueologia pode oferecer no fortalecimento e valorização das comunidades atuais.

No Brasil este momento apresenta uma cor especial. Isto se dá especialmente por conta da conjuntura social e política que atravessa, na qualidade de país em desenvolvimento rumo à era da globalização. À Ar- queologia abrem-se preciosas oportunidades de ocupar espaços ainda vazios, voltados a uma abordagem mais abrangente e pluralista de nossa herança cultural.

E é dentro desta abordagem e conceituação que 0 texto que se segue visa demonstrar uma experiência de trabalho desenvolvido em Arqueologia Pública em uma area da região sul do estado de São Paulo, abrangendo os campos da educação, divulgação, valorização cultural e preservação, com o objetivo de expandir as reflexões aqui apresentadas.

\section{O Programa Arqueológico Mina Limeira}

O Projeto de Ampliação da Mina Limeira, de responsabilidade da empresa Companhia de Cimento Ribeirão Grande (CCRG), vem sendo desenvolvido desde 2002 englobando as diferentes fases de licenciamento ambiental da obra. Abrange terras dos municípios de Capão Bonito e Ribeirão Grande, localizados na região sudeste do estado de São Paulo.

A área integra o que se define como "região do alto Paranapanema", mais precisamente em seu limite meridional, próximo à crista dos divisores de águas com a bacia do rio Ribeira de Iguape. A área-foco da pesquisa é banhada por pequenos córregos que deságuam no rio das Almas que, por sua vez, é um dos formadores do rio Paranapanema, em seu alto curso (Figura 1).

0 vale do alto Paranapanema oferece interessantes questões científicas à Arqueologia. Em primeiro lugar, corresponde a uma zona de transição ambiental entre a região florestada da serra da Paranapiacaba (fisicamente integrada à porção do médio/alto vale da bacia do Ribeira de Iguape), e o planalto paulista. Esta condição geográfica teria, ao menos em parte, influenciado no assentamento dos grupos indígenas pré-coloniais que ali se desenvolveram, fazendo com que aparentem características específicas, e distintas de suas áreas de origem, o planalto central brasileiro (De Blasis 1996, RobrahnGonzález \& De Blasis 1998). 


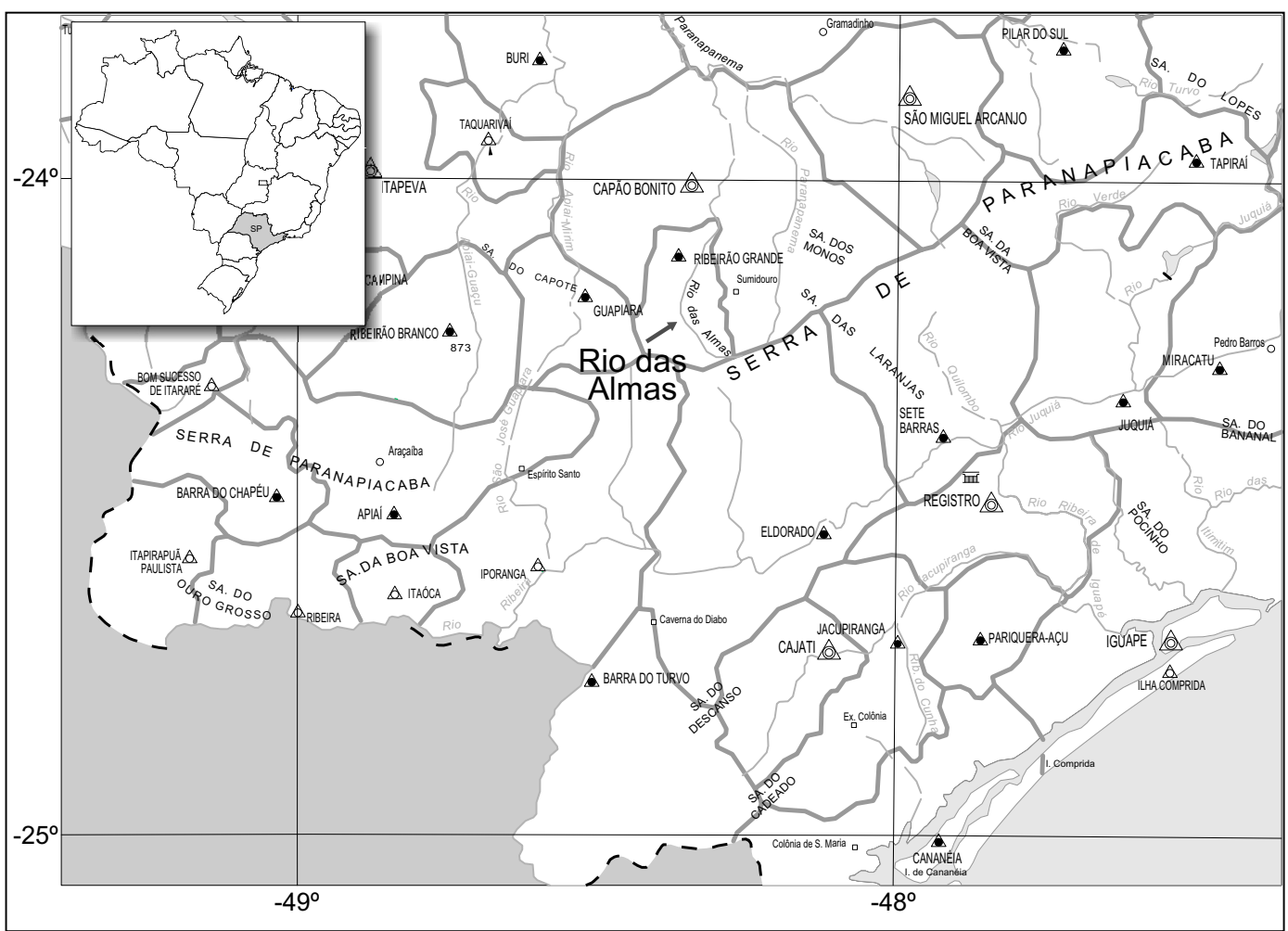

Figura 1 - Região sudeste do Estado de São Paulo, com a Serra do Paranapiacaba definindo os limites entre o vale do Paranapanema (a noroeste) e o vale do rio Ribeira de Iguape (ao sul). Localização regional da área do empreendimento, no vale do rio Almas, um dos formadores do Paranapanema.

Em segundo lugar, o vale do Paranapanema é recorrentemente apontado pela bibliografia arqueológica como possível área de fronteira cultural, delimitando o território de ocupação de grupos indígenas tradicionalmente ligados à região sul brasileira (cujos sítios são genericamente relacionados às denominadas tradições Umbu e Itararé) e grupos indígenas ligados à região sudeste (com sítios relacionados às tradições Tupi-guarani e Humaitá, embora esta última esteja sendo hoje re-avaliada) (De Blasis 1988, 1996; Mello Araújo 2001; Robrahn 1989; Barros Barreto 1988; Hoeltz 1997; Dias 1994; Schimtz 1981, 1987; Kern 1982; RobrahnGonzález \& De Blasis 1998).

No que se refere à delimitação da área de pesquisa, trata-se de um projeto de am- pliação, considerando que a Mina Limeira teve sua exploração iniciada há décadas, sem contudo ter sido, efetivamente, posta em operação. O objeto do atual licenciamento implica tanto na área projetada para ampliar e iniciar a exploração calcária da Mina, como também as obras de apoio que lhe serão relacionadas, a saber:

- o depósito de estéril Leiteria (D.E. Leiteria, também já há décadas em operação);

- o depósito de estéril Barro Branco (D.E. Barro Branco)

- via de acesso a ser aberta entre o D.E. Barro Branco e a fábrica da CCRG.

Estas correspondem às áreas diretamente afetadas pelo empreendimento 
(ADA), e que foram objeto de estudos sistemáticos intensivos. Todavia, visando obter um contexto científico de referência aos vestígios identificados no interior da ADA, os trabalhos de campo e os levantamentos documentais se estenderam pelo que se definiu como área de influência indireta do empreendimento (AII), aqui considerado como abrangendo todo o vale do rio das Almas e os municípios afetados. Por outro lado, muitas das discussões científicas apresentadas pelo texto exigiram a abrangência de um espaço geográfico maior, podendo alcançar todo o planalto meridional brasileiro no que se refere a questões como migrações, territórios de ocupação, contatos extra-culturais, entre outros.

Os trabalhos de campo tiveram início através de prospeç̧ões na ADA, buscando reconhecer o patrimônio arqueológico envolvido. De início foram realizados levantamentos extensivos, consistindo em uma primeira abordagem de reconhecimento da área e de seus vestígios (procedimento especialmente empregado durante os estudos de diagnóstico da área). Em seguida deuse início às prospecções sistemáticas (tipo varredura), implicando na observação dos terrenos tanto em superfície como em profundidade.

Durante estas prospecções sistemáticas as equipes percorreram cada uma das áreas que compõem a ADA caminhando em alinhamentos paralelos distantes entre si de $20 \mathrm{em}$ 20 metros, com realização de poços-teste a cada $20 \mathrm{~m}$ percorridos. Os poços-teste apresentaram dimensões de $0,4 \mathrm{~m}$ de diâmetro e $1,0 \mathrm{~m}$ de profundidade (podendo variar a profundidade de acordo com a espessura de solo presente, podendo alcançar até $2,5 \mathrm{~m}$ ).

Este tática de cobertura por alinhamentos paralelos com distribuição de poços-testes de forma regular permitiu obter dados necessários ao estudo dos padrões de distribuição dos sítios arqueológicos na paisagem. A pesquisa foi responsável pela identificação de 50 sítios arqueológicos, dos quais 17 foram, posteriormente, escavados sistematicamen- te (Figura 2). Dos 50 sítios, 34 são do tipo lítico (ou 68\%), 4 cerâmicos (ou $8 \%$ ), 9 sítios ligados ao período histórico (ou $18 \%$ ) e 2 sítios multicomponenciais (ou seja, sítios que apresentam vestígios relacionados a mais de uma ocupação humana - 4\%) (vide Tabela 1).

0 presente artigo não objetiva detalhar aspectos referentes a estes sítios arqueológicos, às suas indústrias e às filiações arqueológicas regionais, uma vez que estes assuntos estão sendo tratados e serão apresentados na dissertação de Mestrado de Gerson Levi da Silva Mendes (MAE-USP). A utilização dos dados da pesquisa para trabalhos acadêmicos constitui, aliás, outra iniciativa incentivada pelo Programa, proporcionando o detalhamento de análises científicas sobre os temas tratados e resultando em contribuições científicas adicionais e de maior detalhe em focos específicos.

Desta forma apresenta-se, abaixo, uma síntese dos principais horizontes de ocupação humana identificados pelas pesquisas. Estes horizontes partem do contexto mais antigo (paleo-índio), até alcançar a ocupação atual de Ribeirão Grande, buscando incorporar seus diversos passados, por assim dizer: o passado pré-colonial, formado por diferentes grupos indígenas que se desenvolveram na região há pelo menos 5.500 anos atrás, e o passado histórico, que embora na memória da atual comunidade que ali vive recue apenas até a época da mineração (a partir do século XVII), incorpora traços marcantes de tradição indígena em diversas práticas do cotidiano.

Neste contexto, o objetivo maior do presente artigo é incorporar a comunidade atual na história regional, através das diferentes nuances materiais e materiais que constituem a continuidade e herança deste passado milenar. Assim, na apresentação dos chamados "horizontes de ocupação humana", será dada maior ênfase e detalhamento em seus aspectos uma vez que, conforme já mencionado acima, os contextos de ocupação pré-colonial estarão sendo apresentados em trabalho acadêmico. 


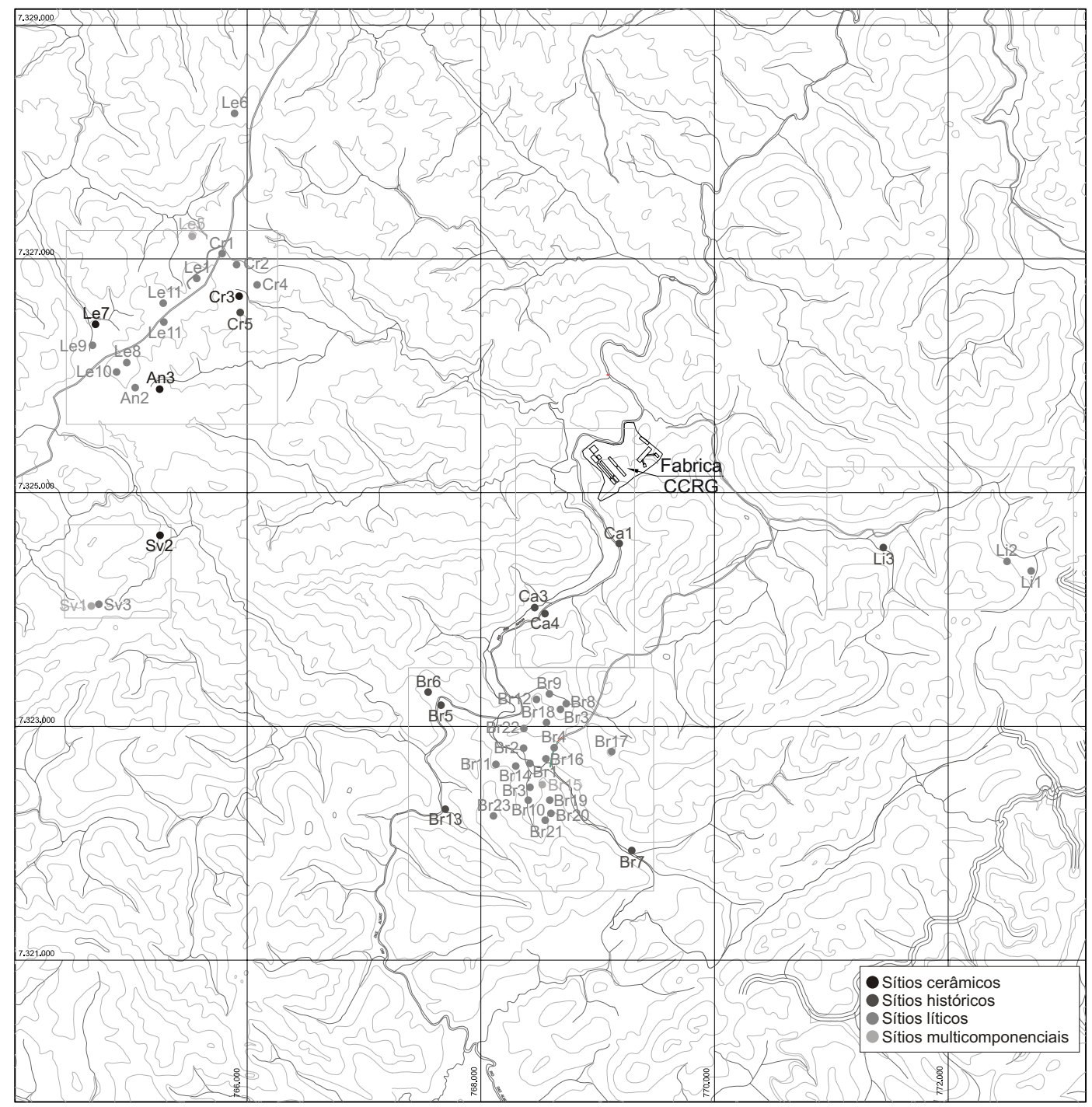

Figura 2 - Localização dos sítios arqueológicosura

Tabela 1

Sítios arqueológicos identificados pelo programa

\begin{tabular}{|c|c|c|c|}
\hline Nome do sítio & Tipo & Área & Coordenada UTM \\
\hline Sitio Leiteria 1 & Lítico & D.E. Leiteria & 22 J 765568/7326832 \\
\hline Sitio Leiteria 2 & Lítico & D.E. Leiteria & 22 J 765281/7326621 \\
\hline Sitio Leiteria 4 & Lítico & Área de Influência Indireta & 22 J 764889/7326690 \\
\hline Sitio Leiteria 5 & Multicomponencial & Área de Influência Indireta & 22 J 765529/7327192 \\
\hline Sitio Leiteria 6 & Lítico & Área de Influência Indireta & 22 J 765892/7328244 \\
\hline Sitio Leiteria 7 & Cerâmico & Área de Influência Indireta & 22 J 764702/7326440 \\
\hline
\end{tabular}


Tabela 1 (cont.)

Sítios arqueológicos identificados pelo programa

\begin{tabular}{|c|c|c|c|}
\hline Nome do sítio & Tipo & Área & Coordenada UTM \\
\hline Sitio Leiteria 8 & Lítico & Área de Influência Indireta & 22 J $764969 / 7326112$ \\
\hline Sitio Leiteria 9 & Lítico & Área de Influência Indireta & 22 J $764676 / 7326260$ \\
\hline Sitio Leiteria 10 & Lítico & Área de Influência Indireta & 22 | $764882 / 7326032$ \\
\hline Sitio Leiteria 11 & Lítico & Área de Influência Indireta & 22 j 765287/7326459 \\
\hline Sitio Anacleto 2 & Lítico & Área de Influência Indireta & $22 \int 765041 / 7325898$ \\
\hline Sitio Anacleto 3 & Cerâmico & Área de Influência Indireta & $22 \int 765251 / 7325885$ \\
\hline Sitio Cristal 1 & Lítico & D.E. Leiteria & 22 J $765786 / 7327045$ \\
\hline Sitio Cristal 2 & Lítico & D.E. Leiteria & 22 J $765909 / 732695$ \\
\hline Sitio Cristal 3 & Cerâmico & Área de Influência Indireta & $22\} 765$ \\
\hline Sitio Cristal 4 & Lítico & Área de Influência Indireta & 22 J $766085 / 7326777$ \\
\hline Sitio Cristal 5 & Histórico & Área de Influência Indireta & 22 J $765940 / 7326541$ \\
\hline Sítio Velho 1 & Multicomponencial & Área de Influência Indireta & $22 \int 764$ \\
\hline Sítio Velho 2 & Cerâmico & Área de Influência Indireta & 22 J 7652 \\
\hline Sítio Velho 3 & Lítico & Área de Influência Indireta & 22 J $764730 / 7324045$ \\
\hline Sitio Limeira 1 & & Mina Limeira & $22 \mathrm{~J} 77271$ \\
\hline Sítio Limeir & & Mina Lim & 22 J 77 \\
\hline Sítio Limeira 3 & Histórico & Mina Limeira & 22 J 7714 \\
\hline Sitio Barro Branco 1 & & D.E. Barro Branco & $22 J 768$ \\
\hline Sitio Barro B & & D.E. Bar & $22\rfloor 7$ \\
\hline Sítio Barro Branco 3 & Lítico a & D.E. Barro Branco & $22 \mathrm{~J} 7684$ \\
\hline Sitio Barro Bran & & D.E. Barro E & $22 \int 768$ \\
\hline Sítio Barro Branco & Histó & Área de Influência Indireta & $22 \int 767$ \\
\hline Sítio Barro Branco 6 & co & Área de Influência Indireta & $22 \int 767$ \\
\hline Sítio Barro Branco 7 & & Área de Influência Indireta & $22 \int 769$ \\
\hline Sitio $B$ & & D.E. Barrc & $22 J 7$ \\
\hline Sitio Barro Branco 9 & Líti & D.E. Barro Branco & 22 J $768587 / 7323278$ \\
\hline Sitio Barro Branco 10 & & D.E. Barro Branco & 22 | $768406 / 7322369$ \\
\hline Sitio Barro Bran & & Área de Influ & $22 \mathrm{j} 7$ \\
\hline Sitio Barro Branco 12 & & Área de Influência Indireta & 22 J $768476 / 732323$ \\
\hline Sítio Barro Branco 13 & Histórico & Área de Influên & $596 / 7322292$ \\
\hline Sitio Barro Branco 14 & & D.E. Barr & $22 J 7$ \\
\hline Sítio Barro Branco 15 & & D.E. Barro Branco & 22 J68 \\
\hline Sítio Barro Branco 16 & Lítico & D.E. Barro Branco & 22 j 768558/7322723 \\
\hline Sítio Barro Branco 17 & & Área de Influência Indireta & 22 J $768562 / 7322784$ \\
\hline Sítio Barro Branco 18 & & Área de Influência Indireta & $22 \mathrm{~J} 768$ \\
\hline Sítio Barro Branco 19 & Lítico & D.E. Barro Branco & 22 J $768590 / 7322370$ \\
\hline Sítio Barro Branco 20 & Lítico & D.E. Barro Branco & 22 J $768600 / 7322256$ \\
\hline Sítio Barro Branco 21 & Lítico & D.E. Barro Branco & 22 J 7685 \\
\hline Sítio Barro Branco 22 & Lítico & Área de Influência Indireta & 22 J $768368 / 7322982$ \\
\hline Sítio Barro Branco 23 & Lítico & Área de Influência Indireta & 22 J $768108 / 7322235$ \\
\hline Sítio Cachoeira 1 & & Área de Influência Indireta & $22 \int 769247 / 7324679$ \\
\hline Sítio Cachoeira 3 & Histórico & Área de Influência Indireta & 22 J68461/7324017 \\
\hline Sítio Cachoeira 4 & Histórico & Área de Influência Indireta & 22 J $768549 / 7323965$ \\
\hline Sítio Ribeirão Velho & Histórico & Área de Influência Indireta & $22 \mathrm{~J} 767636 / 732322$ \\
\hline
\end{tabular}


- Horizonte paleoíndio, com poucos artefatos e lascas encontrados de transienct settlers, com presença de pontas projéteis rabo de peixe planas lascadas por pressão, e pontas de lança com até $20 \mathrm{~cm}$ de comprimento, encontradas em profundidade superior a $150 \mathrm{~cm}$, sempre associados ao entorno de antigas lagunas, hoje banhados de fundos de vale altos. Esses sítios têm uma área potencial entre os bairros dos Caetanos, Caetanos Velhos e dos Cândidos, onde uma ponta de lança foi encontrada a $2,5 \mathrm{~m}$ de profundidade por habitante local. Estes sítios devem ser mais raros e profundos e estudos ulteriores de reconstrução ambiental para as paleolagoas da área apontarão para zonas potenciais de ocorrência. Em outros municípios pontas de lança também foram encontradas, sobretudo em I poranga e em Guapiara, conforme informações de arqueólogos e colecionistas. Foi denominado "horizonte 1".

- Horizonte caçador-coletor antigo, caracterizado pela presença de pontas-projéteis e lascas de acabamento, predominantemente de sílex de boa qualidade, além da presença de artefatos de quartzo hialino, em profundidades superiores a $50 \mathrm{~cm}$ chegando aos $80 \mathrm{~cm}$, situados sempre em topos de colinas e alinhados com outros sítios em situações de implantação muito similares, apontando para uma provável integração em um mesmo período (Foto). Foi denominado "horizonte 2". As indústrias destes horizontes ( 2 e 3) não apresentam mudanças significativas se estudadas tecnotipologicamente ou mesmo em sua va-

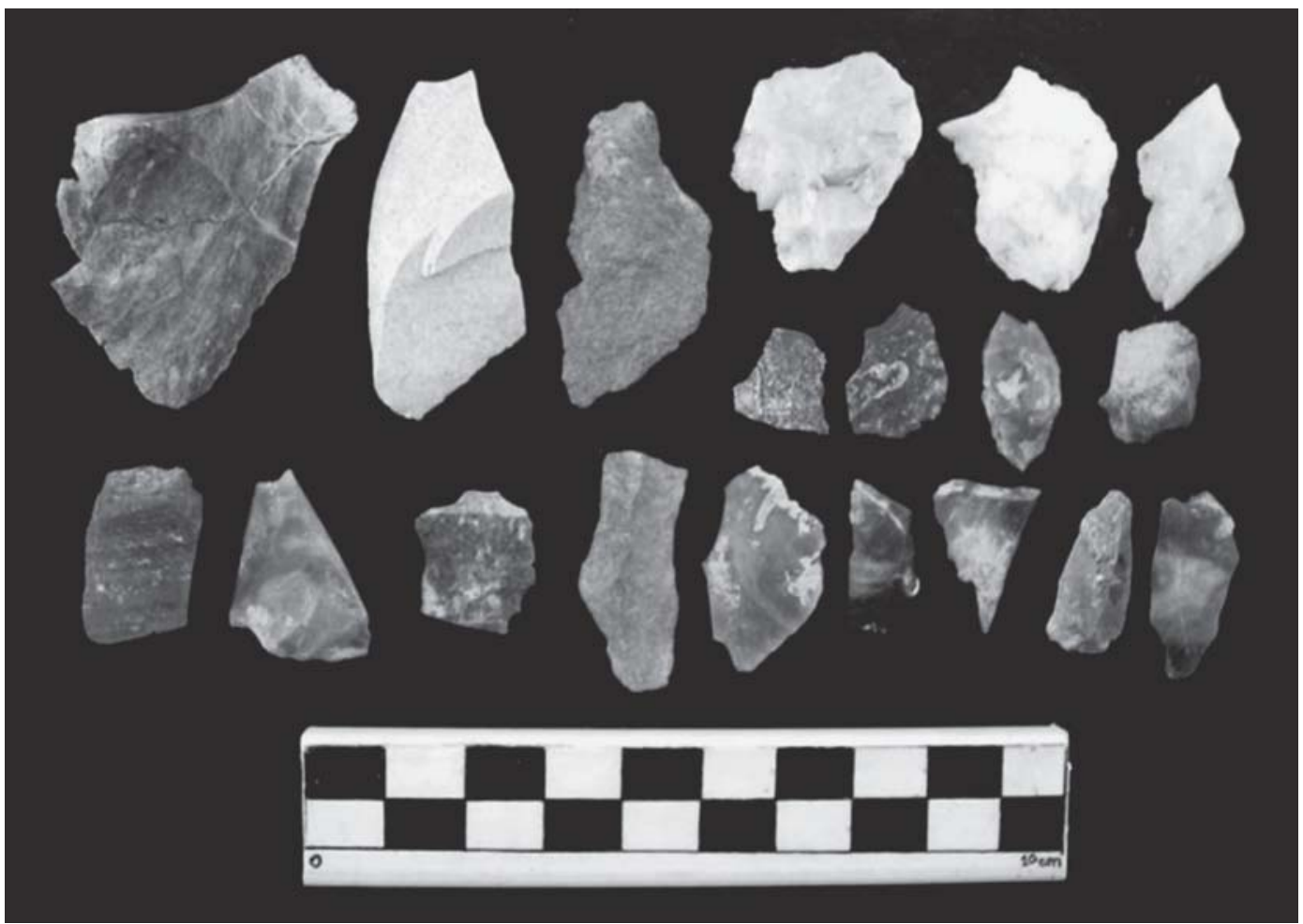

Horizonte 2: vestígios líticos do sítio Barro Branco 21, (Foto: Gérson Levi Méndes). 
riabilidade isocréstica (como apontado por Schmidt Dias 2003 para as indústrias Umbu do extremo nordeste do Rio Grande do Sul, que indica uma continuidade da organização social tecnológica irreal entre os conjuntos artefatuais). Contudo, as mudanças são percebidas quando estudadas num contexto regional amplo de sistema de povoamento e percebidas articuladamente em vales e microbacias hidrográficas (Moraes 2000), pois apontam para as diversas respostas que um mesmo sistema de eventos e povoamento utilizou-se para responder às necessidades econômicas e sociais locais, criandose um diálogo permanente com seu território móvel (Politis \& Cárdenas 2000). Delineiam-se, assim, as escolhas de implantação dos assentamentos para paisagens com fisionomias geomorfoclimáticas diversas e que tendem a se particularizar de vale para vale, cada qual, atualmente, com microclimas e ocorrências de espécies endêmicas próprias, apontando para um mosaico vegetacional complexo e alternado, como indicam as manchas de cerrado em áreas próximas, a presença de araucárias em fundo de vale onde o lençol freático está mais alto e a recente formação da floresta tropical úmida, a Mata Atlântica. Para este horizonte tem-se a data de $5.030+-50$ BP (calibradas em 5.920 a $5.660 \mathrm{BP}$, Laboratório Beta Analytic Inc, amostra 207853).

- Horizonte caçador-coletor recente, caracterizado pela presença de pontas projéteis e lascas de acabamento, predominantemente de quartzo e calcário silicificado (Foto). A maior parte dos sítios arqueológicos desse projeto está associada a esse horizonte. Em todos os

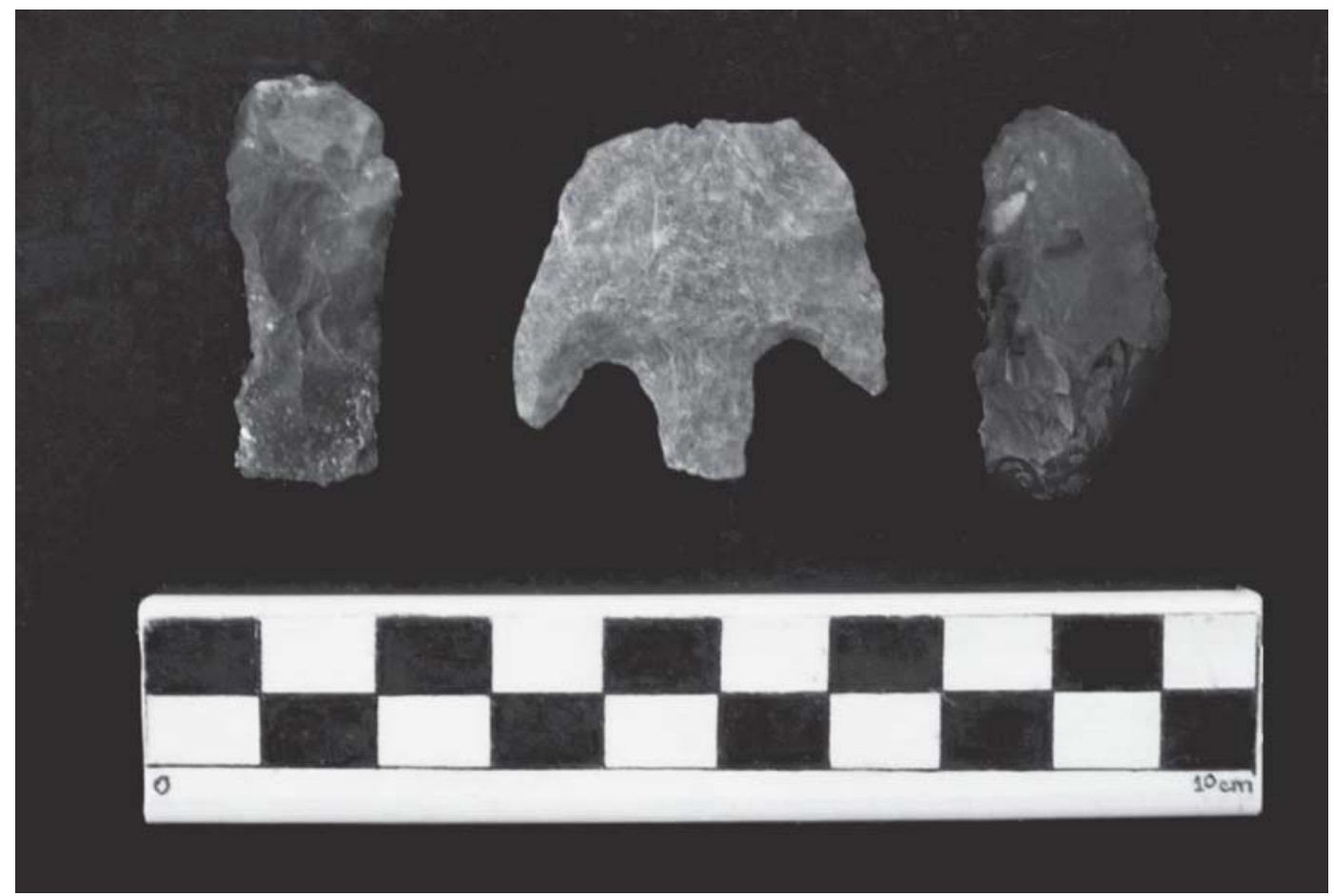

Horizonte 3: Vestígios do Barro Branco 14, camada 1, (Foto: Gérson Levi Méndes). 
seus sítios as pontas projéteis apresentam sinais de reavivamento intenso de matérias-primas como o sílex, apontando para a provável escassez ou esgotamento dessa matéria-prima. Os sítios estão distribuídos por toda a área entre o bairro rural do Assentamento, quase nos divisores de água entre as bacias do Paranapanema e do Ribeira de Iguape, e se estende até as proximidades dos bairros Lagoa de Cima, Cristal, Pêssego e Capoeira Alta, bem como nas imediações de Ribeirão Grande, podendo constar no planalto de Capão Bonito. Formam um território nucleiforme caçador-coletor diferente daquele encontrado no vale do Ribeira de Iguape. Estão situados entre 15 a $40 \mathrm{~cm}$ de profundidade, de acordo com as diversas condições geomorfológicas locais. Foi denominado "horizonte 3". Para este horizonte tem-se a data de 1.010 +- 50 BP (calibradas em 950 a 750 BP, Laboratório Beta Analytic Inc, amostra 207852).

- Horizonte de grupos ceramistas cultivadores, caracterizado pela presença de sítios arqueológicos implantados nas porções mais abertas dos vales, concentrando-se, sobretudo, entre os bairros rurais Barreiro Cabral e Pereira em direção aos terrenos suaves próximos à atual cidade de Ribeirão Grande e nos bairros Alto Rodrigues e Mata-a-Dentro, Nunes e Ferreiras, em direção ao limite com 0 município de Capão Bonito, a oeste. A presença destes grupos nos vales do Barro Branco e Ouro Fino é mais tardia e ocorre após o abandono dos sítios pelos antigos habitantes caçadores-coletores, como indicam os estudos de todos os perfis estratigráficos de sítios escavados. Foi denominado "horizonte 4". Os vestígios cerâmicos encontrados no vale do Barro Branco, de longe o mais conservado e com condições ideais para escavação, apresentam um intervalo de 10 a $20 \mathrm{~cm}$ com o horizonte caçador-coletor. Assim, antes de haver uma continuidade entre esses horizontes 3 e 4, há um silencio de 15 a
$20 \mathrm{~cm}$ de solo que sugere a existência de um período de abandono da região, seja porque os grupos caçadores-coletores entraram em contato com populações agricultoras e, assim, mantiveram relações com os mesmos de tal forma que se sedentarizaram no planalto ou no vale do Ribeira de Iguape, seja porque deveriam estar em confronto com esses grupos agricultores que já habitavam o vale do Ribeira de Iguape e o planalto paulista nas cercanias de Capão Bonito e Alto dos Rodrigues em Ribeirão Grande, e que se restringiam cada vez mais para um recuo de seu território nuclear. Os sítios mais recentes dos grupos caçadores-coletores devem corresponder àqueles mais próximos aos divisores d'água da Serra dos Agudos e entre os Parques Carlos Botelho e Intervales. De qualquer forma, entre esses dois períodos estamos tratando do final da presença de caçadores-coletores nesta região em data posterior àquela detectada pelo projeto Gasbol (De Blasis 2000), ou seja, uma possibilidade muito grande da presença de sítios mais recentes de 800 anos AP. De fato, para este horizonte tem-se a data de 150 +- $40 \mathrm{BP}$ (calibradas em 280 a 0 BP, ou ainda, de 1670 a 1950 A.D., Laboratório Beta Analytic Inc, amostra 207850).

- Horizonte histórico, correspondente ao ciclo da mineração do ouro de aluvião que deslocou habitantes dos arraiais dos médio e alto curso dos afluentes do Ribeira de Iguape em direção às nascentes e à bacia do alto Paranapanema. Ocorreu a partir da segunda metade do século XVII e se prolongou até o terceiro quartel do século XIX. Foi denominado "horizonte 5". No que se refere aos registros arqueológicos, os sítios Cristal 3, 5 e Anacletos 3 e 4 apontam para uma provável relação entre a antiga população ceramista indígena e estes primeiros colonos que aí se estabeleceram por volta do século XVII (uma pederneira de produção local foi encontrada associada 
a fragmentos de cerâmica arqueológica). Trata-se, nesse caso, de colonos associados aos prováveis arraiais dos Campos de Guapiara ou de Apiaí-mirim, frutos de uma situação colonial de mescla entre portugueses e índios Kaingang do vale do Ribeira de Iguape, pressupondo a relação etnográfica com estes grupos (Robrahn 1989). Contudo, com a origem da Freguesia-Velha pouco dessa ocupação mais esparsa foi aglutinada nos pequenos povoados intermontanos e uma reconstrução documental que os relacione ao período de construção das estruturas minerarárias conhecidas como "encanados" e às diversas cavas de prospecção mineral presentes na area, ainda depende de estudo histórico mais detalhado e é discutido mais adiante.

- Horizonte contemporâneo, correspondente à ocupação rural dos vales do Barro Branco, Cristal e Limeira. No primeiro vale a ocupação cabocla é relativamente recente, resultante da migração de tradicionais habitantes da Freguesia-Velha ainda na década de 1970, provenientes, em boa parte, do bairro rural dos Caetanos Velhos e outros bairros mais interiorizados. 0 povoado da Freguesia Velha é o berço do povoamento das áreas entre Ribeirão Grande e Capão Bonito, e seus antepassados eram provenientes do vale do Ribeira de Iguape, sobretudo dos arraiais encontrados no terceiro campo de Guapiara, do Apiaí-mirim e dos arraiais nas proximidades da Serra da Samambaia, Guapiara. Foi denominado "horizonte 6".

\section{Hoje e antes: a herança cultural da comunidade de Barro Branco ${ }^{1}$}

A participação da comunidade do Barro Branco, bairro rural localizado no município

(1) Capítulo de relatório originalmente redigido por Cintia Bendazzoli. de Ribeirão Grande, nas pesquisas de levantamento arqueológico criou um vínculo que, inicialmente tímido frente à reclusão das famílias em suas casas e atividades agrícolas e pastoris, foram dando lugar, devido ao longo período de campo, assim como estratégias selecionadas para acessar essa 'cultura reclusa', a uma relação de curiosidade e descobertas tanto da parte dos pesquisadores quanto dos moradores: o que estávamos fazendo atrás de 'lugares dos antigos' (da parte deles) e como podiam manter uma série de tradições frente à expansão da cultura introduzida recentemente pela mídia nas casas de pau-a-pique do Barro Branco? (de nossa parte).

As lendas, as histórias das famílias, os segredos do sertão, das árvores e plantas, dos diversos animais, os 'causos' e o registro material da presença dos antigos, índios e jesuítas e os "encanados" foram passando de geração em geração.

0 estudo da paisagem e das relações que os antigos habitantes mantinham com seu espaço podem ser acessadas de uma maneira extraordinariamente rica através do estudo dos diversos níveis de relações que as comunidades tradicionais locais mantêm com o espaço atual. Herdeiras de um espaço, com o qual interagem constantemente, a população do Barro Branco mantém as relações que seus antepassados mantinham com a Freguesia-Velha (uma das mais antigas comunidades do Alto Paranapanema) e com os vales intermontanos entre a Serra dos Maciéis e a Serra do Ouro Fino.

Para perceber quais são as diversas intensidades das continuidades indígenas ou coloniais nas relações atuais com o meio e com o simbólico em que vivem os tradicionais moradores do Barro Branco, pesquisas de etnobotânica, cultura imaterial, do universo feminino, infantil e das técnicas construtivas foram postas em prática, tendo, como

(2) Estrutura histórica relacionada à exploração aurífera em cursos fluviais. 
objetivo último, o resgate cultural, a valorização das identidades e a preservação de seus marcos ancestrais.

As pesquisas revelam elementos de continuidade da cultura indígena (técnicas de trançado na produção de cestos, áreas de captação de argila e espécies vegetais, técnicas construtivas, técnica de preparo do campo para o roçado) que encontram analogias em modelos indígenas antigos e atuais de apropriação do espaço, assim como elementos de ruptura e de conformidade com os costumes coloniais (festas religiosas, brincadeiras entre as crianças, etc.).

Este conjunto de fatores acabou por definir a própria missão do Programa Arqueológico Mina Limeira: reconstituir o passado através de sua articulação com o presente, permitindo contribuir para a educação, coesão da comunidade, lazer e desenvolvimento econômico regional, de acordo com o moderno conceito de sustentabilidade social.

$E$ isto ocorreu de diferentes maneiras: no reconhecimento e inclusão de suas formas de viver no que se define como "patrimônio arquitetônico" da região; na inclusão de seus depoimentos e opiniões sobre o que considerar patrimônio, o que preservar, o que é significativo; e na busca de vestígios do elemento africano em uma atividade tradicionalmente relacionada ao colonizador branco europeu: a mineração.

Assim, não se buscou registrar apenas os vestígios físicos da história regional comemorados e consagrados pela história oficial, mas trazer a representação dos cidadãos comuns na formação e transformação desta história. Desta maneira, buscou-se mapear os bens tangíveis e intangíveis, materiais e imateriais, que constituíssem elos de ligação da comunidade com o passado, reconhecidos enquanto partes de sua herança histórica e cultural.

0 texto que se segue traz alguns exemplos deste trabalho, onde a comunidade desenvolveu papel central no "resgate" de seus elementos identitários, de seus registros históricos e tradicionais que, somados àqueles tão mais antigos (as "vestígios de bugre"), completam o ciclo de experiências humanas desenvolvidas em um mesmo espaço geográfico compartilhado, resultando na atual paisagem cultural do Barro Branco. Buscando fornecer uma visão da abordagem do presente Programa, selecionou-se um item de pesquisa para cada tipo de patrimônio: técnicas contrutivas para o patrimônio material, e histórias do bairro Barro Branco, contadas pela própria comunidade, no que se refere ao patrimônio imaterial, conforme texto que se segue.

\section{Técnicas construtivas}

Fazem parte do patrimônio histórico cultural da comunidade do Barro Branco as unidades típicas de moradia e os padrões de construção das mesmas. Não são poucas as edificações existentes que ainda seguem os modos e padrões utilizados há muitos anos. As casas de barro, ou de pau-a-pique, ainda são maioria no bairro. Entretanto, já é possível encontrar alguns outros tipos de construções em alvenaria ou madeira.

As residências são simples, com poucos e pequenos cômodos, a rede elétrica não é presente em boa parte das residências. Sem exceção pode-se afirmar que quando há a construção de banheiros, estes são feitos fora da casa, e não foi encontrado em nenhuma delas a presença de chuveiros, pois os banhos são feitos nos rios, córregos ou açudes. Algumas ainda apresentam uma separação entre os cômodos de estar e a cozinha com forno à lenha. Nas maiores e mais tradicionais propriedades são erguidos paióis para o armazenamento da produção e/ou de bens e utensílios para a prática agrícola. É praticamente comum em todas as moradias a construção de galinheiros, que em geral se assemelham a poleiros erguidos a aproximadamente 1 metro do solo onde grandes cestos são colocados de forma tombada, com a abertura voltada para frente, de modo que as aves possam entrar e sair.

Em algumas propriedades, mas em menor número, é presente também a construção de currais para porcos, denominados 
localmente de "mangueiras". Nos últimos 15 anos as propriedades começaram a abrir um maior número de açudes, objetivando a criação de peixes para consumo próprio. Esta prática se deu principalmente com o auxílio de tratores da Prefeitura de Ribeirão Grande. São quatro os monjolos existentes, sendo um deles de uso comum, localizado na propriedade do senhor Braz Batista Mendes. Dos outros três, um está sem uso, pertencente ao senhor Caetano Mendes de Olivei$\mathrm{ra}$, e os outros dois pertencem a proprietários que não residem na comunidade e fazem pouquíssimo ou quase nenhum uso deles.

Nas propriedades onde a atividade agrícola de subsistência ainda é preponderante, junto às casas existem os terreiros, áreas abertas onde o feijão colhido passa pelo período de secagem e é batido. A localização das casas é sempre próxima às bicas ou a algum dos córregos ou riachos que cortam o bairro. Geograficamente, o bairro do Barro Branco merece destaque por ser um grande manancial de água, e há uma grande facilidade de obtenção da mesma por parte dos moradores. Junto às casas é comum ver-se pequenos canteiros onde desenvolvem plantios de ervas medicinais.

Nas maiores e mais tradicionais propriedades, precisamente na da senhora Maria Francisca do Nascimento e do senhor Caetano Mendes de Oliveira, a disposição das casas segue modelos antigos, formando verdadeiros "arraiais de famílias" dentro do bairro. Nos dois casos, os mais velhos têm as casas como centros gravitacionais, onde perifericamente os filhos ergueram suas moradias. Em ambos os casos, o da matriarca Maria Francisca do Nascimento e do patriarca Caetano Mendes de Oliveira, os filhos se estabeleceram no entorno, sendo que algumas edificações de uso comum ficam juntas à casa destes centros gravitacionais. 0 maior terreiro, o maior paiol e plantações de ervas medicinais ficam juntos à casa dos mais velhos. Este exemplo está presente na família da senhora Maria Francisca e do senhor Caetano Mendes, sendo que este ainda possui o monjolo usado por todos os membros da família.
Consideram-se aqui como propriedades tradicionais aquelas formadas pelas famílias mais antigas nos bairros que, como pode-se constatar nos diferentes resultados e relatórios obtidos nos trabalhos de campo, ainda asseguram alguns elementos culturais ainda não eliminados ou reinterpretados. Essas unidades mais tradicionais são as formadas pelos pioneiros na formação do bairro ou seus descendentes diretos. 0 conceito de maiores propriedades foi adotado a partir das áreas em hectares das propriedades, e não por acaso, as unidades mais tradicionais também constituem algumas das maiores propriedades.

No que se refere aos tipos de construção, o Barro Branco é um bairro que ainda hoje preserva alguns traços culturais antigos, entretanto, a comunidade adquiriu informações e elementos externos que Ihe propiciaram uma reinterpretação cultural em diversos elementos, dentre eles os métodos construtivos e os tipos de edificações presentes. Em linhas gerais, temos três tipos de construções no bairro. São eles:

- Casas de barro: é o modelo mais antigo de construção. Praticamente todos os moradores já habitaram neste tipo de residência. Ainda hoje estas casas são maioria no bairro. Comparadas com casas de barro de outros bairros, são as únicas que apresentam reboco feito com barro branco (o mesmo barro que deu nome ao bairro, Barro Branco).

- Casas de madeira: em geral o uso exclusivo de madeira é para paióis, currais e abrigos para monjolo, sendo que algumas poucas casas são feitas deste material.

- Casas de alvenaria: são casas recentes que se diferenciam apenas pelo material construtivo, pois quanto à forma seguem ainda os padrões de edificação das casas de barro.

- Outros tipos de construções: há algumas pouquíssimas casas feitas com os mais diferentes materiais que não se encaixam a um padrão único de edificação. São construções precárias que empregam o uso de 


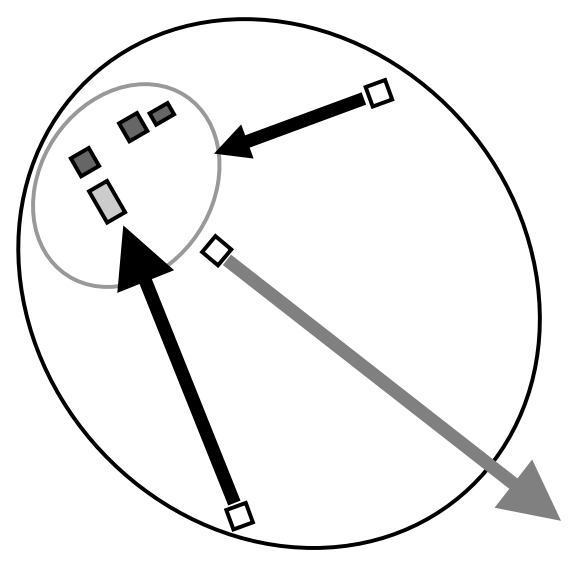

"Arraial familiar" da senhora Maria Francisca do Nascimento

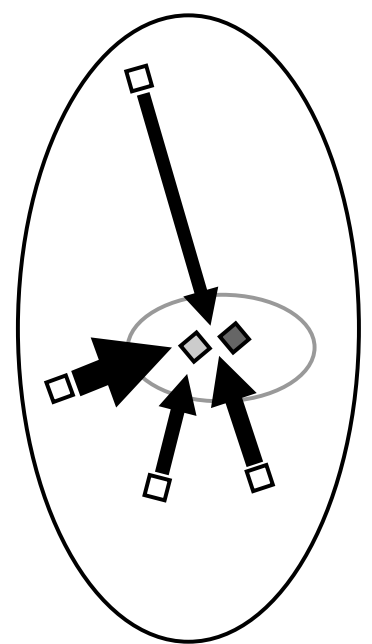

"Arraial familiar" do senhor Caetano Mendes de Oliveira

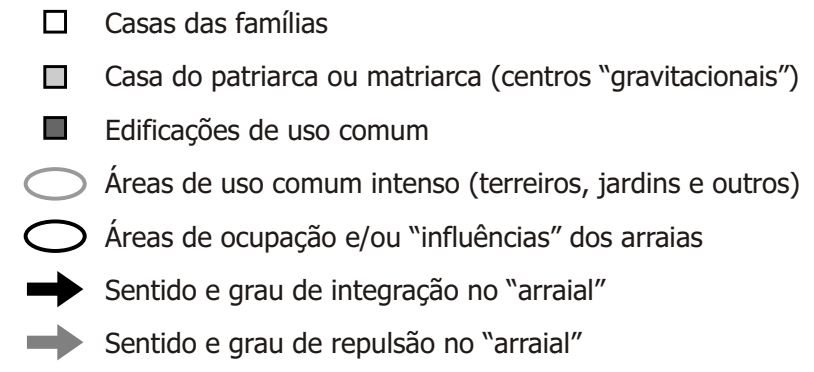

Esquema de círculos representativos dos "arraiais familares". As posições das casas estão de acordo com a localização geográfica encontrada durante as pesquisas em campo. Entretanto, se fosse criado uma figura representando a posição das mesmas unidades familiares considerando a dependência destas unidades em relação aos centros gravitacionais, teríamos outras dimensões e localizações. As áreas de "influências" referem-se as áreas de usos comum e individuais que formam os "arraiais familiares"

lonas, tapetes, restos de madeira e construções. Pertencem exclusivamente a proprietários que não moram no bairro. Os banheiros entram neste grupo por se apresentarem em vários tipos diferentes de propriedade em propriedade.

$O$ texto que se segue traz detalhes referentes às edificações de barro e de madeira, constituindo as mais tradicionais da região.

As costruções de barro são quase totalmente restritas apenas às residências, ha- vendo pouquíssimos celeiros e banheiros com paredes de barro. As casas podem ser divididas em dois modelos: as de um ou dois cômodos e as de três ou mais cômodos. Esta divisão se dá porque as de um ou dois cômodos são ocupadas por pessoas que moram sozinhas, sejam elas viúvas, solteiras ou separadas. No caso das moradias de um único cômodo, quarto e cozinha estão no mesmo espaço; nas de dois cômodos há a divisão entre o espaço de cozinha e o de dormir. Nas famílias constituídas há pelo 
menos três cômodos, o quarto dos pais, 0 quarto dos filhos e uma sala/cozinha, variando de caso para caso.

Em geral os cômodos são pequenos, com um espaço para deslocamento restrito e poucos móveis. As paredes de divisão chegam a uma altura média $1,90 \mathrm{~m}$, no máximo $2 \mathrm{~m}$ e nunca alcançam o forro ou telhado. Não há portas internas e cortinas são utilizadas como forma de separação dos cômodos. As portas de entrada não possuem trincos e são fechadas por fora com o uso de correntes e cadeados e, por dentro, com tramelas. São casas pouco iluminadas em virtude das pequenas janelas que recebem, sempre de formato quadrado com no máximo 50 centímetros de lado, sendo que, em alguns casos, os quartos não têm janelas. Os telhados podem ser de telhas de amianto, zinco ou de cerâmica. Foi encontrada apenas uma casa com cobertura de palha. Há indícios de que esta técnica tinha maior freqüência antigamente.

0 piso é de terra batida, sem nenhuma cobertura. A cozinha pode ou não ser junto à casa. Algumas casas têm cozinhas com fogões à lenha no interior, outras com fogões a gás. As cozinhas externas são sempre as de fogões à lenha. Ali, sobre os fogões à lenha são colocadas carnes para defumarem, conservando assim o alimento. Nestes casos também, podemos atribuir a baixa luminosidade ou o escurecimento das casas devido à ação da fumaça dos fogões, que pretejam telhados e paredes.

As casas de barro são também feitas em dois tipos, as de barro branco para reboco e as sem barro branco para reboco. 0 uso do barro branco, na verdade uma composição de solo de granulometria grosseira mais próxima do silte e de cor esbranquiçada presente na área, serve apenas para o reboco das casas, interna e externamente (Fotos). Pode-se atribuir que estas são casas típicas da comunidade, não encontradas até 0 momento em outros lugares. 0 tal barro branco, por sua granulometria mais grosseira, não se desfaz com facilidade ao longo do tempo através das intempéries climáticas como chuva, sol ou vento. Atribui-se a isso o fato de que, quando seco, esse material de granulometria grosseira fica como poros, antes ocupados pela água, maiores que os de barro marrom, dando espaços para as dilatações e contrações resultantes de variações termais com maior facilidade, não ocorrendo, assim, fissuras nas paredes.

O barro marrom, por ter uma granulometria mais fina, principalmente de argilas, não apresenta estes espaços porosos internos, sendo mais compactos e desta forma não permitindo os movimentos de dilatação e contração, e que quando exposto aos fatores climáticos criam rachaduras com maior facilidade.

Foi diagnosticado que anteriormente eram feitas vasilhas cerâmicas com o barro branco, entretanto não se pode afirmar 0 motivo da escolha desse material para a confecção das mesmas, o que se sabe é que esta já foi uma prática comum e que há tempos está em desuso.

De forma geral, a construção de uma casa de barro branco típica se dá da seguinte forma: escolhido o local a ser construída a casa, aplaina-se o terreno de acordo com as dimensões desejadas. Nas fundações, onde são erguidas as paredes, troncos de madeira, chamados de cernes, são cortados em forma retangular cúbica e colocados na base, praticamente enterrados entre 20 a 25 centímetros no solo com apenas a face superior exposta. Estes são os esteios, que podem ser feitos com trocos de nataleiros, canelas, guatambus ou, se forem encontradas, outras madeiras grossas e que resistam ao tempo tanto quanto as citadas. São os "cernes direitos", assim chamados por possuírem um tronco comprido, reto, grosso e resistente ao tempo.

J unto aos esteios, nas quinas e extremidades de paredes, são fixadas no solo de forma perpendicular às colunas ou travas de cerne direito. As travas ou colunas também são grossas, podendo ser cortados de forma retangular ou colocados como troncos brutos, sem tratamento. 0 diâmetro destas peças varia de $30 \mathrm{a}$ 50 centímetros e podem ser de árvores como a cajarana, o sassafrás, o guatambu, nataleiro ou canela. A altura das colunas ou travas varia 

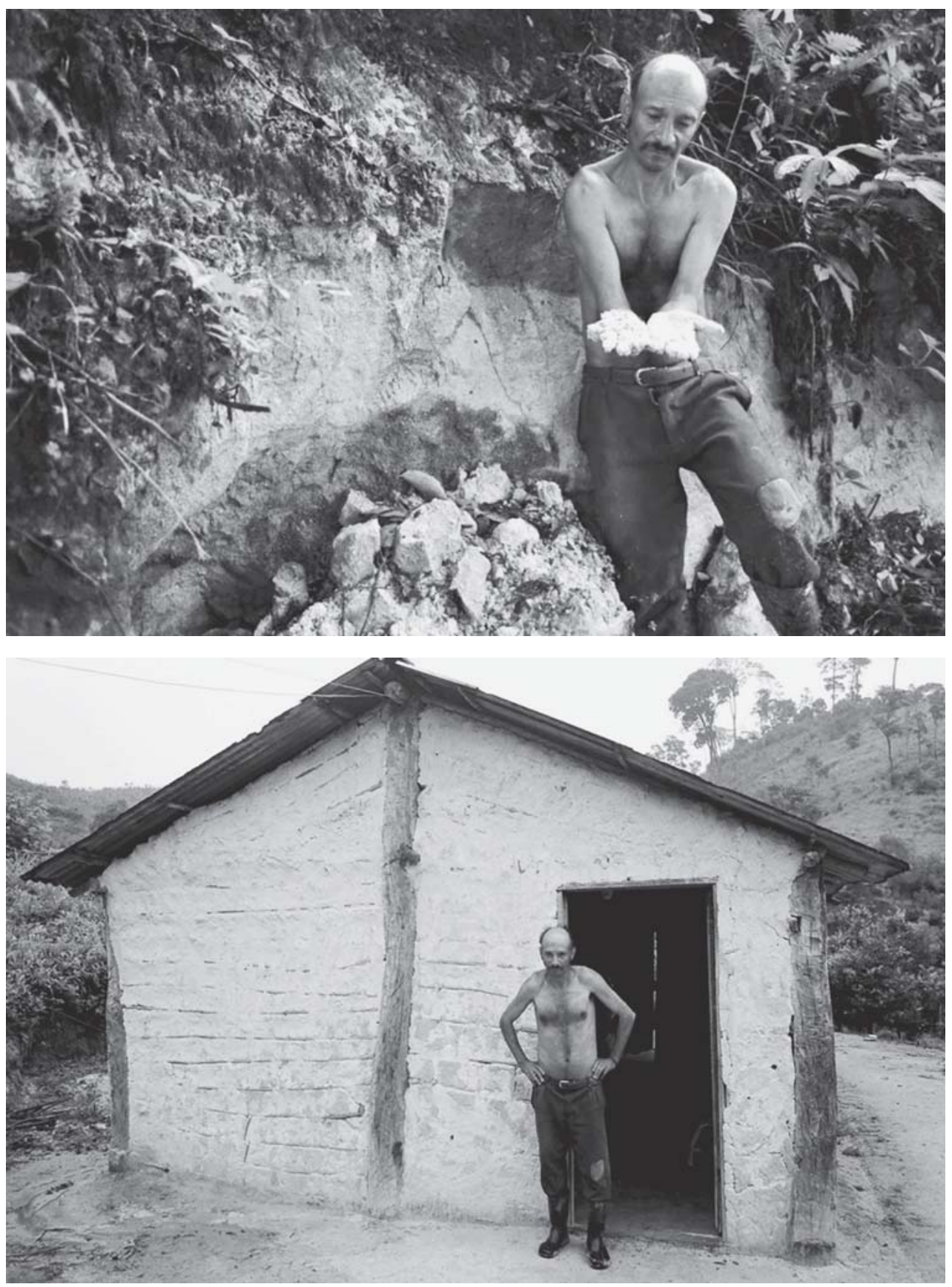

Técnicas construtivas:

A casa de barro branco: este famoso barro, que dá nome ao bairro, é uma argila fina captada localmente nas barrancas, próxima de grotas e córregos. 0 barro é aplicado na estrutura quadriculada de madeiras e preenchem-nas dando formas às casas, assim como aos fornos tradicionais do alto Paranapanema. 
de acordo com a posição em que se encontram, as que estão nas quinas das casas medem menos de 2 metros, e as que chegam ao meio da casa, medem a altura máxima do teIhado, no máximo, 2,50 metros.

Com as colunas já prontas são feitos os madeiramentos das paredes sobre os esteios. São as travessas e barrotes, uma verdadeira malha vazada construída predominantemente com madeiras taquara e guapeva, amarrados entre si com o uso de cipó d'alho. A área vazada, que pode ser retangular ou quadrada, varia de dimensão, mas é nela que se aplica a camada estrutural de barro marrom, retirado de algum barranco próximo ou do próprio local em que se ergue a casa. $O$ barro umedecido e pisoteado é colocado entre os buracos vazados e recobre toda o madeiramento da parede. Após esta etapa, com a parede já seca, é aplicada a camada de reboco feito com o barro branco, também umedecido e pisoteado.

Ainda com relação às travessas, que nas paredes são dispostas em linha horizontal, pelo menos três delas são mais grossas e firmes que as demais, em geral de guatambu e guapeva. Duas delas na parte coberta por barro na parede, e uma acima, no limite superior da mesma. Sobre esta travessa superior da parede é que são passados os caibros para a colocação do telhado. A estrutura do telhado é toda feita com caibros e travessas de guatambu ou guapeva, e sobre elas é que são colocadas as telhas de amianto (brasilite), cerâmica ou palha.

Os moradores atribuem às casas de barro uma característica de vantagem na superação do frio. Segundo eles, as paredes e o piso de terra batida contribuem para uma manutenção do calor gerado pelos fogões à lenha, propiciando uma melhor sensação termal.

Das casas de barro branco, com 3 cômodos ou mais, podemos destacar as propriedades da senhora Maria Francisca do Nascimento, e dos senhores Braz Batista Mendes e Antônio Mendes de Oliveira.

As casas que não recebem o tratamento com o barro branco precisam ser "retocadas" por barro em tempos mais curtos, pois as paredes ressacam e o barro se quebra, deixando exposto o madeiramento e os buracos antes ocupados pelo barro. São casas típicas de barro sem revestimento de barro branco, de um ou dois cômodos a da senhora Tereza Clarinda Vaz, e dos senhores Antônio Jacinto Vaz e Waldomiro José dos Santos, sendo que a deste último é a única encontrada que ainda possui telhado feito com palha.

Apesar de ser mais comum a construção de casas de barro, o senhor Braz Batista Mendes ergueu um paiol com paredes de barro. Os banheiros feitos de barro também são feitos da mesma forma, com acréscimo de piso de madeira, uma vez que estão sobre buraco de fossa.

O tempo médio para construção da casa de barro, descartado o tempo de corte da

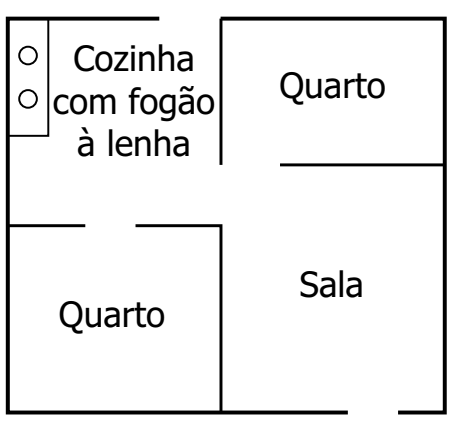

1
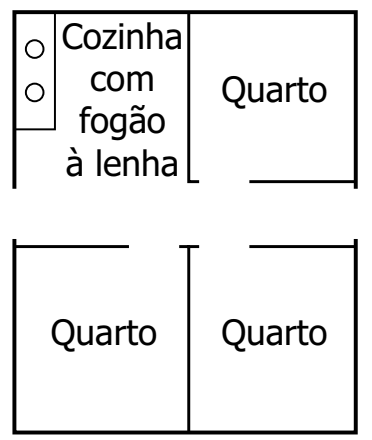

2

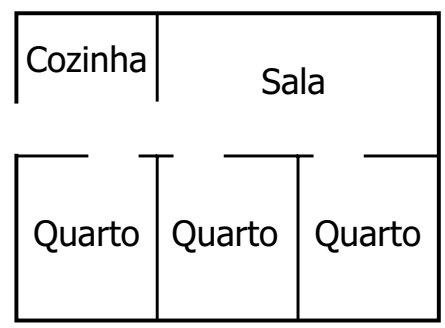

3

Croquis sem escala, apenas para referência de casas de barro branco habitadas por unidades familiares. Respectivamente das famílias do senhor Braz Batista Mendes (1), da senhora Maria Francisca do Nascimento (2) e do senhor Antônio Mendes de Oliveira (3). 


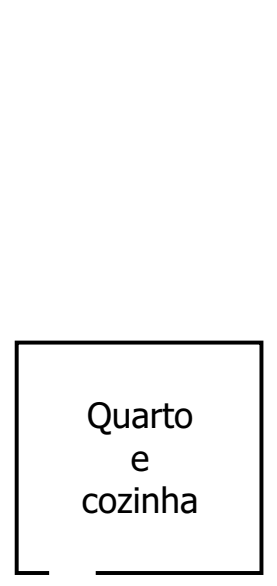

1

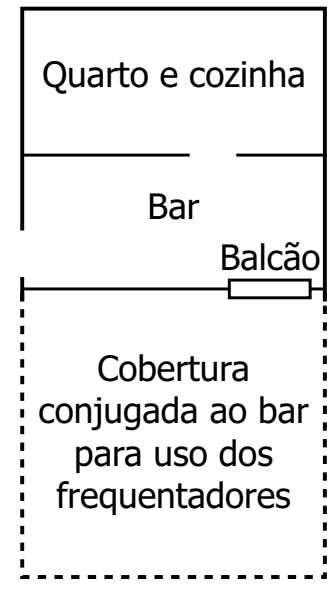

2

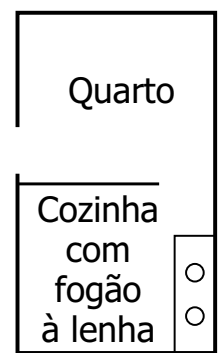

3

Croquis sem escala, apenas para referência de moradias de barro habitadas por um único morador e que não têm reboco de barro branco. Respectivamente da senhora Tereza Clarinda Vaz (1), Antônio Jacinto Vaz (2) e Waldomiro José dos Santos (3).

madeira, é entre quinze a vinte dias, desde que não ocorra nenhum imprevisto climático ou humano que atrapalhe a obra. Ainda hoje as casas de barro são levantadas com auxílio do "puxirão", termo utilizado para designar as atividades realizadas em mutirões de moradores. Durante o "puxirão" para a construção das casas, homens e mulheres realizam os mesmo trabalhos, sendo que as crianças ficam apenas nas etapas de transporte e de amassar o barro com os pés.

Em média, uma casa de barro é habitada por aproximadamente 20 anos, mesmo com todos os reparos e manutenções feitas durante esse período. Passado esse tempo, as casas já apresentam diversos problemas e costumam serem abandonadas para a construção de novas. As casas de barro mais antigas são as da senhora Maria Francisca do Nascimento, com aproximadamente vinte anos e a do senhor Braz Batista Mendes, com dezoito anos, sendo que as colunas e esteios são de datas mais antigas pois eram pertencentes à casa de seu pai.

Já as edificações feitas unicamente de madeira são em maior parte paióis, currais, abrigos para monjolos e alguns banheiros.
Poucas são as casas feitas exclusivamente de madeira. Os paióis de madeira são feitos da mesma forma que as casas de barro e com o mesmo material, distinguindo-se pelo fato de que os paióis não têm janelas, divisões internas ou paredes barro. No caso dos paióis as paredes são todas vazadas, faltando exatamente o barro para revestir as mesmas.

Os abrigos de monjolos geralmente se assemelham aos paióis ( Figuras 3 e 4, fotos). Considerando todas as construções, trata-se de obras mais modestas que não visam a moradia, e sim para o uso conjugado à atividade na lavoura.

O senhor Jaime Olívio de Macedo, proprietário que vai esporadicamente ao bairro do Barro Branco, possui dois exemplos de casa. A residência oficial é feita com diferentes materiais, e uma segunda moradia, não habitada, construída somente com tábuas e pedaços de troncos de nataleiros, guatambus e canela.

O senhor Maximiliano Wilson Godói, que veio para o bairro nos últimos dez anos, possui a única casa de madeira habitada e que junto à mesma possui um bar. No caso do senhor Maximiliano sua propriedade possui um açude e também uma construção de madeira 


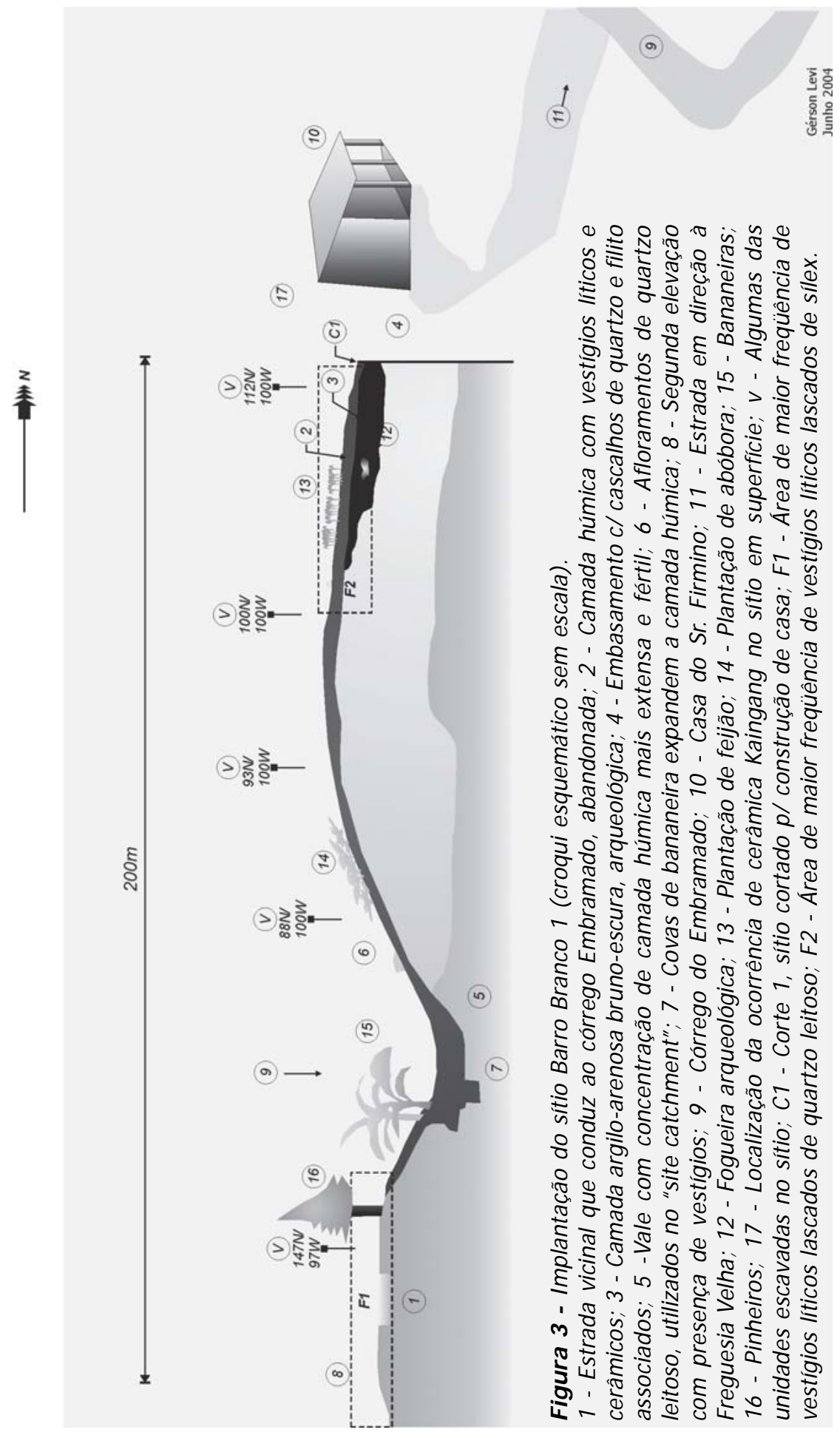




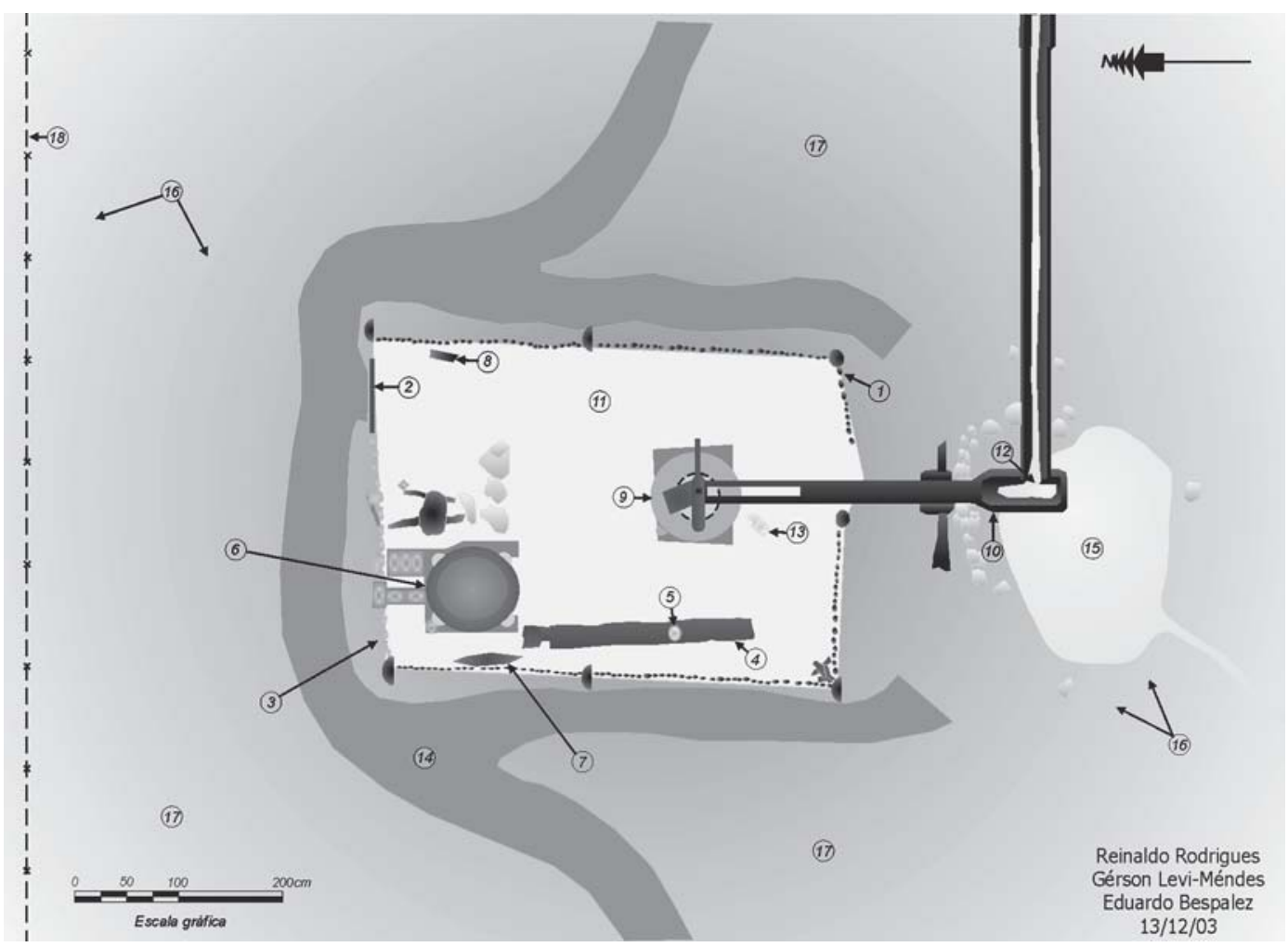

Figura 4 - Croqui do Monjolo Coletivo da Comunidade Barro Branco. 1 - Esteios de sustenção, ripas e varetas da parede da estrutura coberta do monjolo; 2 - Entrada/ porta do interior da estrutura coberta do monjolo; 3 - Telhas, tijolos, fragmentos de blocos rochosos, terra e outros materiais utilizados na sustenção da parede da estrutura coberta; 4 - Resto de suporte danificado de monjolo; 5 - Prato de ágata sobre o suporte danificado de monjolo; 6 - Forno/assador de farinha de milho; 7 - Assador de ferro encostado na parede da estrutura coberta do monjolo; 8 Madeira usada para manter aberta a porta da estrutura coberta do monjolo; 9 - Pilão tampado com um assador de ferro, uma tábua e um socador de monjolo, com a concavidade do pilão e o suporte do monjolo representado pelos tracejados; 10 - Suporte do monjolo; 11 - Chão de terra batida; 12 - Bica d'água que movimenta o monjolo; 13 - Galão branco de plástico; 14 - Trilhas (caminhos) em torno do monjolo; 15 - Limites da poça e canal de drenagem artificial cujas águas movimentam o monjolo; 16 - Barrancos nos limites da área escavada e terraplanada na encosta em que construiu-se o monjolo; 17 - Vegetação de pequeno porte (gramíneas, samambaias, etc) em torno do monjolo; 18 - Cerca de arame farpado.

para seus filhos, muito semelhante a uma palafita, sem paredes, próximo ao açude.

Estas casas de madeira possuem fachadas uniformes, com portas e janelas do mesmo material. Suas divisões internas seguem os mesmos padrões existentes em outros tipos de construções habitacionais do bairro. O emprego delas é restrito por não permiti- rem a construção de fogões à lenha no interior da casa, devido ao riso de incêndio.

As Tabelas 2 e 3, abaixo, mostram as edificação cadastrados no bairro do Barro Branco (unidades, tipos, sub-tipos e características marcantes), trazendo o conhecimento construtivo e os padrões de ocupação das comunidades atuais ali residentes. 


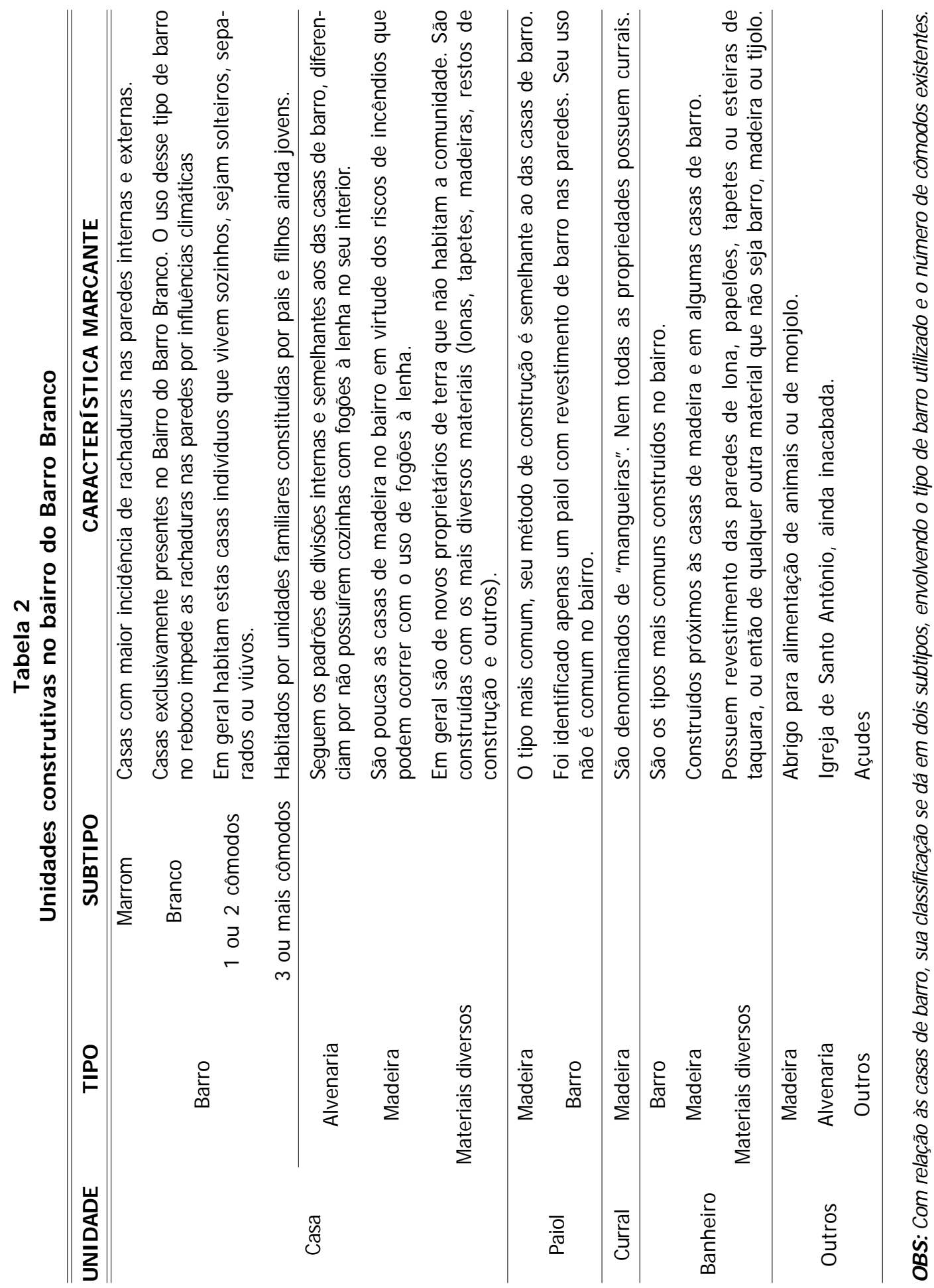




\section{Tabela 3}

Proprietários e construções no bairro do Barro Branco

\begin{tabular}{|c|c|c|}
\hline Proprietário & $\begin{array}{l}\text { Ano de contrução } \\
\text { [estimado] } \\
\text { (confirmado) }\end{array}$ & $\begin{array}{l}\text { Características } \\
\text { e/ ou } \\
\text { observações }\end{array}$ \\
\hline Adão Clarindo Vaz & [posterior a 1995] & $\begin{array}{l}\text { Casa de alvenaria, tida como a primeira a } \\
\text { obter rede elétrica e antena parabólica. }\end{array}$ \\
\hline Alsendino Louzada Melo & $\begin{array}{l}\text { [ sem data certa pois o } \\
\text { proprietário não reside } \\
\text { no local, provavelmente } \\
\text { erguida após 1992] }\end{array}$ & $\begin{array}{l}\text { Casa feita com restos de materiais cons- } \\
\text { trutivos, que não objetivava residência fixa. }\end{array}$ \\
\hline Ana Maria de Oliveira Ferreira & [1998] & Casa de alvenaria. \\
\hline Antônio Favaro & $\begin{array}{l}\text { [sem data certa, } \\
\text { provavelmente erguida } \\
\text { após 1992] }\end{array}$ & Casa de barro marrom. \\
\hline Antônio J acinto Vaz & (1998) & $\begin{array}{l}\text { Dois cômodos, um deles quarto e cozi- } \\
\text { nha e outro como bar. }\end{array}$ \\
\hline Antônio Mendes de Oliveira & (1999) & $\begin{array}{l}\text { É a única de barro branco dos mem- } \\
\text { bros da família do senhor Caetano Men- } \\
\text { des de Oliveira. }\end{array}$ \\
\hline Antônio Souto de Assunção & $\begin{array}{l}\text { [sem data certa pois o } \\
\text { proprietário não reside } \\
\text { no local, provavelmente } \\
\text { erguida após 1992] }\end{array}$ & Casa de alvenaria. \\
\hline Braz Batista Mendes & (1986) (2003) & $\begin{array}{l}\text { São duas residências, a casa de barro } \\
\text { branco, mais antiga, e a casa de alve- } \\
\text { naria, mais recente. }\end{array}$ \\
\hline Braz Franco da Silva & $\begin{array}{c}\text { [sem data certa pois o } \\
\text { proprietário não reside } \\
\text { no local] }\end{array}$ & $\begin{array}{l}\text { Casa de barro marrom, supõe-se que } \\
\text { tida como abandonada. }\end{array}$ \\
\hline Caetano Mendes de Oliveira & (1997) & $\begin{array}{l}\text { Foi a primeira casa de alvenaria feita por } \\
\text { alguém da família de Caetano Mendes de } \\
\text { Oliveira, está situada onde hoje se sabe } \\
\text { da existência de um sítio arqueológico. }\end{array}$ \\
\hline Celina Mendes de Oliveira Cruz & (1998) & Casa de alvenaria \\
\hline Eduardo Clarindo Vaz & -- & $\begin{array}{l}\text { Segundo o relatório sócio-econômico } \\
\text { há a existência de tal residência, po- } \\
\text { rém ela não foi encontrada. }\end{array}$ \\
\hline Eliseu Ursulino de Moura & $\begin{array}{c}\text { sem data certa pois o } \\
\text { proprietário não reside } \\
\text { no local] }\end{array}$ & Casa de barro marrom \\
\hline
\end{tabular}


Tabela 3 (cont.)

Proprietários e construções no bairro do Barro Branco

\begin{tabular}{|c|c|c|}
\hline Proprietário & $\begin{array}{l}\text { Ano de contrução } \\
\text { [estimado] } \\
\text { (confirmado) }\end{array}$ & $\begin{array}{l}\text { Características } \\
\text { e/ ou } \\
\text { observações }\end{array}$ \\
\hline Gilmar Favaro & -- & $\begin{array}{l}\text { Segundo o relatório sócio-econômico } \\
\text { há a existência de tal residência, po- } \\
\text { rém ela não foi encontrada. }\end{array}$ \\
\hline Gumercindo Gonçalves Ribeiro & $(2003)$ & $\begin{array}{l}\text { Obra de alvenaria inacabada, com mui- } \\
\text { to a se fazer, porém, abandonada. }\end{array}$ \\
\hline J aci Raimundo da Silva & (2003) & $\begin{array}{l}\text { Casa de barro marrom, com algumas } \\
\text { partes cobertas por lonas. }\end{array}$ \\
\hline J acinto Martiniano da Costa & $\begin{array}{c}\text { [sem data certa pois o } \\
\text { proprietário não reside } \\
\text { no local] }\end{array}$ & Casa de barro marrom. \\
\hline Jaime Olívio de Macedo & $\begin{array}{l}\text { [sem data certa pois o } \\
\text { proprietário não reside } \\
\text { no local, provavelmente } \\
\text { erguida após 1992] }\end{array}$ & $\begin{array}{l}\text { Casas de madeira ou de restos de ma- } \\
\text { térias construtivos. }\end{array}$ \\
\hline J oão Francisco Mendes & -- & $\begin{array}{l}\text { Segundo o relatório sócio-econômico } \\
\text { há a existência de tal residência, po- } \\
\text { rém ela não foi encontrada. Sabe-se } \\
\text { que ele possui algumas poucas tarefas } \\
\text { no bairro e uma propriedade maior, com } \\
\text { casa, no bairro de Ouro Fino. }\end{array}$ \\
\hline J oão Rodrigues do Nascimento & [sem data certa] & $\begin{array}{l}\text { Casa de barro com banheiro revestido } \\
\text { com material de cestarias. }\end{array}$ \\
\hline Luiz Mendes de Oliveira & (1999) & Casa de alvenaria \\
\hline Maria Aparecida Vaz de Oliveira & (1999) & Casa de alvenaria \\
\hline Maria Assunção & -- & $\begin{array}{l}\text { Não foi possível obter nenhuma infor- } \\
\text { mação a respeito. }\end{array}$ \\
\hline Maria dos Santos Ferreira & -- & $\begin{array}{l}\text { Não foi possível obter nenhuma infor- } \\
\text { mação a respeito. }\end{array}$ \\
\hline Maria Francisca do Nascimento & [1990] & $\begin{array}{l}\text { É uma das casas de barro mais anti- } \\
\text { gas do bairro, porém as datas diver- } \\
\text { gem sobre a construção, e as infor- } \\
\text { mações são mais próximas do ano de } \\
1990 \text {. }\end{array}$ \\
\hline Maximiliano Wilson de Godói & $\begin{array}{l}\text { [sem data certa, } \\
\text { provavelmente erguida } \\
\text { após 1995] }\end{array}$ & $\begin{array}{l}\text { Casa de madeira que também funcio- } \\
\text { na como estabelecimento comercial. }\end{array}$ \\
\hline
\end{tabular}


Tabela 3 (cont.)

Proprietários e construções no bairro do Barro Branco

\begin{tabular}{|c|c|c|}
\hline Proprietário & $\begin{array}{l}\text { Ano de contrução } \\
\text { [estimado] } \\
\text { (confirmado) }\end{array}$ & $\begin{array}{l}\text { Características } \\
\text { e/ ou } \\
\text { observações }\end{array}$ \\
\hline Miguel Vaz de Andrade & [1992] & $\begin{array}{l}\text { Casa de barro marrom, uma das primei- } \\
\text { ras a ser erguida pelos novos morado- } \\
\text { res do bairro. }\end{array}$ \\
\hline Milton César Vaz & -- & $\begin{array}{l}\text { Segundo o relatório sócio-econômico } \\
\text { há a existência de tal residência, po- } \\
\text { rém ela não foi encontrada. }\end{array}$ \\
\hline Milton Souto da Silva & -- & $\begin{array}{l}\text { Segundo o relatório sócio-econômico } \\
\text { há a existência de tal residência, po- } \\
\text { rém ela não foi encontrada. }\end{array}$ \\
\hline Moisés Messias da Silva & [1992] & Casa de barro marrom \\
\hline Octacílio dos Santos & & $\begin{array}{l}\text { Segundo o relatório sócio-econômico } \\
\text { há a existência de tal residência, po- } \\
\text { rém ela não foi encontrada. }\end{array}$ \\
\hline Orlando Fávero & -- & $\begin{array}{l}\text { Segundo o relatório sócio-econômico } \\
\text { há a existência de tal residência, po- } \\
\text { rém ela não foi encontrada. }\end{array}$ \\
\hline Tereza Clarinda Vaz & $(2003)$ & $\begin{array}{l}\text { Casa de barro marrom, a última a ser } \\
\text { erguida no bairro, no primeiro bimestre } \\
\text { de } 2003 \text {. }\end{array}$ \\
\hline Vírgilio Marcos da Cruz & $\begin{array}{c}\text { [sem data certa pois o } \\
\text { proprietário não reside } \\
\text { no local] }\end{array}$ & Casa de barro marrom. \\
\hline Waldomiro José dos Santos & $(2000)$ & $\begin{array}{l}\text { É a única de barro marrom que ainda } \\
\text { utiliza cobertura de palhas sobre a casa, } \\
\text { uma das paredes caiu durante as for- } \\
\text { tes chuvas que ocorreram no início de } \\
\text { janeiro de } 2004\end{array}$ \\
\hline
\end{tabular}

OBS: A tabela acima foi elaborada com dados obtidos nas pesquisas de campo, na consulta do relatório sócio-econômico e dos mapas elaborados e fornecidos pela Companhia de Cimento Ribeirão Grande. Das 44 famílias registradas pelos relatórios sócio-econômicos, 9 deles não possuem casas, das 35 restantes, 24 delas foram identificadas de forma preliminar durante as etapas de campo, sendo que destas, 18 tiveram uma abordagem mais aprofundada. Há um total de 11 unidades familiares que pelos relatórios sócio-econômicos possuem residências, entretanto, as informações obtidas em campo, confrontadas com os dados dos relatórios, são insuficientes para afirmar a existência ou não das residências, exceto por dois únicos casos identificados através dos mapas. 
É latente a percepção de que os indivíduos que possuem propriedades no bairro e não o habitam tendem a construir residências que fogem aos padrões culturais locais. As casas feitas com restos de obras e materiais diversos sinalizam mais para uma ocupação descompromissada com o local e seus hábitos culturais do que unicamente um fator de pobreza. São casas que não representam o patrimônio local e que descaracterizam o bairro.

\section{História de Barro Branco}

A comunidade do Barro Branco é composta por cinco núcleos de uma mesma raiz familiar, havendo, no entanto, dois núcleos principais, cujos membros tem uma relação de parentesco muito próxima e convivem numa mesma área, com pouca distância entre uma residência e outra. Mas como teve inicio esse arraial? Soubemos que os primeiros a se instalarem naquela região foram os pais das duas senhoras mais velhas da comunidade. Não foi precisada a data, mas provavelmente por volta da década de 1930 havia uma fazenda exatamente naquelas terras que empregava mão de obra para trabalhar nas lavouras. Os moradores mais antigos costumam se referir à fazenda de "um japonês" que era o proprietário. Foi então que vieram Antonio Rodrigo do Nascimento, nascido em Bairro Maciel, e Pedra Paulina do Nascimento, nascida em Ouro Fino. ${ }^{3}$

Eles se casaram e os filhos começaram a nascer. Moravam em Sumidouro e apenas trabalhavam na fazenda nessa época, segundo informação de uma das filhas ainda viva. Com o tempo, a fazenda foi desativada e o casal foi convidado a tomar conta das terras tendo permissão para plantar e morar na propriedade. Segundo informação de Dna Lourdes, uma das filhas do

(3) Informação oral obtida através de entrevista com Dna Lourdes e Dona Maria. casal, eles ganharam a terra como doação dos proprietários da fazenda e passaram a viver de subsistência. Plantavam para comer e o que sobrava era vendido nas comunidades vizinhas. Possuíam também criação de galinhas, porcos e algum gado para abastecer a casa de leite e eventualmente de carne. Os filhos desse casal nasceram em parte no Sumidouro e em parte no Barro Branco, sendo ao todo cinco: Celestino, Maria, Lourdes, Ana e Ervelina, e é parte deles e de seus descendentes que hoje nos contam a sua história.

Dos cinco filhos de Antonio e Pedra Paulina duas filhas estão vivas e cada uma é a matriz de um núcleo de organização familiar, ou seja, em torno delas criou-se uma relação estreita de laços de parentesco, formando dois núcleos principais dentro do Barro Branco. Aquela comunidade se organizou em família, porém não há um núcleo só, como talvez tenha havido quando o patriarca ou a matriarca da família estavam vivos. Hoje em dia a comunidade se divide tênuamente entre dois núcleos familiares, um deles centralizado na figura de Dona Maria e outro na de Dona Lourdes. Para facilitar a compreensão da teia de relações que abrange esta comunidade, trataremos de um núcleo de cada vez, mas deve ser ressaltado que essa separação é exclusivamente metodológica e não um reflexo da realidade dessas pessoas.

\section{Núcleo Dona Lourdes}

A Dona Lourdes é uma senhora de 63 anos de idade casada com Seu Caetano e mãe de sete filhos Antonio, Senhorinha, Roque, Luis, Ana, Celina e Dirceu. Como alguns dos filhos e seus descendentes não moram mais em Barro Branco, concentramos o trabalho no perfil feminino e infantil dos moradores que ainda residem lá.

Dos filhos de Dona Lourdes, Senhorinha, Roque e Luis se mudaram e hoje vivem com as famílias em outros bairros próximos. Dirceu morreu com um ano de 
idade de tosse comprida. Portanto, o trabalho se concentrou nas famílias de Antonio, Ana e Celina. Mas primeiramente trataremos da figura ao redor da qual todas as demais pessoas vivem, que é a Dona Lourdes.

Dona Lourdes acha que nasceu no Sumidouro, não sabe ao certo (Foto). Desde pequena, por volta dos 10 anos de idade, começou a ajudar o pai na lavoura, assim como todos os outros irmãos, e quando tinha 13 anos mudou-se com a família para o Barro Branco. Aos 15 anos se casou e teve seis filhos, hoje tem 24 netos e 4 bisnetos. Mesmo depois de casada Dona Lourdes continuou a trabalhar na roça, e possuía criação de animais. Hoje em dia ela não trabalha mais, se diz doente e sem condições, por isso o neto Roque mora com ela e cuida de criação de galinhas e suínos, além de ajudar o avô, Seu Caetano, na lavoura. A nora de Dona Lourdes, Zilda, é quem lava a roupa e faz o serviço de casa mais pesado. Ela não soube dizer ao certo que doença tem, mas "sofre dos pulmões" e já foi desenganada pelos médicos, que receitam apenas remédio para dor. Frente à perspectiva de morte dona Lourdes se mostra conformada e justifica que é a vontade de Deus. Mesmo assim não larga o cigarro de paIha que fuma desde menina, pois aprendeu com o pai fumando um pouquinho com ele todos os dias.

Dona Lourdes é o centro deste núcleo familiar e é chamada de Madrinha por todos os netos, noras e genros. Todos se dirigem pela manhã à casa dela e, unindo as palmas das mãos em frente ao peito, pedem a benção. Ela mora em uma casa de alvenaria construída recentemente como substituta da antiga casa de pau a pique, da qual só restou a antiga cozinha e o fogão à lenha. Ela se diz religiosa e as paredes da sua sala são cobertas de imagem de santos com São Jorge, Cosme e Damião e Nossa Senhora do Bom Parto, que dividem o espaço em meio a brinquedos ganhos nas

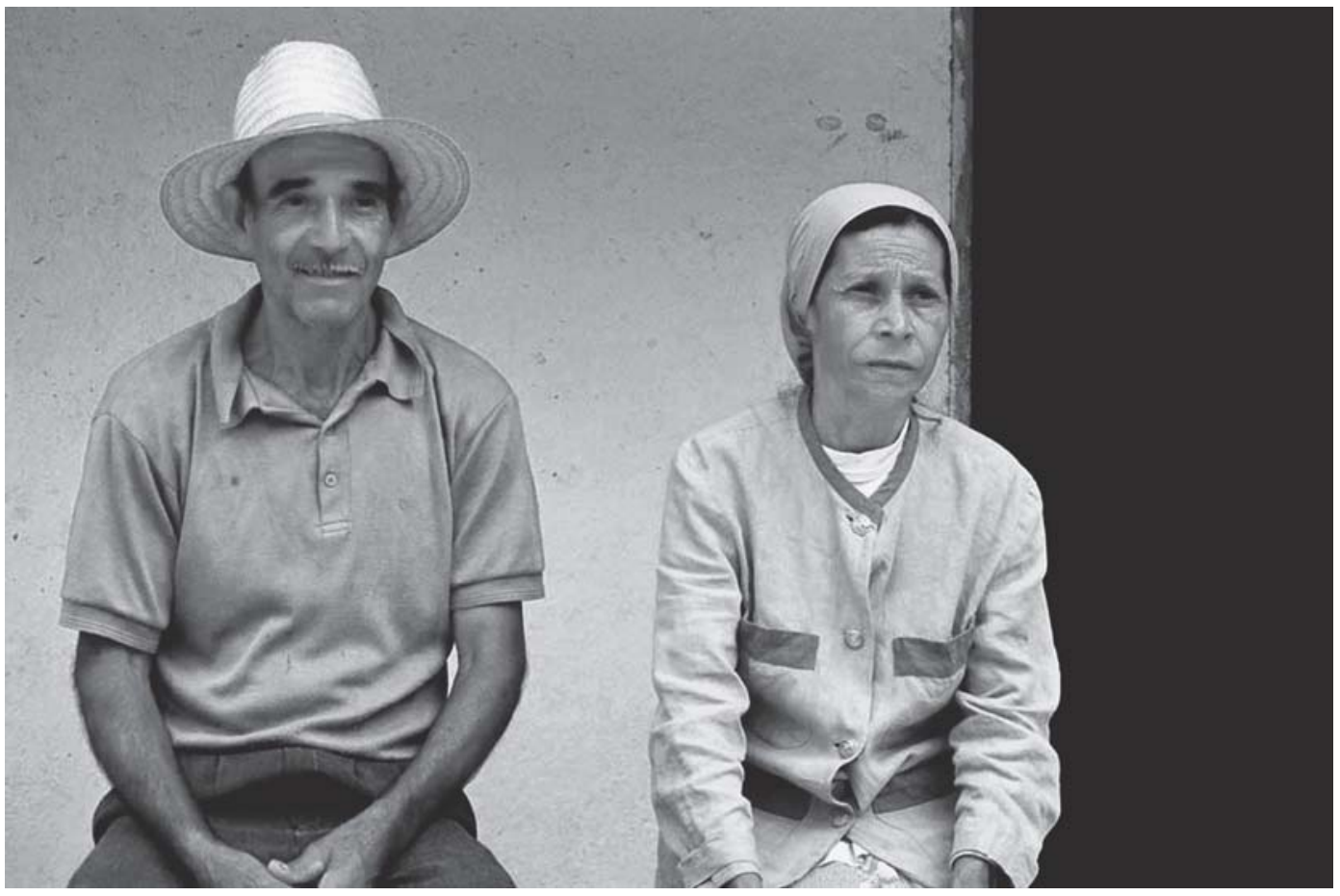




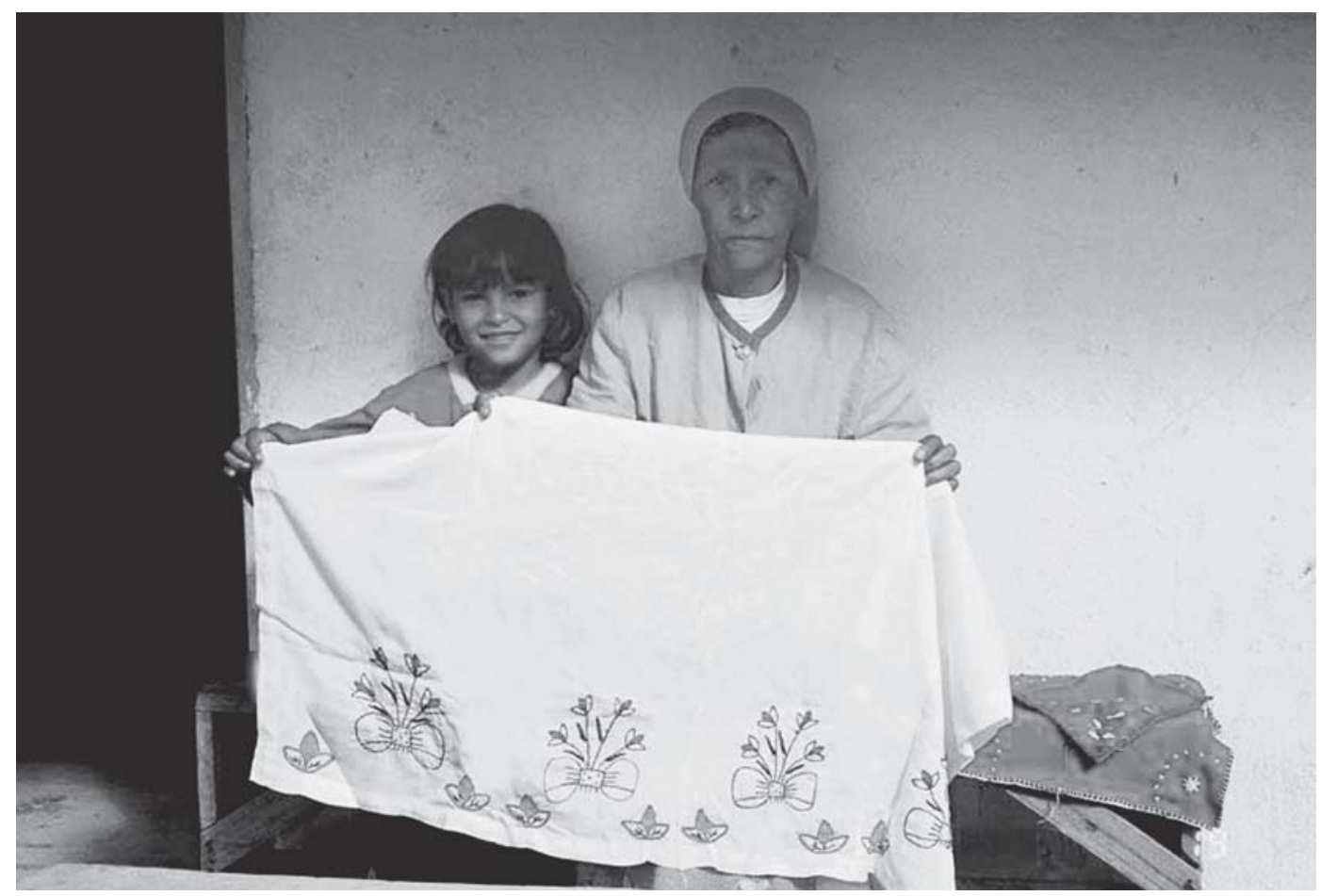

festas e quermesses da região. ${ }^{4}$ Diz que reza todos os dias em um pequenino altar no canto da sala e que quando tem missa ela vai, em média uma vez por mês.

Dona Lourdes foi durante muitos anos a parteira da comunidade e responsável pela maior parte dos nascimentos dos parentes. Dizem que ela e a irmã Ervelina aprenderam sozinhas o ofício, e que Dona Lourdes fez seus próprios partos, sozinha e sem ajuda. A irmã Ervelina já faleceu e Dona Lourdes encerrou as suas atividades há treze anos atrás, quando fez o último parto do nascimento de sua neta Jimerilda. Ela afirma que só o fez porque não deu tempo da mãe chegar ao hospital, porque naquela época já era

(4) Os brinquedos ganhos nas quermesses podem ser encontrados em várias casas do Barro Branco, pendurados nas paredes como se fora um enfeite ou um objeto de ostentação. Mesmo as crianças mantêm os brinquedos dentro das caixas, porque, segundo J osieli "a gente tem dó de usar". proibido. Ao ser indagado o porque da proibição, Dona Lourdes afirma que começaram a dizer que não podia ser feito sem licença, e que ela não tinha formação para realizar aquilo. Então ela deixou de ser parteira, mesmo tendo realizado vários partos, todos bem suscedidos. Hoje em dia, todas as mães do Barro Branco vão para a cidade e têm os seus filhos no hospital de Ribeirão Grande.

Dona Lourdes mostra os trabalhos manuais que aprendeu a fazer com a mãe e que representam uma das poucas atividades que ela ainda realiza. São bordados, colchas de retalhos e forros de estofados que ela coloca nas poltronas e cadeiras da sala (Foto). Os bordados são simples e ela os faz com o aviamento que tiver em casa, fazendo bordas e desenhos em retalhos de panos que se transformam em toalhinhas de sala e cozinha. As colchas de retalhos são feitas com partes de roupas que se estragaram ou que não se usam mais, costurados os retalhos um a um na mão até formarem uma colcha. Já os estofados são feitos com 
muitos pequenos retalhinhos de panos coloridos que são costurados um a um numa base de pano maior, ou entrelaçados na base formando um trançado no avesso de modo a ficarem presos à base sem que se precise usar linha para costurá-lo. Aparentemente esse é o único tipo de atividade artesanal que ela produz, enquanto que o marido, Seu Caetano, faz pilões entalhados na madeira e cestaria em taquara. Ele e um sobrinho, Adão, são os únicos homens que produzem cestaria no Barro Branco. Essa atividade local é masculina e, ao que parece, eles foram os únicos que aprenderam com Seu Jacinto, falecido esposo de Dona Maria e cunhado de Seu Caetano. Nenhum outro homem ou jovem da comunidade sabe como fazer os balaios. Tendo a taquara em mãos, seu Caetano manufatura um cesto em 25 minutos e permitiu filmar e fotografar todas as etapas de seu trabalho (Foto).

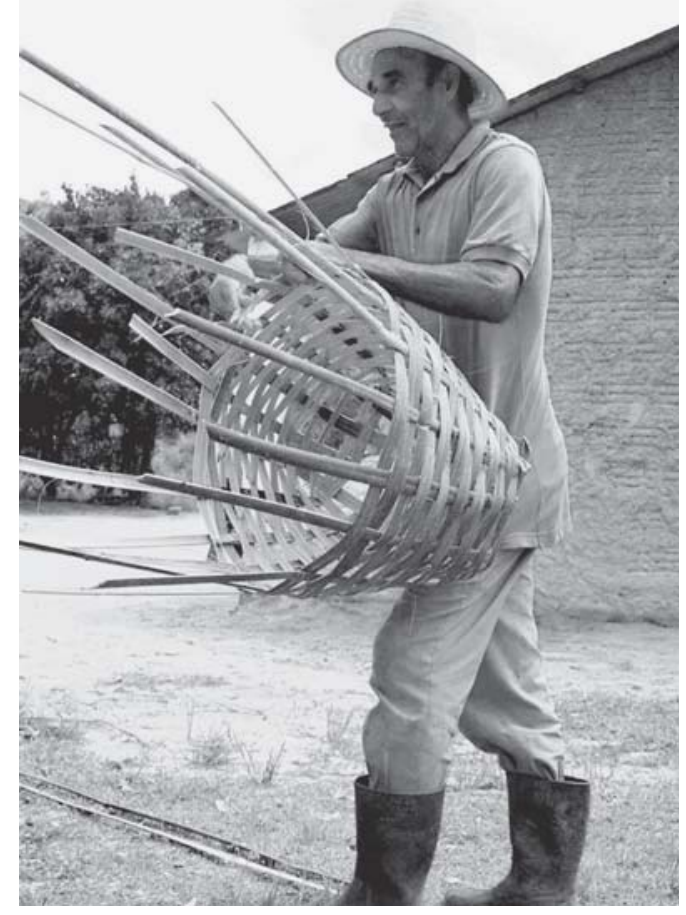

Os cestos são usados para transportar as frutas e legumes da lavoura, para armazenar alimentos em casa, para guardar coisas pessoais, para abrigo das galinhas no galinheiro. Vai produzir muitos mais quando se mudar para a nova casa que está em fase de construção.

Dona Lourdes é uma das maiores conhecedoras das plantas da região e das ervas, raízes e outras plantas que podem ser utilizadas como medicamento. Ela foi responsável pelo ditado de parte da lista de plantas medicinais, suas funções e modo de preparo que consta em anexo. Ela diz que aprendeu sobre as ervas com a mãe e passou os ensinamentos para as filhas e netas, mas ressalta que alguns homens também são conhecedores das plantas. Ao que parece esse conhecimento é mais difundido dentro de um universo feminino, no entanto este saber é de certa forma mais geral, dependendo da inclinação e interesse de cada um no conhecimento desta prática medicinal.

Em entrevista, Dona Lourdes conta que antigamente não havia médico na região, então eles costumavam levar os doentes na curandeira, e usavam os remédios caseiros. Ela própria diz que já foi muito na curandeira quando era nova, mas não se lembra quais os procedimentos médicos e nem que tipo de problema a levou a procurar essa ajuda. Ela conta que antigamente, quando alguém da comunidade morria, era levado na rede pelo antigo peabirú (trilha) para um cemitério. Dona Lourdes conta que hoje em dia os mortos são enterrados no cemitério da cidade.

Antigamente os velórios aconteciam nas casas e muita gente ia e passava a noite inteira velando o morto até que amanhecesse. Os parentes ofereciam almoço e janta para todos. Quando ia se comprar o tecido para fazer a roupa para vestir o defunto, já se comprava pano para vestir o resto da família que estaria em luto. Caso a morte fosse de pai ou mãe, o luto deveria durar um ano, caso fosse marido ou esposa, seis meses, e se não fosse um membro da família a falecer não era obrigado vestir preto. Dona Lourdes conta que se lembra que 


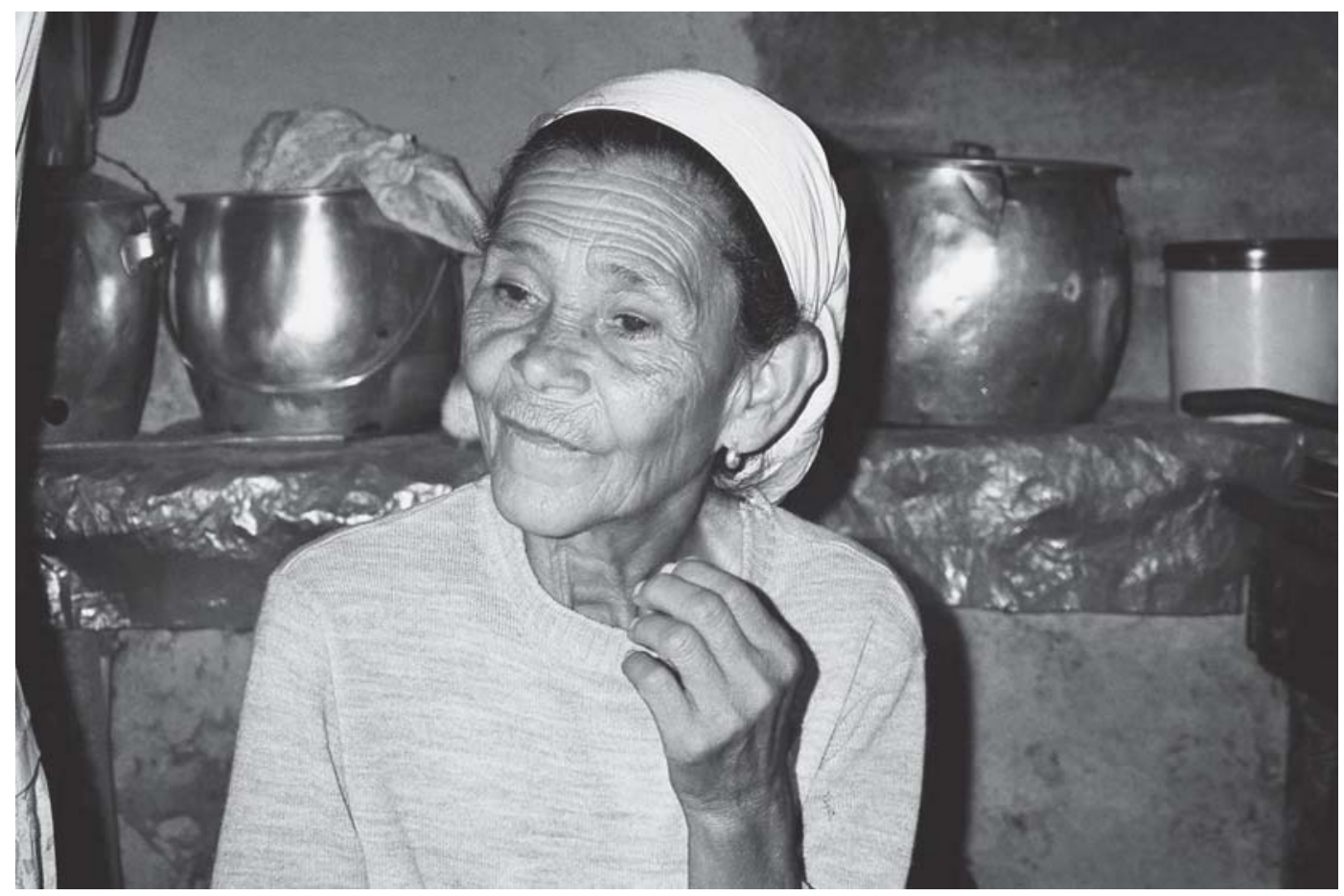

os pais sempre visitavam os mortos, levavam flor e cantavam orações. Hoje em dia no Dia das Almas, ${ }^{5}$ todos levam flor para os mortos, mas estes estão enterrados em Ribeirão Grande.

\section{Núcleo Dona Maria}

O núcleo de Dona Maria é composto por ela, seus filhos e netos. Ela tem 65 anos, é irmã de Dona Lourdes e mora no arraial em casa de pau a pique com a filha solteira chamada Pedra. Dona Maria é cega dos dois olhos e não sabe o que resultou nesta cegueira (Foto). Ela explica dizendo que a menininha dos olhos está tampada. Quando indagada a respeito dessa menininha ela diz que um dia sentiu muita dor num olho e depois no outro, e que depois da dor a menininha dos olhos dela ficou tampada e que agora ela está com problema.

(5) Dia de Finados
Dona Maria nasceu em Ouro Fino, morou no Sumidouro e viveu quase a vida toda no Barro Branco. Nunca foi para a escola porque não tinha nenhuma no bairro, "a única escola que tinha era a roça" afirma ela, que ajudava diariamente o pai na lavoura. Não lembra quantos anos tinha quando começou a trabalhar, mas sabe que o pai levava todos os filhos bem pequenos, pois ele era muito pobre e trabalhava com os filhos carpindo o terreno dos outros. A mãe ficava em casa cuidando das coisas e dos irmãos menores. Dona Maria ajudava o pai a plantar milho, feijão, arroz, tudo para comer em casa e o que sobrava era vendido na cidade, e diz que foi do mesmo modo que os filhos dela se criaram. No entanto, os filhos mais novos de Dona Maria puderam estudar um pouquinho no Mobral.

Dona Maria não se lembra com que idade casou, mas sabe que era nova. O marido, Seu Jacinto, era de Ouro Fino e eles se conheceram quando ela ainda morava com a família no Sumidouro. Os fi- 
Ihos todos nasceram e se criaram no Barro Branco, ajudando Seu Jacinto no roçado. Dona Maria, depois de casada, ia menos à roça, mas o marido continuava trabalhando na plantação, além de lidar com couro e fazer cestaria. Pelo que foi informado, Seu Jacinto foi o pioneiro naquele lugar a trabalhar com cestaria e foi responsável por passar seus conhecimentos ao cunhado Seu Caetano e ao filho Adão, os únicos que preservaram essa atividade. Seu Jacinto faleceu há seis anos, ninguém soube explicar a causa.

Os filhos de Dona Maria nasceram todos em casa e foi a irmã Dona Lourdes quem fez os partos. Mas os netos foram e vão quase todos para o hospital na hora do nascimento. Segundo Dona Maria, o parto em casa era sem remédio nem curativo nessa hora "só Deus que iluminava e os Santos". 0 único remédio que se usava era salmoura para evitar infecção e bebia-se pinga com arruda para recaída.

Dona Maria se diz religiosa e conta que sempre foi com os pais para a igreja no Barro Branco, Ouro Fino e Ribeirão. Foi batizada e crismada "graças a Deus". Ela fez um altarzinho para Nossa Senhora dentro de casa, com São José e outros santinhos pequenos e fala que quando ela mudar o santinho vai junto.

Conta que quando era nova era comum a igreja fazer festas em Ribeirão Grande e em Ouro Fino, como festas de Nossa Senhora, do Bom Jesus, e um monte de outros santos, e que ela e sua família iam a todas. Diz que nestas festas tinha uma procissão para o santo, vinha um padre rezar a missa. Depois era feito um leilão para arrecadar dinheiro para a igreja e que normalmente a comida servida era café com pão, mas que isso já não existe há muitos anos porque os mais velhos se foram e tudo ficou abandonado. Contou também que a festa de Santo Antonio e de São João era muito bonita em Barro Branco, com procissão e missa, e que faziam bolo para vender e assavam carne, mas que tudo isso também foi largado. Segundo ela, antigamente havia batizado e casamento na igreja da comunidade com dança e música de tocador de viola e cantor. Dona Maria diz que hoje em dia não vai mais em festas, e que ninguém mais vai.

Aprendeu a cozinhar com a mãe tudo o que sabe, aprendeu também com a mãe a costurar e fazia colchas de retalho quando ainda tinha visão. Não sabe fazer tricô nem crochê. Ela também ajudou a barrear a casa com a ajuda de toda a família, conta ela. A casa foi feita há 16 anos, antes era outra casa de pau a pique no mesmo lugar, estragava uma, colocava outra. Por fora ela é revestida de barro branco para dar um melhor acabamento. 0 fogão foi a Candinha que fez, mas Dona Maria também sabe fazer e sempre fazia, foi a mãe que ensinou.

Na cozinha de Dona Maria há sobre o fogão um tacho de cobre que era muito utilizado para torrar a farinha de milho do monjolo e para fazer biju. Ela conta que até há pouco tempo atrás a filha Pedra ainda fazia porque ela prefere a farinha do monjolo que a comprada. Tem também um tacho de melado de cana que utilizaram muito para fazer rapadura. Dona Maria conta que foi ela quem ensinou as filhas a cozinharem de tudo. Diz que quando o marido era vivo e tinha muita criação, eles salgavam a carne de porco e penduravam para secar num gancho sobre o fogão a lenha. Até hoje é possível ver o gancho pendurado lá.

Dona Maria tem também em casa um antigo plantador de grãos que o marido e os filhos utilizavam na roça para semear principalmente o feijão. Na parede presa ao lado do semeador há ferragens e estribos de cavalos confeccionados pelo falecido marido, e atrás da porta sua filha Tereza mostra antigas esteiras de palha nas quais, até não muito tempo atrás, todos dormiam, porque não se usava cama em Barro Branco.

Hoje em dia dona Maria passa a maior parte de seu tempo dentro da cozinha na companhia das filhas. Apesar de ser uma 
pessoa idosa e cega, recebeu muito bem a equipe e, lúcida, assim como a irmã dona Lourdes, rememorou muitos fatos e acontecimentos de seu passado e da história de Barro Branco.

\section{Arqueologia Pública e turismo: os encanados de Ribeirão Grande}

Os sítios arqueológicos / históricos conhecidos localmente como "encanados" correspondem a estruturas construtivas associadas ao ciclo da mineração que se desenvolveu, na região do alto Paranapanema e vale do Ribeira de Iguape, entre os séculos XVI e XVIII. Atribuídos em parte aos jesuítas espanhóis que chegaram ao vale do Paranapanema utilizando-se de itinerários indígenas, em parte aos bandeirantes em constante incursão nas áreas de aldeamento já estabelecidas, os "encanados" serviam na lavra do ouro de aluvião, livre das taxações metropolitanas até 1702 , quando o Regimento das Minas estabelecia lei que obrigava a comunicação da descoberta e da exploração da lavra às autoridades portuguesas.

Partindo de vários pontos do litoral paulista, exploradores portugueses buscavam ouro subindo o curso do Ribeira. Data de 1576 expedição de Garcia Rodrigues Paes que fundou o Garimpo Santo Antônio nas proximidades da atual I poranga, estabelecendo um dos núcleos que serviriam de base para a partida de explorações do alto curso do Ribeira e, posteriormente, do alto Paranapanema. Acredita-se, no entanto, que embora inexistam documentos escritos sobre a exploração do ouro de aluvião do alto Ribeira e do Paranapanema antes da primeira metade do século XVI, ela já tivesse ocorrido antes em pequenas incursões e que tenham se consolidado na segunda metade do século XVI, quando as populações autóctones já haviam se integrado aos aldeamentos ou eram transformados em mão-de-obra escrava dos bandeirantes.

Neste cenário em processo de conquista e de expansão territorial colonial, as cons- truções de balos de mineração que arrimavam as barrancas de rios e córregos com muros de pedras sotopostas sem argamassa, assim como no leito dos mesmos, agilizavam a vazão da água, aumentando a velocidade de captação de ouro nas bateias. Estas estruturas de pedra, semelhantes a muros edificados que canalizam consideráveis extensões dos rios e córregos da região, correspondem aos "encanados".

O ouro do Ribeira e do alto Paranapanema foi sendo substituído pelo ouro das Minas Gerais, Goiás e Mato Grosso, fazendo com a atividade mineradora na área ficasse por conta de alguns sertanistas, como Francisco Xavier da Rocha que, transferindo-se com todos seus escravos das Minas Gerais para 0 Paranapanema, fundou em 1728 a Freguesia de Santo Antonio das Minas e, mais tarde, o arraial da Rocinha, hoje cidade de Apiaí.

Com a decadência do ciclo do ouro no vale do Ribeira e do alto Paranapanema, o tropeirismo tornou-se predominante e constituiu-se como novo ciclo econômico e social nesta área, que se passagem das rotas dos tropeiros para as Minas Gerais e para ramais para o interior paulista. Neste período os encanados já não são mais construídos e a mineração se torna menos sistemática. Permanece então apenas a exploração das barrancas dos rios de maior porte, como o Almas, que apresenta poços globulares de onde se retirou ouro acumulado em seus sedimentos aluviais. Testemunho desta atividade são os sítios encanados Barro Branco $\mathrm{V}$ e Barro Branco VI, identificados e cadastrados pela presente pesquisa,.

No município de Ribeirão Grande, situado junto ao divisor de águas das bacias do Ribeira de Iguape e do Paranapanema, tais construções são encontradas em bom estado de conservação e indicam um rico legado histórico nacional. Prospecções realizadas dentro do escopo do presente Programa Arqueológico Mina Limeira resultaram no cadastro de 5 novos sítios "encanados", contando-se ainda com outros 2 anteriormente conhecidos. A Tabela 4, abaixo, traz o nome, coordenadas e fonte de pesquisa destes sítios: 


\section{Tabela 4}

\section{Sítios encanados de Ribeirão Grande}

\begin{tabular}{lll}
\hline \hline Nome do Sítio & \multicolumn{1}{c}{ Coordenadas } & \multicolumn{1}{c}{ Fonte } \\
\hline \hline Encanado I & Rio das Almas & Cadastro Nacional de Sítios Arqueológicos / IPHAN \\
Encanado II & Rio das Conchas & Cadastro Nacional de Sítios Arqueológicos / IPHAN \\
Barro Branco VII & 22J $769211 / 7321987$ & Programa Arqueológico Mina Limeira \\
Barro Branco XIII & Rio das Almas & Programa Arqueológico Mina Limeira \\
Cachoeira III & 22J $768461 / 7324017$ & Programa Arqueológico Mina Limeira \\
Ribeirão Velho & 22J 767636/7323221 & Programa Arqueológico Mina Limeira \\
Limeira III & Mina Limeira & Programa Arqueológico Mina Limeira
\end{tabular}

Destes "encanados", 3 se encontram na área de implantação direta do Projeto Mina Limeira (sítios Limeira III, Barro Branco VII e XIII). Neles foram realizadas ações de registro e resgate, e estão sendo foco, ainda, de análises alternativas de tratamento e valoração, considerando seu potencial de visibilidade em ações museológicas e de turismo patrimonial. Por outro lado, certamente existem ainda vários outros "encanados" na região, considerando a abrangência das atividades de mineração desenvolvidas ao longo dos séculos.

A partir dos dados acima coletados, e considerando 0 atrativo destes sítios integrarem programas turísticos municipais (alguns inclusive já em curso, mas compreendendo iniciativas isoladas e sem enfoque de preservação), foi realizada uma primeira análise sobre o potencial turístico dos sítios "encanados", com base nos seguintes critérios de avaliação:

- Significado histórico-cultural

- Visibilidade para o público

- Estado de conservação

- Condições de acesso e segurança ao visitante

- Alternativas regionais de lazer no entorno do sítio

- Propriedade do bem (pública / particular)
Fazem parte desta avaliação os 5 "encanados" identificados através da presente pesquisa, para os quais contou-se com os dados necessários de análise.

A partir desta avaliação preliminar é possível destacar que, dos 3 sítios localizados na área de intervenção direta do Projeto Mina Limeira, 2 correspondem a estruturas simples ou de baixa preservação/visibilidade (Mina Limeira III e Barro Branco VII). O outro sítio (Barro Branco XIII) apresenta grandes dimensões e bom estado de conservação, devendo receber medidas de aproveitamento museológico.

\section{Considerações finais}

O Brasil é um país formado não apenas por uma enorme diversidade de histórias locais e contextos culturais, mas também por uma estrutura social estratificada onde grande parte da população não tem acesso a recursos críticos, incluindo educação. Por conta disso, a recente prática da Arqueologia Pública no país constitui desafio estimulante, uma vez que oferece oportunidade de criar uma outra visão do passado humano, mais diversificada e tolerante, menos rígida e, principalmente, mais próxima dos legítimos herdeiros desta história. Aproximamo-nos cada vez mais, afinal, à essência de uma ciência social. 


\section{Tabela 5}

Avaliação turistia preliminar - Sítios “Encanados"

\begin{tabular}{|c|c|}
\hline Sítio & Pontos fortes \\
\hline \multirow[t]{2}{*}{ Barro Branco VII } & $\begin{array}{l}\text { Estrutura de baixa visibilidade, fácil } \\
\text { acesso, seguro. Poderia ser integra- } \\
\text { do à visita da Capela do Ouro Fino e } \\
\text { da Caverna do Cherol. }\end{array}$ \\
\hline & Significado histórico-cultural: médio \\
\hline \multirow[t]{2}{*}{ Barro Branco XIII } & $\begin{array}{l}\text { Estrutura composta de grandes di- } \\
\text { mensões no rio das Almas, boa vi- } \\
\text { sibilidade, em excelente estado de } \\
\text { preservação. }\end{array}$ \\
\hline & $\begin{array}{l}\text { Conjunto paisagístico preservado } \\
\text { com presença de queda d'água for- } \\
\text { mando tanque e mata ciliar. Pode- } \\
\text { ria ser integrado em trilhas que se- } \\
\text { guem o rio das Almas curso aci- } \\
\text { ma, com pontos bons em miran- } \\
\text { tes próximos e/ou roteiros mistos } \\
\text { no Ouro Fino. }\end{array}$ \\
\hline
\end{tabular}

Significado histórico-cultural: alto

Cachoeira III

Estrutura simples em ilha fluvial ge-

Propriedade Particular rada pela atividade de mineração no rio das Almas; bem preservada, excelente visibilidade e fácil acesso. Poderia ser integrado aos roteiros de turismo ao Ouro fino

Significado histórico-cultural: médio

Ribeirão Velho Estrutura complexa de grande dimensão (150 metros) no Ribeirão Velho; excelente estado de preserPontos de atenção

Atualmente assoreadoPequenas dimensõesPropriedade particular

Difícil acessoTurismo pode prejudicar mata ciliar e qualidade da água, além das próprias estruturas de mineraçãoBem público vação.

Significado histórico-cultural: alto

Limeira III

Estrutura simples de pequena dimensão fronteiriça à Mina Limeira; estado de preservação comprometido.

Significado histórico-cultural: médio

Baixa visibilidade

Difícil acesso

Baixa integração aos roteiros turísticos potenciais da região 
O desenvolvimento econômico que o Brasil atravessa, nesta virada de século, traz grande impacto ao seu patrimônio arqueológico, considerando os usos e desusos que são feitos de seu território. Pela primeira vez na história da disciplina, creio eu, nos deparamos com uma ameaça que há poucos anos atrás não nos afligia: a de que nosso database é finito.

Assim hoje a Arqueologia necessita incorporar um outro perfil, lado a lado com a comunidade que cria, destrói e preserva seus recursos. Não lhe basta ser multidisciplinar: necessita ser também multicultural, na medida em que incorpora os muitos passados possíveis.

Quais as mudanças necessárias à Arqueologia tradicional, acadêmica e enquanto profissão emergente, para este século XXI? Quem estará à frente desta mudança, desenvolvendo novos programas de treinamento e currículos acadêmicos necessários para o futuro?

O desenvolvimento sistemático de ações em Arqueologia Pública está em grande parte ligado a pesquisas junto a processos de licenciamento ambiental, onde cada vez mais os estudos têm como objetivo definir procedimentos e estratégias de sustentabilidade sócio-ambiental em um contexto capitalista.

Apesar da questão "O que deve ser sustentado?" nunca terá um paradigma unificado, há consenso sobre a efetiva participação da comunidade na pesquisa arqueológica, com base em uma estrutura não hierárquica em que métodos de trabalho e interpretação necessitam interagir.

Desde a Conferência das Nações Unidas sobre Ambiente e Desenvolvimento ocorrido no Rio de Janeiro, em 1992, "desenvolvimento sustentável" se tornou palavra-chave de um discurso político internacional voltado à qualidade de vida, conservação dos recursos naturais e responsabilidade para gerações futuras. Apesar das discussões terem sido inicialmente voltadas às ciências naturais e análises de crescimento populacional, relaciona-se a uma discussão baseada na definição social, histórica e cultural do pro- blema: a viabilidade de serem mantidas relações socialmente definidas entre a natureza e a comunidade durante longos períodos de tempo. Desta forma, o discurso sobre sustentabilidade é basicamente público e estreitamente vinculado a problemas como justiça social e regulamentação política.

Sustentabilidade ou não sustentabilidade corresponde a uma qualidade de condições e processos dentro de um continuum de condições e processos possíveis. Neste sentido, não se pode considerar a sustentabilidade ambiental e a sustentabilidade social de forma isolada. Ao contrário, o foco deve recair na interação entre elas, buscando a viabilidade de suas relações durante longos períodos de tempo. Por outro lado, considerando a rápida transformação por que as sociedades passam atualmente, a sustentabilidade necessita ser concebida dentro de uma perspectiva dinâmica, e não baseada em estruturas estáticas.

Nós, arqueólogos, precisamos nos perguntar: Qual a conexão entre nosso campo de conhecimento e sustentabilidade social? Como podemos contribuir dentro desta perspectiva? Quais novos tópicos devemos incorporar à nossa área de atuação?

Dentre as respostas possíveis, destacase o estímulo à coesão social através do estabelecimento de pontes entre o presente e o passado, preservando histórias e tradições e valorizando a herança cultural. Observase assim, portanto, uma grande mudança de perspectiva na prática da profissão: hoje a Arqueologia parte de um profundo conhecimento do presente para dar significado ao passado e perspectivas de futuro, especialmente em países em desenvolvimento como - Brasil. 0 processo pós-colonial e as informações tecnológicas disponíveis criaram um novo contexto no qual a Arqueologia deve atuar.

Como conseqüência deste conjunto de ações, esperamos, virá a tolerância e a possibilidade de cooperação voltada à construção de uma sociedade mais democrática. Nossa perspectiva é que o trabalho desenvolvido (e ainda em andamento) na pequena 
comunidade de Barro Branco possa ter contribuido neste caminho.

0 trabalho de cadastramento de sítios históricos do tipo "encanados" na área se insere, portanto, dentro de uma iniciativa de valorização e preservação patrimonial, constituindo uma segunda alternativa de aplicação da Arqueologia Pública no Programa Arqueológico que vem sendo desenvolvido.

\section{Agradecimentos}

Venho inicialmente agradecer a comunidade de Barro Branco pela sua paciência, generosidade e compromisso com a presente pesquisa. Sem eles nosso esforço seria em vão. Agradeço ainda à Companhia de Cimento Ribeirão Grande (CCRG) e, em especial, a Luiz Carlos Busato, Antonio Mauro Mendonça Barbosa e Paulo Ricardo Silva Gobbo, incansáveis estimuladores e defensores dos programas socio-ambientais que

\section{Bibliografia em Arqueologia Pública}

\section{ASCHER, ROBERT}

1961 Analogy in archaeological interpretation. Southwestern Journal of Anthropology 17: 317-25

BAHN, PAUL (ED.)

1996 The Cambridge Illustrated History of Archaeology. Cambridge University Press, Cambridge

BENNETT, JOHN W.

1943 Recent developments in the functional interpretation of Archaeological Data.

BERLIN, HEINRICH American Antiquity vol.9, n.2 :208-219

1958 El glifo "emblema" en las inscripciones Mayas. Journal de la Societé des Américanistes vol. 47, :111-119

BINFORD, LEWIS R.

1962 Archaeology as Anthropology. American Antiquity vol.28, n.2, :217-225

1963 Smudge pits and hide smoking: the use of analogy in archaeological reasoning. American antiquity 32: 1-12

1964 Methodological considerations in the use of ethnographic data. In R.B.Lee \& a empresa desenvolve; devo a eles, em grande parte, a oportunidade de desenvolver os estudos e contribuições que o presente artigo busca trazer. Agradeço às instituições que apoiaram as pesquisas, a saber, o Núcleo de Estudos Estratégicos/ Arqueologia Pública da UNICAMP e a Fundação Cultural de Jacarey, no centro das quais ocorreu grande parte das discussões conceituais trazidas por este artigo. Agradeço igualmente aos inúmeros arqueólogos, historiadores, geógrafos e cientistas sociais que, comigo, partilharam destas pesquisas, onde destaco os amigos Dr. Paulo De Blasis, Dr. Andrés Zarankin e Ms. Wagner Gomes Bornal. Agradeço especialmente o enorme empenho e compromisso de Gerson Levi da Silva Mendes em todas as etapas da pesquisa, bem como de Cintia Bendazolli pelo belíssimo trabalho junto ao universo feminino e infantil da comunidade de Barro Branco. A todos eles e aqueles que, por falta de espaço, não pude citar, meus sinceros agradecimentos.
I.DeVore (eds.) Man the hunter, :268-73, Chicago: aldine Publishing Company

1965 Mortuary practices: their study and potential. In J.A.Brown (ed.) Approaches to the Social Dimensions and mortuary practices, SAA, Memoir 25, :58-67, Washington, D.C.

1967 Smudge Pits and Hide-Smoking: The Use of Analogy in Archaeological Reasoning. American Antiquity 32:1-12.

1971 Mortuary practices : their study and their potential. Washington : Society for American Archaeology, 1971, pp:6-29.

BINFORD, S.R. \& BINFORD L.R. (EDS.)

1968 New Perspectives in Archaeology, Aldine, Chicago

BOAS, FRANZ

1913 Archaeological Investigations in the Valley of Mexico by the International School, 1911-12. In Eighteenth International Congress of Americanists, pt.1, 176-179, Londres

1940 Race, Language and Culture Macmillan, New York 
BOLLAERT, WILLIAM

1860 Antiquarian, Ethnological, and other researches in New Granada, Equador, Peru, and Chile. D. Lane, Londres

BORMIDA, MARCELO

1968 Arqueologia de las altas cotas de la Costa Norpatagónica. Thirty-seventh International Congress of Americanists, vol.3, :345374, Buenos Aires

BROWN, J AMES A. (ED.)

1971 Approaches to the social dimensions of mortuary practices. SAA, Memoir 25, Washington D.C.

BROWNE, T.

1658 Hydriotaphis. Urne burial. Londres

CAMPBELL; DONALD T.

1988 Methodology and epistemology for social science: selected papers. Chicago, University of Chicago Press Ed. Samuel Overman

CATHERWOOD, FREDERICK

1844 View of Ancient Monuments in Central America, Chiapas, and Yucatán. Vizetally, Londres

CHANG, KWANG-CHI

1958 Study of the Neolithic Social Grouping: examples from the New World. American Anthropologist vol.60, n.2, :298-334

1967 Major aspects of the interrelationship of archaeology and ethnology. Current Anthropology 8() :227-34

CHARLTON, THOMAS $\mathrm{H}$.

1981 Archaeology, ethnohistory and ethnology: interpretive interfaces. Advances in Archaeological Method and Theory 4:129-76

CHILDE, V. GORDON

1925 The Dawn of European Civilization

1929 The Danube in Prehistory. Oxford, Clarendon Press

1936 Man Makes Himself. Watts, Londres

CIGLIANO, E.M.

1962 Ampajanguense, Inst. de Ãntropologia, Rosario, Univ. Nacional de Litoral

CLAASSEN, CHERYL (ED.)

1992 Exploring gender through archaeology. Monographs in World Archaeology, n.11, Prehistory Press, Madison

CLARK, GRAHAME D.

1936 The Mesolithic Settlement of northern Europe. Cambridge Univ. Press, Cambridge

1937 Archaeology and Society. Methuem, Londres

1939 The reindeer hunting tribes of northern Europe. Antiquity 12:154-171.

1953 The economic approach to Prehistory. Proceedings of the British

Academy vol. 39, :215-238

1970 Prehistory of Africa. London: Thames and Hudson
CLARKE, DAVID

1968 Analytical Archaeology. Methuem, Londres

1972 Models in Archaeology. Methuem, Londres

1977 Spatial Archaeology. Academic Press, Londres

CONKEY, MARGARET W. \& SPECTOR, JANET

1984 Archaeology and the study of gender. In M.B.Schiffer (ed.) Advances in Archaeological Method and Theory, vol. 7, :1-38, Academic Press, New York

CRIST, THOMAS A. J.

2002 Empowerement, Ecology and Evidence: The Relevance of Mortuary Archaeology to the Public. In Little, B.J (org.) Public Benefits of Archaeology. Florida: University Press of Florida, pp:101-117.

CUNHA; MANUELA CARNEIRO (ORG.)

1992 História dos Índios no Brasil. São Paulo, Fapesp e Companhia das Letras.

DE BLASIS, P. A. \& ROBRAHN-GONZÀLEZ, E.M.

2004 Dam contract archaeology in Brazil: some prospects and a case study at the amazonian border. BID, (no prelo)

DEETZ, J AMES J.F.

1960 An Archaeological Approach to kinship change in eighteenth century Arikara Culture. PhD Dissertation, Harvard Univ., Cambridge, Mass.

1965 The dynamics of stylistic change in Arikara Ceramics. University of Illinois Series in Anthropology, n.4, Urbana

1966 Stone Tools, Anthropology Curriculum Study Project. Excerpt in Origins of Humanness: Patterns in Human History. New York.Edwin Dethlefsen, editor, pp. 74-84. Macmillan \& Co.

1968 Cultural patterning of behaviour as reflected by archaeological material. In:Chang, K.C. (ed) Settlement Archaeology. Palo Alto, CA, National Press, pp: 31-42.

1968a The inference of residence and descent rules from Archaeological

data. In S.R.Binford \& L.R.Binford (eds) New Perspectives in Archaeology :41-49, Aldine, Chicago

1968b Late Man in North America: Archaeology of european americans. In B.J.Meggers (ed.) Anthropological Archaeology in the Americas, 121-130, Washington D.C.

DERBY, ORVILLE

1879 Artificial Mounds of the Island of Marajó, Brazil. American Naturalist vol.13, n.4, 224 p.

DE VRIES, B.

2003 In search of sustainability: what can we learn from the past? Paper for the 
Arqueologia e sociedade no município de Ribeirão Grande, sul de São Paulo: ações em arqueologia pública ligadas ao Projeto de Ampliação da Mina Calcária Limeira.

International Symposium on World System History and Global Environment Change, Utrecht, Lund University

DOUGLAS, J.E.

1995 Autonomy and regional systems in the late Prehistoric Southern Southwest. American Antuiquity 60(2):240-257

DRUCKER, PHILLIP

1952 La Venta, Tabasco: a study of Olmec Ceramics and art. Bureau of American Ethnology, Bulletin 153, Washington D.C.

DUNNELL, ROBERT C.

1986 Five decades of American Archaeology. D.J.Meltzer, D.D.Fowler, J.A.Sabloff (eds.) American Archaeology, Past and Future. Smithsonian Institution Press, Washington \& London

FABIAN; JOHANNES

1983 Time and the other: how anthropology makes its object. New York: Columbia University Press,

FAGAN, BRIAN

2002 Epilogue. In: Little, B.J. (org) Public Benefits of Archaeology. Florida: University Press of Florida, pp:253-260.

FARABEE, WILLIAN C.

1921 Exploration at the Mouth of the Amazon, Museum J ournal of the University Museum vol.12, n.13 :142-161, Philadelphia

FAULKNER, N.

2000 Archaeology from below. Public Archaeology I: 21-33

FLANNERY, KENT V.

1967 Culture History vs. Cultural Process: a debate in american Archaeology. Scientific American, vol. 217, :119-122

1968a Archaeological Systems theory and Early Mesoamerica. B.J.Meggers (ed.), Anthropological Archaeology in the Americas, :67-87, Washington D.C.

1968b The Olmec and the valley of Oaxaca: a model for inter-regional interaction in Formative times. In E.P.Benson (ed.), Durbarton Oaks Conference on the Olmec, :79-110, Washington D.C.

1969 Origins and ecological effects of early domestication in Iran and the Near East. In G.W.Dimbleby \& P.J.Ucko (eds.), The domestication and exploitation of plants and animals, :73-100, Aldine, Chicago

1972a The cultural evolution of Civilizations. Annual Review of ecology and systematics. Vol.3, :399-426, Palo Alto

1972b Summary Comments: evolutionary trends in social exchange and interaction. In E,N.Wilmsen (ed.) Social exchange and interaction, :129-136, Univ. of Michigan, Museum of Anthropology, Anthropological Papers n.46, Ann Arbor

1976 The early Mesoamerican village Academic Press, New York

1986 Guila Naquitz: archaic foraging and the early agriculture in Oaxaca, Mexico. Academic Press, Orlando

FIELD, J. ET AL

2000 'Coming back' Aborígines and archaeologists at Cuddie Springs. Public Archaeology Vol. $1: 35-48$

FORD, J.A.

1938 A Chronological method applicable to the Southeast. American Antiquity vol.3, n.3 :260-264

1939 Measurements of some Prehistoric Developments in the Southeastern States. Anthropological Papers of the American Museum os Natural History, vol.44, pt.3, New York

1940 A quantitative method for deriving cultural chronology. Washington Pan American Union Technical Manual I.

1951 Archaeological survey in the lower mississipi alluvial valley, 1940-1947. Cambridge : Peabody Museum

1962 Metodo cuantitativo para estabelecer cronologias culturales. Washington: Union Panamericana.

FOX, CYRIL

1932 The personality of Britain. Man, vol.32, 202 pp.

FUNARI, PEDRO PAULO A.

1995 Mixed features of archaeological theory in Brazil. In P. Ucko (ed.) Theory in Archaeology, a world perspective: 236250, London, Routledge.

1998 A importancia da teoria arqueológica internacional para a Arqueologia sul-americana: o caso brasileiro. In P. P.A. Funari (ed.) Teoria Arqueológica na América do Sul, :13-32, IFCH, Campinas

2004 Western influences in the archaeological thought in Brazil. In G. Politis \& R. Peretti (eds.) Teoria arqueologica en America del Sur: 235-244, Serie Teorica n. 3, INCUAPA, Olavarria.

FUNARI, P.P.A.; HALL, M.; J ONES, S.

1999 Historical Archaeology: back from the edge. Londres, Rouledge.

FUNARI, P.P.A. \& ROBRAHN-GONZÁLEZ, E.M.

2005 Ethics, capitalism and public archaeology in Brazil.

GALLATIN, ALBERT

1845 Notes on the Semi-Civilized Nations of Mexico, Yucatan, and Central America. 
Transactions of the American Ethnological Society vol.1, New York

GERO, JOAN M. \& CONKEY, MARGARET (EDS.)

1991 Engendering Archaeology: women and Prehistory. Basil Blackwell, Londres

GIFFORD, J.C.

1960 The type-variety of ceramic classification as na indicator of cultural phenomena. American Antiquity, 25: 341-7

GOSDEN, C.

2000 Postcolonial Archaeology. In Archaeological Theory Today (ed. I. Hodder), :241-261, Polity Press, Cambridge

GOELDI, EMILIO

1900 Excavações archaeológicas en 1895. Memoires do Museu Goeldi, Belém

GONZÁLEZ, ALBERTO R.

1963 Cultural development in Northwestern Argentina. In B.J. Meggers \& C. Evans (eds.) Aboriginal cultural development in Latin America: na interpretative review. Smithsonian Miscellaneous Collection, vol. 1240, n.1, :103-118, Washington D.C.

GOSDEN, CHRIS

2001 Postcolonial Archaeology: Issues of Culture, Identity, and Knowledge. In: Hodder (ed.) Archeological Theory Today, :241-261, Cambridge, Polity Press

GOULD, RICHARD

1967 Notes on hunting, butchering and sharing of game among Ngatajara and their neighbours in the west Australian desert. Kroeber Anthropological Society Paper, 36

1968 Living Archaeology: the Ngatatjara of Western Australia. Southwestern Journal of Anthropology 24: 101-22

1969 Subsistence behavior among the Western Desert Aborigines of Australia. Oceania, 39: 253-74

1974 Some current problems in ethnoarchaeology. In C.B.Donnan \& C.W.Clewlow (eds.) Ethnoarchaeology :29-48, Inst. of Archaeology Monograph, 4. Los angeles: Univ. of California.

1980 Living archaeology. New York: Cambridge Univ. Press

1981 Cave art of australian desert aborigines. In H.J.Shafer (ed.) Ancient Texans, :2049, Austin: Texas Monthly Press

1990 Recovering the Past. Univ. od New Mexico GOULD, R.A. \& WATSON, PATTY JO

1982 A dialogue on the meaning and use of analogy in ethnoarchaeological reasoning. Journal of Anthropological Archaeology 1: 355-81

GROEVIUS, M. \& GRONOVIUS, A.

1694 Thesaurus antiquitatum. Traj. Ad Rhenum
HANDLER, JEROME

1968 The Amerindian Slave Population of Barbados in the Seventeenth and Early Eighteenth Centuries.

HARTMAN, CARL V.

1901 Archaeological Research in Costa Rica. Royal Ethnological Museum, Stockholm

HARTT, CHARLES F.

1871 The Ancient indian pottery of Mararjó, Brazil. American Naturalist vol.5, :259-271

HELM, JUNE

1962 The ecological approach to Anthropology. American J ournal of Anthropology, vol. 67, n.6, :630-639

HEMPEL, C.G.

1966 Philosophy of Natural History. PrenticeHall, Englewood Cliffs, N.J.

HILL, J AMES N.

1968 Broken K Pueblo: patterns of form and function. In S.R.Binford \& L.R.Binford, New Perspectives in Archaeology :103143, Aldine, Chicago

HODDER, IAN

1978 Social organization and human interaction: the development of some tentativa hypothesis in terms of material culture. In I.Hodder (ed.) The spatial organization of culture. Duckworth, Londres

1982 Symbols in action: ethnoarchaeological studies of material culture. New York: Cambridge Univ. Press

1985 Postprocessual Archaeology. In M. Schiffer (ed.) Advances in Archaeological Method and theory vol.8:1-26, Academic Press, New York

1987 The contribution if the Long Term. In I.Hodder (ed.) Archaeology as Long-Term History :1-8, Cambridge Univ. Press, Cambridge

1991a Postprocessual Archaeology and the Current debate. In R.W.Preucel (ed.) Processual and Postprocessual archaeologies: multiple ways of knowing the past. :3041. Center for Archaeological Investigations, Southern Illinois Univ., Occasional Paper n.10, Carbondale

1991b Reading the past: current approaches to interpretation in archaeology. Cambridge Univ. Press, Cambridge

1994 Interpretación em Arqueología. Corrientes Actuales. Crítica, Barcelona

2001 A review of contemporary theoretical debates in Archaeology. In I. Hodder (ed.) Archaeological Theory Today. :1-13, Cambridge, Polity Press

HOLE, FRANK \& HEIZER, ROBERT

1966 An introduction to Prehistoric Archaeology. Holt, Rinehart and Winston, New York 
Arqueologia e sociedade no município de Ribeirão Grande, sul de São Paulo: ações em arqueologia pública ligadas ao Projeto de Ampliação da Mina Calcária Limeira.

Erika Marion Robrahn-González

HODGE, FREDERICK W. (ED.)

1907-10 Handbook of American Indians North of Mexico 2 pts. Bureau of American Ethnology, Bulletin 30, Washington D.C.

HOLMES, WILLIAM H.

1895-97 Archaeological Studies among the ancient Cities of Mexico. Filed Columbian Museum Anthropological Series, vol.1, n.1, Chicago

HRDLICKA, ALES ET ALII

1911 Early Man in South America. Bureau of American Ethnology, Bulletin 52, Washington D.C.

HUDDLESTON, LEE E.

1967 Origins of the American Indians: European Concepts, 1492-1729. Austin, University of Texas Press.

HUFFMAN, T.

1982 Archaeology and ethnohistory of the African Iron Age.Annual Review of Anthropology 11: 133-150

IHERING, HERMANN VON

1895 A civilização prehistórica do Brazil meridional. Rev. do Museu Paulista vol.1, :34-159

JOYCE, THOMAS

1914 Mexican Archaeology. Putnam, Londres KIDDER, ALFRED V.

$1924 \mathrm{Na}$ introduction to the study of Southwestern Archaeology, with a preliminary account of the excavations at Pecos. Papers of the Southwestern Expedition, Phillips Academy n.1, Yale Univ. Press, New Haven

KNOROSOV, Y.V.

1967 Selected Chapters from the Writing of the Maya Indians, translated by Sophie Coe, Russian Translation Series of the Peabody Museum, vol.4, Cambridge, Mass.

KRIEGER, A.D.

1944 The typological concept. American Antiquity, 9: $271-88$

KROEBER, ALFRED L.

1927 Coast and Highland in Prehistoric Peru. American Anthropologist vol.29, :625-653

1944 Peruvian Archaeology in 1942. Viking Fund Publications in Anthropology n.4, New York

KUWANWISIWMA, L.

2002 Hopi Understanding of the Past. A Colaborative Approach. In: Public benefits of Archaeology. Ed. Barbara J. Little, University Press of Florida, 46-51.

LATHRAP, DONALD W.

1958 The culture sequence at Yarinacocha, Eastern Peru. American Antiquity vol.23, n. $4,: 379-388$

1970 The Upper Amazon. Praeger, New York

1973 The Tropical forest and the cultural context of Chavin. In E.P.Benson (ed.)
Dumbarton Oaks Conference on Chavín, :73-100, Washington D.C.

LAMPHEAR; J.

1982 The People of the Grey Bull: The Origin and Expansion of the Turkana. Journal of African History 29:27-39.

LEAKEY, L.S.B.

1960 Adam's ancestors: the evolution of man and his culture. New York, Harper \& Row

1969 The progress and evolution of man in Africa. Londres, Oxford Univ. Press

1973 Hacia el desvelamiento del origen del Hombre: diez decenios de investigatión sobre la evolución humana. Madrid, Aguilar.

LEE, RICHARD B.

1979 The !Kung San: men, women and work in a foraging society. Cambridge: Cambridge Univ. Press

LERNER, S.

1991 Saving Sites: Preservation and Education. In: Smith, G. and Ehrenhard, J. (eds). Protecting the Past, CRC Press, Boca Raton, Florida, 103-8. Leone, Mark

1968 Neolithic economic autonomy and social distance. Science vol. 162, n. 3858, :1150-1151

1982 Some opinions about recovering Mind. American Antiquity vol. 47, :742- 760

1984 Interpreting ideology in historical archaeology: using the rules of perspective in the William Paca Garden in Annapolis, Maryland. In D.Miller \& C.Tilley (eds.) Ideology, Power and Prehistory :2535, Cambridge Univ. Press, Cambridge

LIPE, WILLIAM D.

2002 Public Benefits of Archaeological Research. In: Little; B. J. Public Benefits of Archaeology. Florida: University Press of Florida, pp:20-28.

LITTLE, B.J .

2002 Archaeology as a Shared Vision. Public Benefits of Archaeology (e. B. J.

Little) 1-19. Florida: University Press of Florida.

LONGACRE, WILLIAM A.

1968 Some aspects of Prehistoric Society in EastCentral Arizona. In S.R.Binford \& L.R.Binford (eds.) New Perspectives in Archaeology :89-102, Aldine, Chicago

LOWENTHAL, D.

1981 Conclusions: Dilemmas of Preservation. In: Our Past BeforeUs: Why Do We Save it? Ed. D. Lowenthal and M. Binney, 213-37, London, Temple Smith.

1985 The Past is a Foreign country. Cambridge, cambridge University Press. 
LUND. PETER

1950 Memorias sobre a paleontologia brasileira Instituto Nacional do Livro, Rio de Janeiro.

LUMBRERAS, LUIS G.

1971 Towards a re-evaluation of Chavin. In E.P.Benson (ed.) Dumbarton Oaks on Chavin. Dumbarton Oaks, Washington D.C.

LUMBRERAS, L.G.

1960 Algunos problemas de arqueologia peruana. In Antiguo Peru: espacio y tiempo. (ed. R. Matos) : 129-148, Editorial J. Mejía Baca, Lima. Malina, Jaroslav \& Vasícek, Zdenek

1990 Archaeology yesterday \& today. Cambridge University Press, Cambridge

MARCANO, G.

1889 Ethnographie précolombienne du Venezuela, Vallées dÁragua et de Caracas. Mémoires dÁntropologie ser.2, vol.4, :1-86

MARTIN, PAUL S.

1974 Early development in Mogollon research. In G.R.Willey (ed.) Archaeological Researches in Retrospect, :3-33, Winthrop, Cambridge

MCGEE, R.J . \& WARMS, R.L.

1996 Anthropological Theory - na introductory history. Mayfield Publishing Company, California

MCGUIRE, RANDALL H.

1992 A Marxist Archaeology. Academic Press Inc., California

MCMANAMON, F.P.

1991 The Many Publics for Archaeology. American Antiquity, 56 (1), 121-30.

1994 Presenting Archaeology to the Public in the USA. In: The Presented Past, Heritage, Museums and education. Ed. P. G. Stone and B. L. Molyneaux, 61-81, New York, Routledge.

1994a Changing relationships between Native Americans and Archaeologists. Historic preservation Forum 8 (2): 15-20.

2000 Archaeological messages and messengers. Public Archaeology 1:5-20

2002 Heritage, History and Archaeological Educators. In: Public benefits of Archaeology. Ed. Barbara J. Little, University Press of Florida, 31-45

MCNEISH, R.S.

1958 Preliminary Archaeological investigations in the Sierra de Tamaulipas, Mexico. Transactions, American Philosophical Society, vol. 48, pt.6, Philadelphia

1959 Investigations in the Southwest Yukon: Part 1I, Archaeological excavation, comparison and speculation. Papers of the R.S.Peabody Foundation for Archaeology, vol. 16, n.1, Andover, Mass
1960 Investigations in the Southwest Yukon: Part II, Archaeological excavation, comparisons and speculations. Papers of the R.S.Peabody Foundation for Archaeology, vol.6, n.1, Andover, Mass.

1967 A summary of the subsistence. In D.S.Byers (ed.) Prehistory of the Tehuacan Valley vol.1 :290-309, Univ. of Texas Press, Austin

MEGGERS, BETTY

1954 Environmental limitation on the development of culture. American Anthropologist vol.56, n.5, :801-824

1956 Functional and evolutionary implications of community patterning. In R. Wauchope (ed) Seminars in Archaeology: 1955. SAA, Memoir 11, Washington D.C

1957 Environment and culture in the Amazon Basin: na appraisal of the theory of environment determinism. In A. Palerm et alii (eds.) Studies in Human Ecology, :7190. Pan American Union Social Sciences Monograph, n.3, Washington D.C.

1966 Field testing of cultural law: a reply to Morris Opler. Southwestern Journal of Anthropology, vol. 17, n.14, :352-354

MEGGERS, B. \& EVANS, C.

1957 Archaeological investigations at the Mouth of the Amazon. Bureau of American Ethnology, Bulletin 167, Washington D.C.

MENDONÇA-DE-SOUZA, S. M. F.,

1991 Mendonça de Souza, A. - História da arqueologia brasileira. Pesquisas em Antropologia, n. 46.

MENGHIN, OSWALD F.

1957 Das Protolithikum in Amerika. Acta Praehistorica, n.1

MENZEL, DOROTHY

1964 Style and time in the middle Horizon. Nawpa Pacha n.2, :1-106

MESKELL, LYNN

2001 Archaeologies of Identity. In I. Hodder (ed.) Archaeological Theory Today :187213, Cambridge, Polity Press

MILLON, RENÉ F.

1967 Teotihuacán. Scientific American, vol. 216, n. $6,: 38-48$

MOLYNEAUX, B.L.

1994 Introduction: the represented Past. In The Presented Past: heritage, museums and education (ed. P. G. Stone \& B. L. Molyneaux, 1-13, London, Rouledge.

MOSER, S

2001 Archaeological Represtantion: the visual conventions for constructiong knowledge about the past. In Archaeological Theory 
Arqueologia e sociedade no município de Ribeirão Grande, sul de São Paulo: ações em arqueologia pública ligadas ao Projeto de Ampliação da Mina Calcária Limeira.

Erika Marion Robrahn-González

Today (ed. I. Hodder), Polity Press, Cambridge.

MULVANEY, D.J.

1969 The Prehistory of Australia. Londres, Thames ans Hudson.

NARROLL, RAOUL S.

1962 Floor area and settlement population. American Antiquity vol. 27, n.4, :587-589 National Center for History in the Schools.

1996 National Standards for History. Basic Editions. Los Angeles: university of California Press.

NELSON,N.C.

1916 Chronology of the Tano Ruins. American Anthropologist, New Mexico, 18 (2): 159-180

NEVES, E.

2001 Twenty Years of Amazonian Archaeology in Brasil. Antiquity 72 (277): 625-32

NEVES, W.A.

1996 Arqueologia brasileira: algumas considerações. Boletim do Museu Paraense Emilio Goeldi, Antropologia 2:200-205.

NEVES, W.A. ET ALII

1999 Cranial morphological variation in South America and the colonization of the New World: towards a four migration model? Ciência e Cultura Journal of the Brazilian Association for the Advancement of Science 51, 151-165.

NDORO, W. \& PWITI, G.

2001 Heritage management in Southern Africa. Public Archaeology vol. 2: 21-34

ORSER, C.E.

1990 Archaeological approaches to New World plantation slavery. In M.B. Schiffer (ed.) Archaeological Method and Theory vol. 2: 111-154, Tucson, University of Arizona Press.

1992 Introdução à arqueologia histórica. Belo Horizonte : Oficina de Livros.

ORTON, C.; TYERS, P.; VINCE, A.

1995 Pottery in Archaeology. Cambridge Manuals in Archaeology. Cambridge. Cambridge Univ. Press

OUTES, FELIX F.

1897 Los Querandies Impreuta Martin Biedma, Buenos Aires

1898 La Edad de la piedra en Patagonia.Anales del Museo Nacional de Buenos Aires vol $12,: 203-575$

1907 Arqueología de San Blas, Provincia de Buenos Aires. Anales del Museo Nacional de Buenos Aires vol.14, :249-275

PATTERNSON. THOMAS C.

1989 History and the Post-Processual Archaeology. Man, vol.24 :555-566
PEERS. L.

1999 "Many tender ties": the shifting contexts and meanings of the S Black bag. World Archaeology 31: 288-302.

PESSIS, A. M.

1989 Apresentação gráfica e apresentação social na tradição nordeste de pintura rupestre no Brasil. Clio 5:11-17,

PLOG, FRED T.

1974 The study of Prehistoric Change Academic Press, New York

1976 Measurement of Prehistoric Interaction between communities. In K. Flannery (ed.) The early mesoamerican village, New York, Academic Press

PREUCEL, R.W.

1991 Processual and Postprocessual anchaeologist: multiple ways of knowing the past. Center for Archaeological Investigations, Occasional Paper n.10, Southern Illinois Univ., Cabondale

PROUS, A.

1991 Arqueologia Brasileira, 605 pp. UnB, Brasília. PROUS, A.

1994 L'archéologie brésilienne aujourd'hui, Problèmes et tendances. Recherches Brésiliennes, Besançon, 9-43.

PYBURN, K. ANN AND RICHARD R. WILK.

1995. Responsible Archaeology Is Applied Anthropology. In: Ethics in Archaeology: Challenges for 1990s, ed. M. J. Lynott and A. Wylie, 71-76, Washington, D. C.: Society for American Archaeology.

RATHJE, WILLIAM L.

1970 Socio-political implications of Lowland Maya Burials: methodology and tentative hypotheses. World Archaeology voll, n.3 :359-374

1974 Garbage Project: a new way of looking at the problems of Archaeology. Archaeology vol.27, n. $4: 236-241$

1978 Archaeological Ethnography...because sometimes it is better to give than to receive. In R. Gould (ed) Explorations in Ethnoarchaeology, :49-75. School of American Research, Advanced Seminar Series, Univ. of New Mexico Press, Albuquerque

REDMAN, C.L.

1973 Research and theory in current Archaeology: na introduction. In C.L.Redman (ed.) Research and theory in current archaeology :5-26, Wiley, New York

1991 Distinghished lecture in Archaeology. In defense of the seventies - the adolescence of New Archaeology. American Anthropologist vol.93, :295-307 
RENFREW, C. \& BAHN, P.

1996 Archaeology - Theories, Methods and Practice. Thames ans Hudson, 2. Edition, Londres

RESTREPO, VICENTE

1895 Los Chibchas antes de la Conquista Espanola.Imprensa de La Luz, Bogotá

RIBEIRO, M. A.

2000 Ecologizar. Pensando o ambiente humano. Belo Horizonte, Rona Editora

ROBRAHN-GONZALEZ, E. M.

1996 Os grupos ceramistas pré-coloniais do Centro-Oeste brasileiro. Revista do Museu de Arqueologia e Etnologia vol. 6: 83-122, São Paulo.

2000 Reflexionen ueber den Gedrauch der historischen Analogie in Brasilien. In: A. Gramsch (ed.) Vergleichen als archaeologische Methode. Analogien in den Archaeologien, BAR International Series, arbeitsgemeinschaft Theorie ( $T$ AG). Berlim, 131-142

2001 El uso de la Analogía en la Etnoarqueología Brasileña. Anais da /I Reunión Internacional de Teoría Arqueológica en América del Sur. Argentina.

ROUSE, I.G.

1939 Prehistory in Haiti. A study in method. Yale Univ. Publications in Anthropology, n.24, New Haven

1960 The classification of artifacts in Archaeology. American Antiquity, 25: 313-23

ROWE, JOHN H.

1963 Urban Settlements in Ancient Peru. Nawpa Pacha vol.1, n.1 :1-27

ROWLANDS, M.

1998 The archaeology of colonialism. In K. Kristiansen \& M. Rowlands, Social Transformations in Archaeology: global and local perspectives, 327-33, London, Routledge.

SALMON, MERRILEE H.

1992 Postprocessual explanation in Archaeology. In L.Embree (ed.) Meta-Archaeology, Boston Studies in the Philosophy of Science. Kluwer Academic Press, Boston

SANDERS, WILLIAM T.

1956 Tierra y Agua. Phd Dissertation, Harvard University, Cambridge.

1957 The Cultural Ecology of the Teotihuacan Valley, Pennsylvania State University, University Park

SANDERS, W.T.; MERINO, JOSEPH

1970 New orld Prehistory. Archaeology of the American Indians. Foundations of Modern Anthropology Series. Prentice-Hall, Englewood Cliffs, N.J.
SANDERS, W.T. \& PRICE, BARBARA

1968 Mesoamerica, the evolution of a civilizarion. Random House, New York

SANTOS, BOAVENTURA DE SOUZA.

2003 Prefácio. In: Boaventura de Souza Santos (org). Reconhecer para Libertar. Os caminhos do Cosmopolitismo Multicultural. Rio de Janeiro. Civilização Brasileira. 13-68.

SCHIFFER, M.B.

1976 Behavioral Archaeology. Academic Press, New York

SCHORTMAN, M. \& URBAN, P.A.

1989 Interregional interaction in Prehistory: the need for a new perspective. American Antiquity 54(1) :52-65

1992 Current trends in interaction research. In M.Schortman \& P.A.Urban (eds.) Resources, power and interregional interaction. Plenum Press, New York

SCHUYLER, ROBERT L.

1970 Historical and Historic Sites Archaeology as Anthropology: basic definitions and relationships. Historical Archaeology vol.4 :83-89

SCHWARCZ, LILIA MORITZ.

1993 O Espetáculo das Raças: Cientistas, Instituições e Questão Racial no Brasil - 18701930. São Paulo, Companhia das Letras.

SHACKEL, P.

2002 Broadening the Interpretation of the Past at Harpers Ferry National Historical Park. In: Public benefits of Archaeology. Ed. Barbara J. Little, University Press of Florida, 157-167.

SHANKS,MICHAEL \& TILLEY, CRISTOPHER

1987 Social Theory and Archaeology. Polity Press, Cambridge

1989 Archaeology into the 1990s. Norwegian archaeological Review, vol. 22:1-12

SHANKS, MICHAEL \& HODDER, IAN

1995 Processual, postprocessual and interpretive Archaeologies. Ian Hodder et alii (eds.) Interpreting Archaeology - finding meaning in the past. Rouledge, London and New York, :3-29

SEARS, WILLIAN H.

1961 The study of social and religious systems in North American Archaeology. Current Anthropology vol.2, n.3, :223-231

SHIVA, $\mathrm{V}$

2003 Monoculturas da mente. Perspectivas da biodiversidade e da biotecnologia. São Paulo, Editora Gaia.

SMITH, G. AND EHRENHARD, J.

2002 Protecting the Past to Benefit the Public. In: Public benefits of Archaeology. Ed. Barbara J. Little, University Press of Florida, 121-130 
Arqueologia e sociedade no município de Ribeirão Grande, sul de São Paulo: ações em arqueologia pública ligadas ao Projeto de Ampliação da Mina Calcária Limeira.

Erika Marion Robrahn-González

SPAULDING, ALBERT C.

1988 Disntinguished lecture: archaeology and anthropology. American Anthropologist vol. $90: 263-271$

SPIER, L.

1917 Na outline for a chronology of Zuñi ruins. Anthropological Papers of the American Museum of Natural History, 18, Nova lorque :207-331

SPINDEN, HERBERT J.

1917 The origin and distribution of agriculture in America. Proceedings, Niineteenth International Congress of Americanists, :269-276, Washington D.C.

1928 Ancient Civilizations of Mexico and Central Mexico. American Museum of Natural History Handbook Series, n.3, New York

SQUIER, EPHRAIM G.

1849 Aboriginal Monuments of New York. Smithsonian Contributions to Knowledge, vol. 2, Washington, D.C.

STAHL, A.

1994 Change and Continuity in the Banda Area, Ghana: The Direct Historical Approach. Journal of Field Archaeology, 21, pp:181-203.

STEERE, J.B.

1927 The Archaeology of the Amazon, Univ. of Michigan Official Publications vol.29, n.9, Univ. of Michigan, Ann Arbor

STEINEN, KARL VON DEN

1904 Ausgrabungen am Valenciasee. Globus vol.86, n.77, :101-8

STEWARD, JULIAN H.

1937 Ecological aspects of Southwestern Society. Anthropos vol.32, :87-104

1938 The direct historical approach to Archaeology. American Antiquity vol.7 n.4 :337-433

1946-50 The Handbook of South American Indians, 6 vols., Bureau of American Ethnology, Bulletin 143, Washington D.C.

1949 Cultural Causality and Law: a trial formulation of the development of early civilizations. American Anthropologist vol.51, :1-27

1950 Theory of Cultural Change. Univ. of Illinois Press, Urbana

1955 Civilizaciones antiguas del viejo mundo y de america : symposium sobre las civilizaciones de regadio. Washington, DC : Union Panamericana.

1966 Toward understanding cultural evolution. Science vol.153, :729-730

STEWARD, LINCOLN J.

1942 The maya calendar of the ixil of guatemala. Washington : Carnegie Institution of Washington,
STIRLING, MATTHEW W.

1943 Stone Monuments of southern Mexico. Bureau of American Ethnology, Bulletin 138, Washington D.C.

STOW, J.

1603 A survey of London. London

STRONG, WILLIAM D.

$1935 \mathrm{Na}$ introduction to Nebraska Archaeology Smithsonian Miscellaneous Collections, vol.93 n.10, Washington D.C.

STURTEVANT, WILLIAM C.

1960 The significance of Ethnological similarities between Southeastern North America and the Antilles. Yale Univ. Publications in anthropology, n.64, New Haven

TAYLOR. WALTER W. JR.

1948 A study of Archaeology. Memoir Series of the American Anthropological Association, n.69,, Menasha, Wis.

THOMAS, CYRUS

1894 Report of the Mound Explorations of the Bureau of Ethnology. Washington, D.C.

THOMAS, DAVID

1988 Saints and soldiers at Santa Catarina: Hispanic Designs for colonial America. In M.P.Leone \& P.B.Potter Jr (eds.) The recovery of meaning: historical archaeology in the eastern United States. :73-140, Smithsonian Institution Press, Washington D.C.

2000 Skull Wars: Kennewick Man, Archaeology and the Battle for Native American Identity. New York, Basic Books.

THOMPSON, J.E.S.

1950 Maya Hierogliphic Wrinting: na introduction. Publications of the Carnegie Institution of Washington, n.589, Washington D.C.

TRIGGER, BRUCE G.

1963 Settlement as na aspect of I roquois adaptation at the time of contact. American Anthropologist vol.65, n.1, :86-101

1967 Settlement Archaeology - its goals and promise. American Antiquity vol.32, n.1 :149-161

1968 The determinants of settlement patterns. In K.C.Chang (ed,) Settlement Archaeology :53-78, Nation Press Books, Palo Alto

1989 A history of Archaeological Thought. Cambridge University Press, Cambridge

1991 Constraint and freedom: a new synthesis for Archaeological explanation. American Anthropologist vol.93, :551-569

UHLE, MAX

1903 Pachacamac. Niversity of Pannsylvania Press, Philadelphia.

VAILLANT, GEORGE C.

1927 The chronological significance of Maya 
Ceramics. PhD dissertation, Harvard Univ., Cambridge.

VAN MELLEN, J.

1679 Historia urnae sepulchralis sarmaticae. Jena

WATSON, PATTY JO

1979 The idea of ethnoarchaeology: notes and comments. In C.Kramer (ed.) Ethnoarchaeology: implications of ethnography for archaeology. :277-88, New York: Columbia Univ. Press

1990 A Parochial Primer: the new dissonance as seen from the Midcontinental USA. In R.W.Preucel (ed.) Processual and Postprocessual Archaeologies: multiple ways of knowing the past. :265-274, Center for Archaeological Investigations, Occasional Paper n.10, Southern Illinois Univ., Carbondale

WATSON, PATTY JO; LEBLANC, S.A. \& REDMAN, CHARLES L.

1971 Expalnation in Archaeology, anexplicitly Scientific Approach. Columbia Univ. Press, New York

WATSON, RICHARD A.

1991 What the New Archaeology has Accomplished. Current Anthropology 32(3):275-291

WAUCHOPE, ROBERT

1962 Lost Tribes and Sunken Continents. University of Chicago Press, Chicago.

1964-76 Handbook of Middle American Indians, vol. 1-16, Univ. of Texas Press, Austin

WEDEL, WALDO R.

1953 Some aspects of human ecology in the Central Plains. American Anthropologist vol.55, :499-514

WHALLON, R. JR.

1967 Investigations of late Prehistoric social organization in New York State. In S.R.Binford \& L.R.Binford (eds.) New Perspectives in Archaeology :223-244, Aldine, Chicago

1968 A new approach to pottery typology. American Antiquity, 37: 13-33

1974 Spatial analysis of occupation floors (II): the application of nearest neighbour analysis. American Antiquity 39 (1), 1634. Salt Lake City. Society American Archaeology
WHITE, LESLIE A.

1959 The Evolution of Culture. McGraw-Hill, New York

WILLEY, G.

1945 Horizon Styles ans pottery traditions in Peruvian Archaeology. American Antiquity vol.11:49-56

1946 Comments on cultural and social Anthropology. In S. Tax et alii (eds.) $\mathrm{Na}$ appraisal of Anthropology today. :229230, Univ. of Chicago Press, Chicago.

1947 Prehistoric Settlement Patterns in the New World. Viking Fund Publications in Anthropology, n.23, New York

1948 The early great styles and the rise of the pre-Columbian civilizations. American Anthropologist vol.64, n.1, :1-14

1953 Prehistoric settlement patterns in the Virú Valley, Peru. Washington : U.S. Govt. Print. Off

1956 Prehistoric Settlement Patterns in the New World. Viking Fund Publications in Anthropology No. 23, New York.

WILLEY, G.R. \& PHILLIPS, PHILIP

1955 Method and theory in American Archaeology, II: historical-developmental interpretations. American Anthropologist vol.57, :723-819

1958 Method and theory in American Anchaeology. Univ. of Chicago Press, Chicago

WILLEY, G.R. \& SABLOFF, J.A.

1993 A History of American Archaeology. W.H. Freeman and C., New York, 3. Edition

WYLIE, A.

1985 The reaction against analogy. Advances in Arch. Method and Theory 8: 63-111

1988 'Simple'analogy and the role of relevance assumptions: implications of Archaeological Practice. International Studies in the Philosophy of Science 2:134-150

1989 The interpretive Dilemna. V.Pinsky \& A.Wylie (ed.) Critical Traditions in Contemporary Archaeology: essays in the Philosophy, History and socio-politics of Archaeology. :18-27, Cambridge Univ. Press, Cambridge

1991 Gender theory and the Archaeological record. In J.M.Gero \& M.W.Conkey (eds.) Engendering Archaeology, women and prehistory. :31-56, Basil Blackwell, Londres 


\section{Bibliografia Arqueológica/ Histórica}

AMBROSETTI, JUAN B.

1897 La antigua Ciudad de Quilmes (Valle Calchaqui). Boletin Instituto Geografia Argentino, vol. 17: 33-70

1898 El Sepulero de 'La Paya' ultimamente descubierto en los Lalles Callchaquies (Provincia de Salta). Arqueologia Argentina vol1, ser.3, :119-148

1899 Exploraciones arqueológicas en la Pampa Grande (Prov. De alta). Revista de la Universidad de Buenos Aires vol. 6, n. 1

1906 El hacha de huaycama. In: Anales del Museo Nacional de Buenos Aires, ser.3, v.16, t.9, p. 15-23.

1908 Exploraciones arqueológicas en la ciudad pre-historica de 'La Paya (Valle Calchaqui, Provincia de Salta). Revista de la Universidad de Buenos Aires, vol.8, n.3

1912 Memoria del Museo Etnográfico (1906 a 1912). Buenos Aires : Compañía Sud-Americana de Billetes de Banco, 1912

AMEGHINO, FLORENTINO

1911 Une nouvelle industrie lithique. Anales del Museo Nacional de Buenos Aires vol.12, ser.3, :189-204

1918 La Antiguedad del Hombre en El Plata. Cultura Argentina, Buenos Aires

ASCHER, ROBERT

1961 Analogy in archaeological interpretation. Southwestern Journal of Anthropology 17: $317-25$

BAHN, PAUL (ED.)

1996 The Cambridge Illustrated History of Archaeology. Cambridge University Press, Cambridge

BARRETO, CRISTIANA.

2000 A construção de um passado pré-colonial: uma breve história da arqueologia do Brasil. In Dossiê Antes de Cabral: arqueologia brasileira I, Revista da USP,São Paulo. P 32-51

2002 Exploring the Amazon, explaining the Unknown Amazon: views from the Past. In: McEwan, Colin, Barreto, Cristiana e Neves, Eduardo. Unknown Amazon. Londres, British Museum, pp:232-251.

BENNETT, JOHN W.

1943 Recent developments in the functional interpretation of Archaeological Data. American Antiquity vol.9, n.2 :208-219

BERLIN, HEINRICH

1958 El glifo "emblema" en las inscripciones Mayas. Journal de la Societé des Américanistes vol. 47, :111-119
BINFORD, LEWIS R.

1962 Archaeology as Anthropology. American Antiquity vol.28, n.2, :217-225

1963 Smudge pits and hide smoking: the use of analogy in archaeological reasoning. American antiquity 32: 1-12

1964 Methodological considerations in the use of ethnographic data. In R.B.Lee $\&$ I.DeVore (eds.) Man the hunter, :268-73, Chicago: aldine Publishing Company

1965 Mortuary practices: their study and potential. In J.A.Brown (ed.) Approaches to the Social Dimensions and mortuary practices, SAA, Memoir 25, :58-67, Washington, D.C.

1967 Smudge Pits and Hide-Smoking: The Use of Analogy in Archaeological Reasoning. American Antiquity 32:1-12.

1971 Mortuary practices : their study and their potential. Washington : Society for American Archaeology, 1971, pp:6-29.

BINFORD, S.R. \& BINFORD L.R. (EDS.)

1968 New Perspectives in Archaeology, Aldine, Chicago

BOAS, FRANZ

1913 Archaeological Investigations in the Valley of Mexico by the International School, 1911-12. In Eighteenth International Congress of Americanists, pt.1, 176-179, Londres

1940 Race, Language and Culture Macmillan, New York

BOLLAERT, WILLIAM

1860 Antiquarian, Ethnological, and other researches in New Granada, Equador, Peru, and Chile. D. Lane, Londres

BORMIDA, MARCELO

1968 Arqueologia de las altas cotas de la Costa Norpatagónica. Thirty-seventh International Congress of Americanists, vol.3, :345374, Buenos Aires

BROWN, JAMES A. (ED.)

1971 Approaches to the social dimensions of mortuary practices. SAA, Memoir 25, Washington D.C.

BROWNE, T.

1658 Hydriotaphis. Urne burial. Londres

CALDARELLI, S. B. \& SANTOS, M.C.M.M. DOS

2000 Arqueologia de contrato no Brasil. In: Neves, Walter A. (org.) Antes de Cabral: arqueologia brasileira. Revista USP 44:3251, São Paulo, Univ. de S. Paulo.

CAMPBELL; DONALD T.

1988 Methodology and epistemology for social science: selected papers. Chicago, 
University of Chicago Press Ed. Samuel Overman

CATHERWOOD, FREDERICK

1844 View of Ancient Monuments in Central America, Chiapas, and Yucatán. Vizetally, Londres

CHANG, KWANG-CHI

1958 Study of the Neolithic Social Grouping: examples from the New World. American Anthropologist vol.60, n.2, :298-334

1967 Major aspects of the interrelationship of archaeology and ethnology.

Current Anthropology 8( ) :227-34

CHARLTON, THOMAS $\mathrm{H}$.

1981 Archaeology, ethnohistory and ethnology: interpretive interfaces. Advances in Archaeological Method and Theory 4:129-76

CHILDE, V. GORDON

1925 The Dawn of European Civilization

1929 The Danube in Prehistory. Oxford, Clarendon Press

1936 Man Makes Himself. Watts, Londres

CIGLIANO, E.M.

1962 Ampajanguense, Inst. de Ãntropologia, Rosario, Univ. Nacional de Litoral

CLAASSEN, CHERYL (ED.)

1992 Exploring gender through archaeology. Monographs in World Archaeology, n.11, Prehistory Press, Madison

CLARK, GRAHAME D.

1936 The Mesolithic Settlement of northern Europe. Cambridge Univ. Press, Cambridge

1937 Archaeology and Society. Methuem, Londres

1939 The reindeer hunting tribes of northern Europe. Antiquity 12:154-171.

1953 The economic approach to Prehistory. Proceedings of the British Academy vol. 39, :215-238

1970 Prehistory of Africa. London: Thames and Hudson

CLARKE, DAVID

1968 Analytical Archaeology. Methuem, Londres

1972 Models in Archaeology. Methuem, Londres

1977 Spatial Archaeology. Academic Press, Londres

CONKEY, MARGARET W. \& SPECTOR, JANET

1984 Archaeology and the study of gender. In M.B.Schiffer (ed.) Advances in Archaeological Method and Theory, vol. 7, :1-38, Academic Press, New York

CRIST, THOMAS A. J.

2002 Empowerement, Ecology and Evidence: The Relevance of Mortuary Archaeology to the Public. In Little, B.j (org.) Public Benefits of Archaeology. Florida: University Press of Florida, pp:101-117.
CUNHA; MANUELA CARNEIRO (ORG.)

1992 História dos Índios no Brasil. São Paulo, Fapesp e Companhia das Letras.

DE BLASIS, P. A. \& ROBRAHN-GONZÀLEZ, E.M.

2004 Dam contract archaeology in Brazil: some prospects and a case study at the amazonian border. BID, (no prelo)

DEETZ, J AMES J.F.

1960 An Archaeological Approach to kinship change in eighteenth century Arikara Culture. PhD Dissertation, Harvard Univ., Cambridge, Mass.

1965 The dynamics of stylistic change in Arikara Ceramics. University of Illinois Series in Anthropology, n.4, Urbana

1966 Stone Tools, Anthropology Curriculum Study Project. Excerpt in Origins of Humanness: Patterns in Human History. New York.Edwin Dethlefsen, editor, pp. 74-84. Macmillan \& Co.

1968 Cultural patterning of behaviour as reflected by archaeological

MATERIAL. IN:CHANG, K.C.

(ed) Settlement Archaeology. Palo Alto, CA, National Press, pp: 31-42.

1968a The inference of residence and descent rules from Archaeological

data. In S.R.Binford \& L.R.Binford (eds) New Perspectives in Archaeology:41-49, Aldine, Chicago

1968b Late Man in North America: Archaeology of european americans. In B.J.Meggers (ed.) Anthropological Archaeology in the Americas, 121-130, Washington D.C.

DERBY, ORVILLE

1879 Artificial Mounds of the Island of Marajó, Brazil. American Naturalist vol.13, n.4, 224 p.

DE VRIES, $B$.

2003 In search of sustainability: what can we learn from the past? Paper for the International Symposium on World System History and Global Environment Change, Utrecht, Lund University

DOUGLAS, J.E.

1995 Autonomy and regional systems in the late Prehistoric Southern Southwest. American Antuiquity 60(2):240-257

DRUCKER, PHILLIP

1952 La Venta, Tabasco: a study of Olmec Ceramics and art. Bureau of American Ethnology, Bulletin 153, Washington D.C.

DUNNELL, ROBERT C.

1986 Five decades of American Archaeology. D.J.Meltzer, D.D.Fowler, J.A.Sabloff (eds.) American Archaeology, Past and Future. Smithsonian Institution Press, Washington \& London 
Arqueologia e sociedade no município de Ribeirão Grande, sul de São Paulo: ações em arqueologia pública ligadas ao Projeto de Ampliação da Mina Calcária Limeira.

Erika Marion Robrahn-González

FABIAN; JOHANNES

1983 Time and the other: how anthropology makes its object. New York: Columbia University Press,

FAGAN, BRIAN

2002 Epilogue. In: Little, B.J. (org) Public Benefits of Archaeology. Florida: University Press of Florida, pp:253-260.

FARABEE, WILLIAN C.

1921 Exploration at the Mouth of the Amazon, Museum J ournal of the University Museum

FAULKNER, N. vol.12, n.13 :142-161, Philadelphia

2000 Archaeology from below. Public Archaeology I: 21-33

FLANNERY, KENT V.

1967 Culture History vs. Cultural Process: a debate in american Archaeology. Scientific American, vol. 217, :119-122

1968a Archaeological Systems theory and Early Mesoamerica. B.J.Meggers (ed.), Anthropological Archaeology in the Americas, :67-87, Washington D.C.

1968b The Olmec and the valley of Oaxaca: a model for inter-regional interaction in Formative times. In E.P.Benson (ed.), Durbarton Oaks Conference on the Olmec,:79-110, Washington D.C.

1969 Origins and ecological effects of early domestication in Iran and the Near East. In G.W.Dimbleby \& P.J.Ucko (eds.), The domestication and exploitation of plants and animals, :73-100, Aldine, Chicago

1972a The cultural evolution of Civilizations. Annual Review of ecology and systematics. Vol.3, :399-426, Palo Alto

1972b Summary Comments: evolutionary trends in social exchange and interaction. In E,N.Wilmsen (ed.) Social exchange and interaction, :129-136, Univ. of Michigan, Museum of Anthropology, Anthropological Papers n.46, Ann Arbor

1976 The early Mesoamerican village Academic Press, New York

1986 Guila Naquitz: archaic foraging and the early agriculture in Oaxaca, Mexico. Academic Press, Orlando

FIELD, J. ET AL

2000 'Coming back' Aborígines and archaeologists at Cuddie Springs. Public Archaeology Vol. $1: 35-48$

FORD, J.A.

1938 A Chronological method applicable to the Southeast. American Antiquity vol.3, n.3 :260-264

1939 Measurements of some Prehistoric
Developments in the Southeastern States. Anthropological Papers of the American Museum os Natural History, vol.44, pt.3, New York

1940 A quantitative method for deriving cultural chronology. Washington Pan American Union Technical Manual I.

1951 Archaeological survey in the lower mississipi alluvial valley, 1940-1947. Cambridge : Peabody Museum

1962 Metodo cuantitativo para estabelecer cronologias culturales. Washington: Union Panamericana.

FOX, CYRIL

1932 The personality of Britain. Man, vol.32, 202 pp.

FUNARI, PEDRO PAULO A.

1995 Mixed features of archaeological theory in Brazil. In P. Ucko (ed.) Theory in Archaeology, a world perspective: 236250, London, Routledge.

1998 A importancia da teoria arqueológica internacional para a Arqueologia sulamericana: o caso brasileiro. In P. P.A. Funari (ed.) Teoria Arqueológica na América do Sul, :13-32, IFCH, Campinas

2004 Western influences in the archaeological thought in Brazil. In G. Politis \& R. Peretti (eds.) Teoria arqueologica en America del Sur: 235-244, Serie Teorica n. 3, INCUAPA, Olavarria.

FUNARI, P.P.A.; HALL, M.; JONES, S.

1999 Historical Archaeology: back from the edge. Londres, Rouledge.

FUNARI, P.P.A. \& ROBRAHN-GONZÁLEZ, E.M.

2005 Ethics, capitalism and public archaeology in Brazil.

GALLATIN, ALBERT

1845 Notes on the Semi-Civilized Nations of Mexico, Yucatan, and Central America. Transactions of the American Ethnological Society vol.1, New York

Gaspar, M.D.

1998 Considerations on the sambaquis of the Brazilian coast. Antiquity 72 (277) :592-615

GERO, JOAN M. \& CONKEY, MARGARET (EDS.)

1991 Engendering Archaeology: women and Prehistory. Basil Blackwell, Londres

GIFFORD, J.C.

1960 The type-variety of ceramic classification as na indicator of cultural phenomena. American Antiquity, 25: 341-7

GOSDEN, C.

2001 Postcolonial Archaeology. In Archaeological Theory Today (ed. I. Hodder), :241-261, Polity Press, Cambridge 
GOELDI, EMILIO

1900 Excavações archaeológicas en 1895. Memoires do Museu Goeldi, Belém

GONZÁLEZ, ALBERTO R.

1963 Cultural development in Northwestern Argentina. In B.J.Meggers \& C.Evans (eds.) Aboriginal cultural development in Latin America: na interpretative review. Smithsonian Miscellaneous Collection, vol. 1240, n.1, :103-118, Washington D.C.

GOSDEN, CHRIS

2001 Postcolonial Archaeology: Issues of Culture, Identity, and Knowledge. In: Hodder (ed.) Archeological Theory Today, :241-261, Cambridge, Polity Press

GOULD, RICHARD

1967 Notes on hunting, butchering and sharing of game among Ngatajara and their neighbours in the west Australian desert. Kroeber Anthropological Society Paper, 36

1968 Living Archaeology: the Ngatatjara of Western Australia. Southwestern Journal of Anthropology 24: 101-22

1969 Subsistence behavior among the Western Desert Aborigines of Australia. Oceania, 39: $253-74$

1974 Some current problems in ethnoarchaeology. In C.B.Donnan \& C.W.Clewlow (eds.) Ethnoarchaeology :29-48, Inst. of Archaeology Monograph, 4. Los angeles: Univ. of California.

1980 Living archaeology. New York: Cambridge Univ. Press

1981 Cave art of australian desert aborigines. In H.J.Shafer (ed.) Ancient Texans, :2049, Austin: Texas Monthly Press

1990 Recovering the Past. Univ. od New Mexico GOULD, R.A. \& WATSON, PATTY JO

1982 A dialogue on the meaning and use of analogy in ethnoarchaeological reasoning. Journal of Anthropological Archaeology 1: 355-81

GROEVIUS, M. \& GRONOVIUS, A.

1694 Thesaurus antiquitatum. Traj. Ad Rhenum

HANDLER, JEROME

1968 The Amerindian Slave Population of Barbados in the Seventeenth and Early Eighteenth Centuries.

HARTMAN, CARL V.

1901 Archaeological Research in Costa Rica. Royal Ethnological Museum, Stockholm

HARTT, CHARLES F.

1871 The Ancient indian pottery of Mararjó, Brazil. American Naturalist vol.5, :259-271

HELM, JUNE

1962 The ecological approach to Anthropology. American Journal of Anthropology, vol. 67, n.6, :630-639
HEMPEL, C.G

1966 Philosophy of Natural History. PrenticeHall, Englewood Cliffs, N.J.

HILL, J AMES N.

1968 Broken K Pueblo: patterns of form and function. In S.R.Binford \& L.R.Binford, New Perspectives in Archaeology :103143, Aldine, Chicago

HODDER, IAN

1978 Social organization and human interaction: the development of some tentativa hypothesis in terms of material culture. In I.Hodder (ed.) The spatial organization of culture. Duckworth, Londres

1982 Symbols in action: ethnoarchaeological studies of material culture. New York: Cambridge Univ. Press

1985 Postprocessual Archaeology. In M. Schiffer (ed.) Advances in Archaeological Method and theory vol.8 :1-26, Academic Press, New York

1987 The contribution if the Long Term. In I.Hodder (ed.) Archaeology as Long-Term History :1-8, Cambridge Univ. Press, Cambridge

1991a Postprocessual Archaeology and the Current debate. In R.W.Preucel (ed.) Processual and Postprocessual archaeologies: multiple ways of knowing the past::30-41. Center for Archaeological Investigations, Southern Illinois Univ., Occasional Paper n.10, Carbondale

1991b Reading the past: current approaches to interpretation in archaeology. Cambridge Univ. Press, Cambridge

1994 Interpretación em Arqueología. Corrientes Actuales. Crítica, Barcelona

2001 A review of contemporary theoretical debates in Archaeology. In I. Hodder (ed.) Archaeological Theory Today. :1-13, Cambridge, Polity Press

HOLE, FRANK \& HEIZER, ROBERT

1966 An introduction to Prehistoric Archaeology. Holt, Rinehart and Winston, New York

HODGE, FREDERICK W. (ED.)

1907-10 Handbook of American Indians North of Mexico 2 pts. Bureau of American Ethnology, Bulletin 30, Washington D.C.

HOLMES, WILLIAM H.

1895-97 Archaeological Studies among the ancient Cities of Mexico. Filed Columbian Museum Anthropological Series, vol.1, n. 1, Chicago

HRDLICKA, ALES ET ALII

1912 Early Man in South America. Bureau of American Ethnology, Bulletin 52, Washington D.C. 
Arqueologia e sociedade no município de Ribeirão Grande, sul de São Paulo: ações em arqueologia pública ligadas ao Projeto de Ampliação da Mina Calcária Limeira.

HUDDLESTON, LEE E.

1967 Origins of the American Indians: European Concepts, 1492-1729. Austin, University of Texas Press.

HUFFMAN, T.

1982 Archaeology and ethnohistory of the African Iron Age.Annual Review of Anthropology 11: 133-150

IHERING, HERMANN VON

1895 A civilização prehistórica do Brazil meridional.Rev. do Museu Paulista vol.1, :34-159

JOYCE, THOMAS

1914 Mexican Archaeology. Putnam, Londres KIDDER, ALFRED V.

$1924 \mathrm{Na}$ introduction to the study of Southwestern Archaeology, with a preliminary account of the excavations at Pecos. Papers of the Southwestern Expedition, Phillips Academy n.1, Yale Univ. Press, New Haven

KNOROSOV, Y.V.

1967 Selected Chapters from the Writing of the Maya Indians, translated by Sophie Coe, Russian Translation Series of the Peabody Museum, vol.4, Cambridge, Mass.

KRIEGER, A.D.

1944 The typological concept. American Antiquity, 9: 271-88

Kroeber, Alfred L.

1927 Coast and Highland in Prehistoric Peru. American Anthropologist vol.29, :625-653

1944 Peruvian Archaeology in 1942. Viking Fund Publications in Anthropology n.4, New York

KUWANWISIWMA, L.

2002 Hopi Understanding of the Past. A Colaborative Approach. In: Public benefits of Archaeology. Ed. Barbara J. Little, University Press of Florida, 46-51.

LATHRAP, DONALD W.

1958 The culture sequence at Yarinacocha, Eastern Peru. American Antiquity vol.23, n.4, :379-388

1970 The Upper Amazon. Praeger, New York

1973 The Tropical forest and the cultural context of Chavin. In E.P.Benson (ed.) Dumbarton Oaks Conference on Chavín, :73-100, Washington D.C.

LAMPHEAR; J .

1982 The People of the Grey Bull: The Origin and Expansion of the Turkana.J ournal of African History 29:27-39.

LEAKEY, L.S.B.

1960 Adam's ancestors: the evolution of man and his culture. New York, Harper \& Row

1969 The progress and evolution of man in Africa. Londres, Oxford Univ. Press
1973 Hacia el desvelamiento del origen del Hombre: diez decenios de investigatión sobre la evolución humana. Madrid, Aguilar.

LEE, RICHARD B.

1979 The !Kung San: men, women and work in a foraging society. Cambridge: Cambridge Univ. Press

LERNER, S.

1991 Saving Sites: Preservation and Education. In: Smith, G. and Ehrenhard, J. (eds). Protecting the Past, CRC Press, Boca Raton, Florida, 103-8. Leone, Mark

1968 Neolithic economic autonomy and social distance. Science vol. 162, n.3858, :11501151

1982 Some opinions about recovering Mind. American Antiquity vol. 47, :742-760

1984 Interpreting ideology in historical archaeology: using the rules of perspective in the William Paca Garden in Annapolis, Maryland. In D.Miller \& C.Tilley (eds.) Ideology, Power and Prehistory :25-35, Cambridge Univ. Press, Cambridge

LIPE, WILLIAM D.

2002 Public Benefits of Archaeological Research. In: Little; B. J. Public Benefits of Archaeology. Florida: University Press of Florida, pp:20-28.

LITTLE, B.J .

2002 Archaeology as a Shared Vision. Public Benefits of Archaeology (e. B. J. Little) 119. Florida: University Press of Florida.

LONGACRE, WILLIAM A.

1968 Some aspects of Prehistoric Society in EastCentral Arizona. In S.R.Binford \& L.R.Binford (eds.) New Perspectives in Archaeology :89-102, Aldine, Chicago

LOWENTHAL, D.

1981 Conclusions: Dilemmas of Preservation. In: Our Past BeforeUs: Why Do We Save it? Ed. D. Lowenthal and M. Binney, 213-37, London, Temple Smith.

1985 The Past is a Foreign country. Cambridge, cambridge University Press.

LUND. PETER

1950 Memorias sobre a paleontologia brasileira Instituto Nacional do Livro, Rio de Janeiro.

LUMBRERAS, LUIS G.

1971 Towards a re-evaluation of Chavin. In E.P.Benson (ed.) Dumbarton Oaks on Chavin. Dumbarton Oaks, Washington D.C.

LUMBRERAS, L.G.

1960 Algunos problemas de arqueologia peruana. In Antiguo Peru: espacio y tiempo. (ed. R. Matos) : 129-148, Editorial J. Mejía Baca, Lima. Malina, Jaroslav \& Vasícek, Zdenek 
1990 Archaeology yesterday \& today. Cambridge University Press, Cambridge

MARCANO, G.

1889 Ethnographie précolombienne du Venezuela, Vallées dÁragua et de Caracas. Mémoires dÁntropologie ser.2, vol.4, :1-86

MARTIN, PAUL S.

1974 Early development in Mogollon research. In G.R.Willey (ed.) Archaeological Researches in Retrospect, :3-33, Winthrop, Cambridge

McGee, R.J. \& Warms, R.L.

1996 Anthropological Theory - na introductory history. Mayfield Publishing Company, California

MCGUIRE, RANDALL H.

1992 A Marxist Archaeology. Academic Press Inc., California

MCMANAMON, F.P.

1991 The Many Publics for Archaeology. American Antiquity, 56 (1), 121-30.

1994 Presenting Archaeology to the Public in the USA. In: The Presented Past, Heritage, Museums and education. Ed. P. G. Stone and B. L. Molyneaux, 61-81, New York, Routledge.

1994a Changing relationships between Native Americans and Archaeologists. Historic preservation Forum 8 (2): 15-20.

2000 Archaeological messages and messengers. Public Archaeology I:5-20

2002 Heritage, History and Archaeological Educators. In: Public benefits of Archaeology. Ed. Barbara J. Little, University Press of Florida, 31-45

MCNEISH, R.S.

1958 Preliminary Archaeological investigations in the Sierra de Tamaulipas, Mexico. Transactions, American Philosophical Society, vol. 48, pt.6, Philadelphia

1959 Investigations in the Southwest Yukon: Part II, Archaeological excavation, comparison and speculation. Papers of the R.S.Peabody Foundation for Archaeology, vol. 16, n.1, Andover, Mass

1960 Investigations in the Southwest Yukon: Part II, Archaeological excavation, comparisons and speculations. Papers of the R.S.Peabody Foundation for Archaeology, vol.6, n.1, Andover, Mass.

1967 A summary of the subsistence. In D.S.Byers (ed.) Prehistory of the Tehuacan Valley vol.1 :290-309, Univ. of Texas Press, Austin

MEGGERS, BETTY

1954 Environmental limitation on the development of culture. American Anthropologist vol.56, n.5, :801-824
1956 Functional and evolutionary implications of community patterning. In R. Wauchope (ed) Seminars in Archaeology: 1955. SAA, Memoir 11, Washington D.C

1957 Environment and culture in the Amazon Basin: na appraisal of the theory of environment determinism. In A. Palerm et alii (eds.) Studies in Human Ecology, :7190. Pan American Union Social Sciences Monograph, n.3, Washington D.C.

1966 Field testing of cultural law: a reply to Morris Opler. Southwestern Journal of Anthropology, vol. 17, n.14, :352-354

MEGGERS, B. \& EVANS, C.

1957 Archaeological investigations at the Mouth of the Amazon. Bureau ofAmerican Ethnology, Bulletin 167, Washington D.C.

MENDONÇA-DE-SOUZA, S. M. F.,

1991 Mendonça de Souza, A. - História da arqueologia brasileira. Pesquisas em Antropologia, n. 46.

MENGHIN, OSWALD F.

1957 Das Protolithikum in Amerika. Acta Praehistorica, n.1

MENZEL, DOROTHY

1964 Style and time in the middle Horizon. Nawpa Pacha n.2, :1-106

MESKELL, LYNN

2001 Archaeologies of Identity. In I. Hodder (ed.) Archaeological Theory Today :187213, Cambridge, Polity Press

MILLON, RENÉ F.

1967 Teotihuacán. Scientific American, vol. 216, n. $6,: 38-48$

Molyneaux, B.L.

1994 Introduction: the represented Past. In The Presented Past: heritage, museums and education (ed. P. G. Stone \& B. L. Molyneaux, 1-13, London, Rouledge.

MOSER, S.

2001 Archaeological Represtantion: the visual conventions for constructiong knowledge about the past. In Archaeological Theory Today (ed. I.Hodder), Polity Press, Cambridge.

MULVANEY, D.J .

1969 The Prehistory of Australia. Londres, Thames ans Hudson.

NARROLL, RAOUL S.

1962 Floor area and settlement population. American Antiquity vol. 27, n.4,: 587-589

NATIONAL CENTER FOR HISTORY IN THE SCHOOLS.

1996 National Standards for History. Basic Editions. Los Angeles: university of California Press.

NELSON,N.C.

1916 Chronology of the Tano Ruins. American 
Arqueologia e sociedade no município de Ribeirão Grande, sul de São Paulo: ações em arqueologia pública ligadas ao Projeto de Ampliação da Mina Calcária Limeira.

Anthropologist, New Mexico, 18 (2): 159-180

NEVES, E.

2001 Twenty Years of Amazonian Archaeology in Brasil. Antiquity 72 (277): 625-32

NEVES, W.A.

1996 Arqueologia brasileira: algumas considerações. Boletim do Museu Paraense Emilio Goeldi, Antropologia 2:200-205.

NEVES, W.A. ET ALII

1999 Cranial morphological variation in South America and the colonization of the New World: towards a four migration model? Ciência e Cultura Journal of the Brazilian Association for the Advancement of Science 51, 151-165.

NDORO, W. \& PWITI, G.

2001 Heritage management in Southern Africa. Public Archaeology vol. 2: 21-34

ORSER, C.E.

1990 Archaeological approaches to New World plantation slavery. In M.B. Schiffer (ed.) Archaeological Method and Theory vol. 2: 111-154, Tucson, University of Arizona Press.

1992 Introdução à arqueologia histórica. Belo Horizonte : Oficina de Livros.

ORTON, C.; TYERS, P.; VINCE, A.

1995 Pottery in Archaeology. Cambridge Manuals in Archaeology. Cambridge. Cambridge Univ. Press

OUTES, FELIX F.

1897 Los Querandies Impreuta Martin Biedma, Buenos Aires

1898 La Edad de la piedra en Patagonia.Anales del Museo Nacional de Buenos Aires vol 12, :203-575

1907 Arqueología de San Blas, Provincia de Buenos Aires. Anales del Museo Nacional de Buenos Aires vol.14, :249-275

PATTERNSON. THOMAS C.

1989 History and the Post-Processual Archaeology. Man, vol.24:555-566

PEERS. L.

1999 "Many tender ties": the shifting contexts and meanings of the $\mathrm{S}$ Black bag. World Archaeology 31: 288-302.

PESSIS, A. M.

1989 Apresentação gráfica e apresentação social na tradição nordeste de pintura rupestre no Brasil. Clio 5:11-17,

PLOG, FRED T.

1974 The study of Prehistoric Change Academic Press, New York

1976 Measurement of Prehistoric Interaction between communities. In K. Flannery (ed.) The early mesoamerican village, New York, Academic Press
PREUCEL, R.W.

1991 Processual and Postprocessual anchaeologist: multiple ways of knowing the past. Center for Archaeological Investigations, Occasional Paper n.10, Southern Illinois Univ., Cabondale

PROUS, A.

1991 Arqueologia Brasileira, 605 pp. UnB, Brasília. PROUS, A.

1994 L'archéologie brésilienne aujourd'hui, Problèmes et tendances. Recherches Brésiliennes, Besançon, 9-43.

PYBURN, K. ANN AND RICHARD R. WILK.

1995 Responsible Archaeology Is Applied Anthropology. In: Ethics in Archaeology: Challenges for 1990s, ed. M. J. Lynott and A. Wylie, 71-76, Washington, D. C.: Society for American Archaeology.

RATHJE, WILLIAM L.

1970 Socio-political implications of Lowland Maya Burials: methodology and tentative hypotheses. World Archaeology vol1, n.3 :359-374

1974 Garbage Project: a new way of looking at the problems of Archaeology. Archaeology vol.27, n. $4: 236-241$

1978 Archaeological Ethnography....because sometimes it is better to give than to receive. In R. Gould (ed) Explorations in Ethnoarchaeology, :49-75. School of American Research, Advanced Seminar Series, Univ. of New Mexico Press, Albuquerque

REDMAN, C.L.

1973 Research and theory in current Archaeology: na introduction. In C.L.Redman (ed.) Research and theory in current archaeology : 5-26, Wiley, New York

1991 Distinghished lecture in Archaeology. In defense of the seventies - the adolescence of New Archaeology. American Anthropologist vol.93, :295-307

RENFREW, C. \& BAHN, P.

1996 Archaeology - Theories, Methods and Practice. Thames ans Hudson, 2. Edition, Londres

RESTREPO, VICENTE

1895 Los Chibchas antes de la Conquista Espanola.Imprensa de La Luz, Bogotá

RIBEIRO, M. A.

2000 Ecologizar. Pensando o ambiente humano. Belo Horizonte, Rona Editora

ROBRAHN-GONZALEZ, E. M.

1996 Os grupos ceramistas pré-coloniais do Centro-Oeste brasileiro. Revista do Museu de Arqueologia e Etnologia vol. 6: 83-122, São Paulo. 
2000 Reflexionen ueber den Gedrauch der historischen Analogie in Brasilien. In: A. Gramsch (ed.) Vergleichen als archaeologische Methode. Analogien in den Archaeologien, BAR International Series, arbeitsgemeinschaft Theorie (T-AG). Berlim,131-142

2001 El uso de la Analogía en la Etnoarqueología Brasileña. Anais da /I Reunión Internacional de Teoría Arqueológica en América del Sur. Argentina.

ROUSE, I.G.

1939 Prehistory in Haiti. A study in method. Yale Univ. Publications in Anthropology, n.24, New Haven

1960 The classification of artifacts in Archaeology. American Antiquity, 25: 313-23

ROWE, JOHN H.

1963 Urban Settlements in Ancient Peru. Nawpa Pacha vol.1, n.1 :1-27

ROWLANDS, M.

1998 The archaeology of colonialism. In K. Kristiansen \& M. Rowlands, Social Transformations in Archaeology: global and local perspectives, 327-33, London, Routledge.

SALMON, MERRILEE H.

1992 Postprocessual explanation in Archaeology. In L.Embree (ed.) Meta-Archaeology, Boston Studies in the Philosophy of Science. Kluwer Academic Press, Boston

SANDERS, WILLIAM T.

1956 Tierra y Agua. Phd Dissertation, Harvard University, Cambridge.

1957 The Cultural Ecology of the Teotihuacan Valley, Pennsylvania State University, University Park

SANDERS, W.T.; MERINO, JOSEPH

1970 New orld Prehistory. Archaeology of the American Indians. Foundations of Modern Anthropology Series. Prentice-Hall, Englewood Cliffs, N.J.

SANDERS, W.T. \& PRICE, BARBARA

1968 Mesoamerica, the evolution of a civilizarion. Random House, New York

SANTOS, BOAVENTURA DE SOUZA.

2003 Prefácio. In: Boaventura de Souza Santos (org). Reconhecer para Libertar. Os caminhos do Cosmopolitismo Multicultural. Rio de Janeiro. Civilização Brasileira. 13-68.

SCHIFFER, M.B.

1976 Behavioral Archaeology. Academic Press, New York

SCHORTMAN, M. \& URBAN, P.A.

1989 Interregional interaction in Prehistory: the need for a new perspective. American Antiquity 54(1):52-65
1992 Current trends in interaction research. In M.Schortman \& P.A.Urban (eds.) Resources, power and interregional interaction. Plenum Press, New York

SCHUYLER, ROBERT L.

1970 Historical and Historic Sites Archaeology as Anthropology: basic definitions and relationships. Historical Archaeology vol.4 :83-89

SCHWARCZ, LILIA MORITZ.

1993 O Espetáculo das Raças: Cientistas, Instituições e Questão Racial no Brasil - 1870-

SHACKEL, P. 1930. São Paulo, Companhia das Letras.

2002 Broadening the Interpretation of the Past at Harpers Ferry National Historical Park. In: Public benefits of Archaeology. Ed. Barbara J. Little, University Press of Florida, 157-167.

SHANKS,MICHAEL \& TILLEY, CRISTOPHER

1987 Social Theory and Archaeology. Polity Press, Cambridge

1989 Archaeology into the 1990s. Norwegian archaeological Review, vol. 22:1-12

SHANKS, MICHAEL \& HODDER, IAN

1995 Processual, postprocessual and interpretive Archaeologies. Ian Hodder et alii (eds.) Interpreting Archaeology - finding meaning in the past. Rouledge, London and New York, :3-29

SEARS, WILLIAN $\mathrm{H}$.

1961 The study of social and religious systems in North American Archaeology. Current Anthropology vol.2, n.3, :223-231

SHIVA, $\mathrm{V}$

2003 Monoculturas da mente. Perspectivas da biodiversidade e da biotecnologia. São Paulo, Editora Gaia.

SMITH, G. AND EHRENHARD, J.

2002 Protecting the Past to Benefit the Public. In: Public benefits of Archaeology. Ed. Barbara J. Little, University Press of Florida, $121-130$

SPAULDING, ALBERT C.

1988 Disntinguished lecture: archaeology and anthropology. American Anthropologist vol. $90: 263-271$

SPIER, L.

1917 Na outline for a chronology of Zuñi ruins. Anthropological Papers of the American Museum of Natural History, 18, Nova Iorque :207-331

SPINDEN, HERBERT J.

1917 The origin and distribution of agriculture in America. Proceedings, Niineteenth International Congress of Americanists, :269-276, Washington D.C. 
Arqueologia e sociedade no município de Ribeirão Grande, sul de São Paulo: ações em arqueologia pública ligadas ao Projeto de Ampliação da Mina Calcária Limeira.

1928 Ancient Civilizations of Mexico and Central Mexico. American Museum of Natural History Handbook Series, n.3, New York

SQUIER, EPHRAIM G.

1849 Aboriginal Monuments of New York. Smithsonian Contributions to Knowledge, vol. 2, Washington, D.C.

STAHL, A.

1994 Change and Continuity in the Banda Area, Ghana: The Direct Historical Approach. Journal of Field Archaeology, 21, pp:181-203.

STEERE, J.B.

1927 The Archaeology of the Amazon, Univ. of Michigan Official Publications vol.29, n.9, Univ. of Michigan, Ann Arbor

STEINEN, KARL VON DEN

1904 Ausgrabungen am Valenciasee. Globus vol.86, n.77, : 101-8

STEWARD, JULIAN H.

1937 Ecological aspects of Southwestern Society. Anthropos vol.32, :87-104

1938 The direct historical approach to Archaeology. American Antiquity vol.7 n.4 :337-433

1946-50 The Handbook of South American Indians, 6 vols., Bureau of American Ethnology, Bulletin 143, Washington D.C.

1949 Cultural Causality and Law: a trial formulation of the development of early civilizations. American Anthropologist vol.51, :1-27

1950 Theory of Cultural Change. Univ. of I llinois Press, Urbana

1955 Civilizaciones antiguas del viejo mundo y de america : symposium sobre las civilizaciones de regadio. Washington, DC : Union Panamericana.

1966 Toward understanding cultural evolution. Science vol.153, :729-730

STEWARD, LINCOLN J.

1942 The maya calendar of the ixil of guatemala. Washington: Carnegie Institution of Washington,

STIRLING, MATTHEW W.

1943 Stone Monuments of southern Mexico. Bureau of American Ethnology, Bulletin 138, Washington D.C.

STOW, J.

1603 A survey of London. London

STRONG, WILLIAM D.

1935 Na introduction to Nebraska Archaeology Smithsonian Miscellaneous Collections, vol.93 n.10, Washington D.C.

STURTEVANT, WILLIAM C.

1960 The significance of Ethnological similarities between Southeastern North America and the Antilles. Yale Univ. Publications in anthropology, n.64, New Haven
TAYLOR. WALTER W. JR.

1948 A study of Archaeology. Memoir Series of the American Anthropological Association, n.69, Menasha, Wis.

THOMAS, CYRUS

1894 Report of the Mound Explorations of the Bureau of Ethnology. Washington, D.C.

THOMAS, DAVID

1988 Saints and soldiers at Santa Catalina: Hispanic Designs for colonial America. In M.P.Leone \& P.B.Potter J r (eds.) The recovery of meaning: historical archaeology in the eastern United States.:73-140, Smithsonian Institution Press, Washington D.C.

2000 Skull Wars: Kennewick Man, Archaeology and the Battle for Native American Identity. New York, Basic Books.

THOMPSON, J.E.S.

1950 Maya Hierogliphic Wrinting: na introduction. Publications of the Carnegie Institution of Washington, n.589, Washington D.C.

TORRES, LUIS M.

1907 Arqueologia de la Cuenca del Rio Paraná. Revista del Museo de la Plata vol.14 :53-122

1911 Los primitivos habitantes del delta del Paraná Univ. Nac. de La Plata, Biblioteca Centenaria vol 4, Buenos Aires

TRIGGER, BRUCE G.

1963 Settlement as na aspect of Iroquois adaptation at the time of contact. American Anthropologist vol.65, n.1, :86-101

1967 Settlement Archaeology - its goals and promise. American Antiquity vol.32, n.1 :149-161

1968 The determinants of settlement patterns. In K.C.Chang (ed,) Settlement Archaeology :53-78, Nation Press Books, Palo Alto

1989 A history of Archaeological Thought. Cambridge University Press, Cambridge

1991 Constraint and freedom: a new synthesis for Archaeological explanation. American Anthropologist vol.93, :551-569

UHLE, MAX

1903 Pachacamac. Niversity of Pannsylvania Press, Philadelphia.

VAILLANT, GEORGE C.

1927 The chronological significance of Maya Ceramics. PhD dissertation, Harvard Univ., Cambridge.

VAN MELLEN, J.

1679 Historia urnae sepulchralis sarmaticae. J ena WATSON, PATTY JO

1979 The idea of ethnoarchaeology: notes and comments. In C.Kramer (ed.) Ethnoarchaeology: implications of ethnography for archaeology. :277-88, New York: Columbia Univ. Press 
1990 A Parochial Primer: the new dissonance as seen from the Midcontinental USA. In R.W.Preucel (ed.) Processual and Postprocessual Archaeologies: multiple ways of knowing the past. :265-274, Center for Archaeological Investigations, Occasional Paper n.10, Southern Illinois Univ., Carbondale

WATSON, PATTY JO; LEBLANC, S.A. \& REDMAN, CHARLES L.

1971 Expalnation in Archaeology, anexplicitly Scientific Approach. Columbia Univ. Press, New York

WATSON, RICHARD A.

1991 What the New Archaeology has Accomplished. Current Anthropology 32(3):275-291

WAUCHOPE, ROBERT

1962 Lost Tribes and Sunken Continents. University of Chicago Press, Chicago.

1964-76 Handbook of Middle American Indians, vol. 1-16, Univ. of Texas Press, Austin

WEDEL, WALDO R.

1953 Some aspects of human ecology in the Central Plains. American Anthropologist vol.55, :499-514

WHALLON, R. JR.

1967 Investigations of late Prehistoric social organization in New York State. In S.R.Binford \& L.R.Binford (eds.) New Perspectives in Archaeology :223-244, Aldine, Chicago

1968 A new approach to pottery typology. American Antiquity, 37: 13-33

1974 Spatial analysis of occupation floors (II): the application of nearest neighbour analysis. American Antiquity 39 (1), 1634. Salt Lake City. Society American Archaeology

WHITE, LESLIE A.

1959 The Evolution of Culture. McGraw-Hill, New York

WILLEY, G.

1945 Horizon Styles ans pottery traditions in Peruvian Archaeology. American Antiquity vol.11:49-56

1946 Comments on cultural and social Anthropology. In S. Tax et alii (eds.) Na appraisal of Anthropology today. :229230, Univ. of Chicago Press, Chicago.

1947 Prehistoric Settlement Patterns in the New World. Viking Fund Publications in Anthropology, n.23, New York

1948 The early great styles and the rise of the
pre-Columbian civilizations. American Anthropologist vol.64, n.1, :1-14

1953 Prehistoric settlement patterns in the Virú Valley, Peru. Washington: U.S. Govt. Print. Off

1956 Prehistoric Settlement Patterns in the New World. Viking Fund Publications in Anthropology No. 23, New York.

WILLEY, G.R. \& PHILLIPS, PHILIP

1955 Method and theory in American Archaeology, II: historical-developmental interpretations. American Anthropologist vol.57, :723-819

1958 Method and theory in American Anchaeology. Univ. of Chicago Press, Chicago

WILLEY, G.R. \& SABLOFF, J.A.

1993 A History of American Archaeology. W.H. Freeman and C., New York, 3. Edition

WYLIE, A.

1985 The reaction against analogy. Advances in Arch. Method and Theory 8: 63-111

1988 'Simple'analogy and the role of relevance assumptions: implications of Archaeological Practice. International Studies in the Philosophy of Science 2:134-150

1989 The interpretive Dilemna. V.Pinsky \& A.Wylie (ed.) Critical Traditions in Contemporary Archaeology: essays in the Philosophy, History and socio-politics of Archaeology. :18-27, Cambridge Univ. Press, Cambridge

1991 Gender theory and the Archaeological record. In J.M.Gero \& M.W.Conkey (eds.) Engendering Archaeology, women and prehistory. : 31-56, Basil Blackwell, Londres

WÜST, I.

1992 Contribuições arqueológicas, etnoarqueológicas e etno-históricas para o estudo dos grupos tribais do Brasil Central: o caso Bororo. Revista do Museu de Arqueologia e Etnologia 2: 13-26. Universidade de São Paulo, São Paulo.

1994 The Eastern Bororo from an archaeological perspective. A.C. Roosevelt (ed.), Amazonian Indians. From Prehistory to Present. The University of Arizona Press, Tucson \& London, pp. 315-342.

1998 Continuities and discontinuities: archaeology and ethnoarchaeolgy in the heart of the Eastern Bororo territory, Mato Grosso, Brazil. Antiquity 72(277): 663-675.

WUST, I. \& BARRETO, C.

1999 The ring villages of Central Brazil: a challenge for Amazonian Archaeology. Latin American Antiquity 10 (1): 3-23 